\title{
Statistical Analysis of Existing Models for Flexural Strengthening of Concrete Bridge Beams using FRP Sheets
}

\author{
Alfredo M. Ceci ${ }^{\mathrm{a}} \quad$ Joan R. Casas ${ }^{\mathrm{b}} \quad$ Michel Ghosn $^{\mathrm{c}}$
}

(a) Dipartimento di Ingegneria delle Strutture, delle Acque e del Terreno, University of L'Aquila, Italy

(b) Professor of Bridge Engineering, Technical University of Catalonia, Barcelona, Spain

(c) Professor of Civil Engineering, the City College of New York / CUNY, New York, NY, USA

\begin{abstract}
This paper performs a statistical analysis of previously proposed models for resisting the debonding of FRP sheets used in strengthening reinforced and prestressed concrete beams. End debonding and intermediate crack-induced debonding modes of failure are studied for beams in flexure. Two different databases are assembled from published experimental debonding tests on concrete beams of different span lengths. The first database contains the results of four point bending tests performed to study the behavior of the FRP-concrete bond at the end of the FRP sheet. The second database which includes four point bending tests, three point bending tests and one point loading tests, has been created to examine intermediate crack-induced debonding. These two databases are significantly larger than those used in developing any of the existing debonding strength models and provide a solid basis for assessing the performance of such models. A regression analysis reviews the relationship between the experimentally measured loads that caused debonding to the model predicted values as well as the bias and the variability in the prediction models. This regression analysis allows for drawing conclusions on the most appropriate and accurate models, from a statistical point of view, that may be used in a follow up reliability-based calibration of partial safety factors. The applicability of such information for the development of design specifications for strengthening of deteriorated concrete bridges is highlighted. This will be implemented in a forthcoming companion paper.
\end{abstract}

Keywords: fiber-reinforced plastic, flexural strengthening, model uncertainty 


\section{Introduction}

Bonding of Fiber-Reinforced Polymer (FRP) to the tension face of concrete beams has become a frequent strengthening method over the last decade. The application of FRP to the tension face of a concrete beam or slab has multiple benefits, including: increased ultimate flexural strength capacity, increased post-cracking stiffness, as well as concrete crack control whereby the bonding of FRP sheets to concrete beams results in finer and more evenly distributed cracks when compared to the cracks that develop in unstrengthened beams. Because of these benefits, it is clear that flexural strengthening of reinforced concrete beams with FRP has a great potential for becoming a primary strengthening scheme for deteriorated infrastructure systems. However, because of the relative novelty of this technology, a more complete understanding of the behavior of FRPstrengthened beams and their failure mechanisms need to be gained before the wide spread adoption of this technology in engineering practice. As a minimum, the confidence levels in the safety margins of existing and proposed design criteria should be ascertained. This would require an objective estimation of the biases implied in existing and recently proposed design criteria and an analysis of the variability of the expected loads that cause failure from the predicted loads.

The fibers used in common FRP strengthening schemes are usually made of glass, carbon or aramid. To bond the fibers together and to the substrate surface on which they are being applied, a resin matrix is used. Two methods of application are frequently used. In situ installations require placing the fibers in an open mold, attaching the assembly to the surface and then saturating the assembly with resin. More commonly, the fibers may be first saturated with epoxy and then bonded to the prepared surface of concrete. In situ assemblies of the fibers are usually referred to as wet lay-up. Preimpregnated plates or sheets of fibers (prepreg) can also be installed by applying resin to bond the sheets to the concrete surface.

Hollaway and Teng [1] recognized six main failure mechanisms for reinforced concrete beams flexurally strengthened with FRP. These are represented in Figure 1 as: a) FRP rupture, b) crushing of concrete, c) intermediate crack-induced interfacial debonding, d) concrete cover separation, e) plate end interfacial debonding, f) concrete shear failure and g) critical diagonal cracking. Modes a), b) and f) are classical concrete beam failure mechanisms and have been analyzed to a great extent in the past $[2,3,4]$. The remaining failure mechanisms are specific to FRP strengthened beams and are characterized as premature failure modes because they take place before realizing the full potential of the strengthening scheme. Modes d), e) and g) are often indistinguishable and in fact, Smith and Teng [5,6] identified a mixed failure mode where the failure occurs at the same time by the concrete cover separation and the plate end interfacial debonding mode. In this paper, modes d), e) and the combined mode will be grouped under the label end debonding failure mode. Yao et al. [7] explain that intermediate crack induced debonding, identified as mode c), normally initiates in the high moment region due to a flexural or flexural-shear crack. On the other hand, end debonding is initiated by high interfacial stresses at the plate end as explained by Yao et al [7].

Failures of FRP strengthened beams due to concrete crushing are easily predicted and this mode of failure would allow for the most efficient use of the materials while preserving an acceptable level of ductility. FRP rupture is also a mode failure that can be easily determined. Although, the FRP rupture mode is permitted in most existing guidelines, it would be preferable to avoid it as it may lead to brittle failures.

When designing an FRP strengthening scheme, it is generally most difficult to predict and control the debonding modes of failure. In fact, a large number of experimental studies reported premature failures by debonding rather than concrete crushing or FRP rupture. For this reason, considerable research effort has been expended on understanding the underlying factors that cause FRP debonding, to develop models for predicting debonding, and to propose design guidelines to minimize the risk of its occurrence under design loading conditions $[2,8,9,10]$.

Most analytical and experimental studies have focused on studying the end debonding mode of failure, while intermediate crack induced debonding has received much less attention and few 
models have been developed for predicting its occurrence. Nevertheless, the debonding failure mechanisms are still found to be complicated processes that are not fully understood, making it difficult for engineers to estimate the actual capacity of FRP-strengthened concrete beams and thus making them reluctant to use this new technology on a wide scale.

Over the last decade, several guidelines for use of FRP in construction have been developed $[11,12,13,14,15]$. Many of these guidelines are under constant refinement as more information is gathered on the behavior of structural components strengthened using FRP. In particular, the American Concrete Institute (ACI) published the first version of its guidelines in 2002 and released a revised version in 2008. Most of these and other proposed design criteria have used equations that provide lower bounds for the beam's capacity based on limited sets of experimental data or else developed advanced fracture mechanics models without following modern methods for developing reliability-based design codes and specifications that would take into consideration the uncertainties associated with the input parameters as well as the modeling assumptions. Triantafillou in 1992 [16] was the first to propose reliability-based sets of design equations for FRP-strengthened beams but only looked at the concrete crushing and FRP rupture modes. A recent study by Atadero and Karbhari [17,18] developed reliability-based criteria for debonding using fracture mechanics models but the approach considered only randomness in the input parameters and did not account for the modeling uncertainties, also known as systemic uncertainties, which in many cases may be more significant than the parametric uncertainties. The implementation of reliability-based design specifications is extremely important for FRP-strengthened concrete beams due to the large level of variability observed in experimental tests results and the uncertainties in determining the material properties.

The objective of a study currently underway at the Technical University of Catalonia (UPC), in Barcelona is to propose appropriate reliability-based design equations with properly calibrated safety factors that can be used during the design of a strengthening scheme to enhance the flexural capacity of existing concrete bridge beams. In a first step of this study, a statistical analysis of available models is performed and presented in this paper. The goal of this analysis is to study the systemic uncertainties associated with existing models. To this end, experimental results on strengthened concrete beams that failed due to either end debonding or intermediate crack induced debonding are compared to several available proposed predictive and design models to determine the most appropriate ones for implementation in design codes. The experimental database was carefully constructed from an extensive survey of the published literature, and presented in Appendix A and Appendix B. The statistical analysis of the selected existing debonding models will provide the necessary information to calibrate appropriate safety factors that should be applied in conjunction with the selected models so that future design codes would provide the engineers with the tools necessary to use FRP-based concrete beam strengthening schemes that would lead to uniform and consistent reliability levels.

\section{Experimental Database}

Several models have been developed over the last two decades to predict the debonding of FRPstrengthened concrete beams or to propose design equations to avoid its occurrence. Many of these models were calibrated using a limited database generated by each model's own developers. To validate the accuracy of existing models, it is important to compare the predicted results against a very broad set of experimental laboratory and in-situ data that mimic as closely as possible the size and environmental conditions where FRP-strengthened beams will be applied. To perform a valid statistical analysis, each model should be compared to a wide data set that extends beyond the limited set which was used to calibrate the model. A rigorous statistical analysis that investigates the biases and variability of a model is the necessary first step toward performing a reliability 
analysis of strengthened concrete beams and calibrating a set of appropriate safety factors for implementation in design specifications.

Over the last few years, several authors such as Smith \& Teng [6], Colotti et al. [19] and Wu and Niu [3] have assembled from the existing literature exhaustive and useful experimental databases following clearly defined criteria. Due to the continuous ongoing effort in testing FRP strengthened beams, an updating of these previously published databases has been undertaken as part of this study to assemble a more comprehensive list that specifically includes recent test results and, to the extent possible, those conducted on large scale beams which may prove to be critical for the statistical analysis given the importance of scale effects. To that end, two large databases are assembled from the available literature, as reported in Appendix A and Appendix B. The databases include results for FRP strengthened concrete beams and small scale beam specimens. The first database provided in Appendix A includes 161 four-point bending tests that resulted in end debonding failures (see tables A.1 to A.6). The database was assembled from 34 testing programs carried out between 1991 and 2007. The test data is classified based on the material type and installation process as follows: 90 beams were reinforced by wet lay-up carbon sheets, 57 beams reinforced by prepeg carbon plates, 7 beams reinforced by wet lay-up glass sheets, and 7 beams reinforced by prepeg glass plates. This database includes beams that failed by end debonding including failures due to concrete cover separation, plate end interfacial debonding, mixed concrete cover separation, end interfacial debonding mode, and critical diagonal crack debonding. Table 1 gives a summary of the experimental programs including the reference from which the information was collected, the number of beams, the beam sizes, the FRP type and thickness as well as the shear load at failure. All the tests were performed for four-point bending labeled (f.p.b.t.) in Table 1. It is noted that all the tests were performed on laboratory scale models where the longest beam was about $4.5 \mathrm{~m}$ in length. The maximum observed failure load was $125 \mathrm{kN}$. These maximum length and load ranges are significantly smaller than would be expected in many structural applications particularly for bridges.

The second database provided in Appendix B includes strengthened beams that failed as a result of intermediate crack induced debonding (tables B.1 to B.6). The data set consists of 187 beam tests from 38 experimental programs carried out between 1996 and 2007, as summarized in Table 2. When separated by material type, the list includes 125 beams reinforced by carbon sheets, 4 beams reinforced by glass sheets, and 32 beams reinforced by aramid sheets. The loading configurations for these test specimens consisted of: a) four-point bending (f.p.b.t); b) three-point bending (3.p.b.t); and c) one-point bending of cantilevered beams (c.b.t). In this case, several researchers tested longer beams with spans up to $7.2 \mathrm{~m}$ and reported failure loads of up to $548.5 \mathrm{kN}$.

The experimental tests selected from the literature were those for which most material and geometric characteristics were clearly reported. To assemble a consistent database, the following criteria were used:

- all beams and slabs have rectangular cross-sections, are conventionally reinforced with steel rebars and strengthened with constant-thickness carbon, glass or aramid FRP sheets;

- failure of the beam was by end debonding or intermediate crack-induced debonding;

- the FRP sheet was neither prestressed nor anchored in any form at its ends;

- the beam did not experience prior cyclic loading after being repaired with FRP and before being tested statically to debonding failure;

- sufficient details about various geometric and material parameters were provided to enable the use of the results with confidence.

The above stated criteria mostly follow those previously set by Smith and Teng [6]. However the $4^{\text {th }}$ criterion has been restricted to eliminating repaired beams that were subjected to cyclic 
loading before the test. Therefore, the database assembled in this study will include beams that have been strengthened with FRP after being damaged from statically applied high loads. Because many of the reports did not provide all the data required as input for some models, a few assumptions are made to fill in the gaps. For that purpose, the recommendations of Smith and Teng [6] were followed. Specifically, when information is not provided, the concrete cover is assumed to be $10 \%$ of the total depth. This value was suggested for being the average concrete cover ratio used in the beams that provided cover information. Also, a modulus of elasticity of $200 \mathrm{GPa}$ was adopted for steel reinforcement when the modulus was not specified [6].

To calculate the concrete material characteristics, the ACI440 [11] models were used, as follows:

$$
E_{c}=4730 \sqrt{f^{\prime}{ }_{c}} \quad f_{c t}=0.53 \sqrt{f^{\prime}{ }_{c}} \quad{f^{\prime}}_{c}=0.8 f_{c u}
$$

where $E_{c}$ (in $\mathrm{MPa}$ ) is the elastic modulus of concrete, $f_{c t}$ (in $\mathrm{MPa}$ ) is the splitting tensile strength of concrete, $f_{c}^{\prime}$ (in $\mathrm{MPa}$ ) the concrete cylinder compressive strength, and $f_{c u}$ (in $\mathrm{MPa}$ ) the concrete cube compressive strength. These relationships are expected to produce on the average comparable results to experimental data [6].

In many instances, the adhesive layer thickness was not reported. In such cases, as proposed by Smith and Teng [6], the average thickness obtained from available test data was adopted. Specifically, the adhesive layer thickness of pultruded plates was assumed, where it is not specified, to $b e t_{a}=2 \mathrm{~mm}$. For wet lay-up installations, the adhesive layer thickness is worked out using the following formulas for a single layer of FRP:

$$
\begin{aligned}
& t_{a}=\frac{t_{f r p, g}-t_{\text {sheet }}}{2} \\
& t_{\text {frp }}=t_{a}+t_{\text {sheet }}
\end{aligned}
$$

Where $t_{f r p, g}$ is the gross thickness of all the FRP and adhesive layers assuming two equal layers of adhesive above and below the layer of fibers. $t_{\text {frp }}$ represents the total effective thickness of each single layer of FRP in the strengthened beam. If more than one sheet were used, $t_{f r p}$ must be multiplied by the number of sheet layers. If the available information was still insufficient for using Eq. (2) and (3), $t_{a}$ was assumed to be $0.42 \mathrm{~mm}$ based on measurements of samples formed from wet lay-up sheet by Smith and Teng [6]. Due to this additional uncertainty with wet lay-up plates, test data of beams with wet lay-up plates and those with pultruded plates are appropriately differentiated from each other during the data analysis process.

When the modulus of elasticity of the adhesive was not provided, a value of $8500 \mathrm{MPa}$ was used, as proposed by Smith and Teng [6].

The databases listed in appendix A and appendix B, provide the RC beam details as follows: width of beam $b$, overall depth of beam $h$, distance from beam compression face to centroid of steel tension reinforcement $d_{s}$, distance from beam compression face to centroid of steel compression reinforcement $d_{s}^{\prime}$. . The properties of concrete are listed if available from the experimental investigation or using Eq. (1).

The properties of the steel reinforcement are provided for the moduli of elasticity of the steel tension reinforcement $E_{s}$, steel compression reinforcement $E_{s}{ }_{s}$ and steel shear reinforcement (stirrups) $E_{s v}$. The yield strengths of the tension, compression and shearing reinforcements are denoted respectively as $f_{y s}, f_{y s}^{\prime}$ and $f_{y s}$. The corresponding cross-sectional areas are respectively denoted by $A_{s}, A^{\prime}$, and $A_{s v}$. 
The FRP material and installation procedure are provided under the column labeled "type" using the letters $\mathrm{C}, \mathrm{G}$ or A in reference to Carbon, Glass or Aramid Fibers respectively. The letters $\mathrm{W}$ and $\mathrm{P}$ refer to wet lay-up procedure and pultruded fibers sheets respectively.

The FRP material properties are listed for the modulus of elasticity $E_{\text {frp }}$, and the tensile strength in the main fiber direction $f_{f r p}$, sheet thickness $t_{f r p}$, and sheet width $b_{f r p}$ as well as the distance from the support to the nearer end of the soffit plate $a$.

The adhesive properties provided are the modulus of elasticity $E_{a}$, and thickness of adhesive layer $t_{a}$. The width of resin layer $\mathrm{b}_{\mathrm{a}}$ is assumed to be always equal to the FRP width $\mathrm{b}_{\text {frp }}$.

The loading configuration and the failure load are described by the distance from the support to the nearest applied load, $B$, the span of the beam, $L$ and the maximum shear force in the beam at debonding $V_{\text {exp }}$.

The statistical analysis of existing analytical and design models is verified by comparing the results predicted by the models to the experimental results assembled in the database. The analytical and design models that have been studied are briefly discussed next.

\section{Review of models for debonding of FRP-strengthened RC beams}

An exhaustive review of existing debonding models for end-debonding or intermediate crack (IC) debonding in FRP-strengthened RC beams was performed. A distinction between models developed from beam tests (type-A models) and models based on prism tests (type-B models) was done. A preliminary analysis of both type-A and type-B models was performed to investigate their reliability. The models were applied to two different databases assembled from the scientific literature; one database is for prism tests and the other is for beam tests. A better agreement, between analytical and experimental results was shown by the models which were developed based on beam tests [20]. Therefore, this paper will only analyze the models which seem to provide the best representation of the bending behavior of strengthened RC beams.

Fifteen models, which had been proposed between 1990 and 2007 and validated by experimental tests were selected for this analysis. From a theoretical point of view, the existing models for debonding behavior may be classified into three categories based on their approach, namely: models based on: a) materials strength, b) on fracture mechanics and c) on experimental data fitting. However, in practice, it is difficult to find models purely based on just only one of the mentioned approaches. In fact, many models are a combination of strength of materials and experimental fitting $[21,22,23]$. Other models are based on fitting experimental data into empirical equations or used data fitting techniques to supplement or correct the strength of materials or fracture mechanics models, as done in the models by Zhang et al. [28], Wang and Ling (cited in [5]) and Raoof and Hassanen [25]. The Ziraba model [26] combines the strength model with fracture mechanics approaches. The group of models based on fracture mechanics look at the delamination of FRP sheets from the concrete substrate when a crack forms and propagates along the interface between the two materials. This group includes the Raoff and Zhang model [24], the Wang and Ling model (cited in [5]), Raoff and Hassanen model [25], Ziraba et al. model [26], Wu and Niu model [3], and Casas and Pascual model [27]. Several of these models had been previously studied by Smith and Teng [5] and are analyzed again in this paper using a consistent statistical method that is appropriate for implementation during the reliability-calibration of partial safety factors. The statistical analysis serves to provide a common basis for comparing the various models to the extended database assembled in this study.

Table 3 provides a summary of the principal methods used to predict the end-debonding and intermediate crack induced debonding along with the material parameters that these methods require as input. A rough classification of the models into the three groups $\mathrm{a}, \mathrm{b}$ and $\mathrm{c}$ listed above is provided based on the primary principles used to develop them even though, as mentioned earlier, 
most theoretical models utilized empirical corrections to modify the equations. It is noted that the classification in Table 3 is different than that used by Smith and Teng [6]. Smith and Teng [6] used a classification where the models are grouped into: shear capacity based models, concrete tooth models and interfacial stress based model. The first group includes the models based on the shear strength of the concrete with no or only partial contribution of the steel shear reinforcement $[5,6,21,22]$. The concrete tooth models take into account the concept of a cantilevered concrete "tooth" between two adjacent cracks. [5,24,25]. The last group assumes that end debonding occurs due to high interfacial stresses between the FRP and concrete cover [3,26,27]. Additional information on the models analyzed in this paper is provided in this section.

\section{Oehlers' model}

One of the first models applied to study the debonding of FRP-strengthened RC beams was the model proposed by Oehlers [21] which was originally developed for RC beams strengthened with steel plates. The model is based on the shear force acting at the plate end while taking into account the effect of any coexistent moment. Using the classic ultimate strength analysis method, the flexural capacity of an externally plated reinforced concrete beam can be determined, considering the plate as part of the reinforcement. The moment applied to the end of the plate, which provoked the peeling, is given by the following equation:

$$
M_{d b, f}=\frac{\left(E_{c} I_{0, c}\right) f_{c t}}{0.901 E_{f i p} t_{f p p}}
$$

where $M_{d b, f}$ is the moment capacity of the strengthened section; $I_{0, c}$ is the cracked strengthened section's moment of inertia transformed into equivalent concrete. The value 0.901 is a constant which is applied to obtain a safe characteristic design value.

The Oehlers' model also uses the shear capacity of the concrete in the $\mathrm{RC}$ beam alone $\mathrm{V}_{\mathrm{c}}$, based on the Australian code equation, given as:

$$
V_{d b, s}=V_{c}=[1.4-(d / 2000)] b d\left(\rho_{s} f_{c}^{\prime}\right)^{1 / 3}
$$

where $\rho_{s}=A_{s} / b d$ is the steel tension reinforcement ratio. The moment-shear interaction equation that should be used for checking the adequacy of an FRP-strengthened design is:

$$
\frac{M_{d b, \text { end }}}{M_{d b, f}}+\frac{V_{d b, \text { end }}}{V_{d b, s}} \leq 1.17
$$

which considers the applied shear and moment at the end of the FRP plate, $M_{\mathrm{db}, \text { end }}$ and $V_{\mathrm{db}, \text { end }}$.

\section{Smith and Teng's model}

For the cases when the ratio of the applied moment to the ultimate moment capacity $M_{d b \text {,end }} / M_{u} \leq 0.67$, Smith and Teng [6] proposed a safe design equation that considers only the shear force: 


$$
V_{d b, \text { end }} \leq 1.5 V_{c}
$$

where $\mathrm{V}_{\mathrm{c}}$ is the concrete beam's shear capacity as specified by the design codes.

\section{Teng and Yao's model}

An empirical predictive model for flexural debonding of a plate end located in a pure bending region, was proposed by Teng and Yao [22,23]. Accordingly, the moment capacity is expressed as:

$$
M_{d b, f}=\frac{0.488 M_{u, 0}}{\left(\alpha_{f l e x} \alpha_{a x i a l} \alpha_{w}\right)^{1 / 9}} \leq M_{u, 0}
$$

where $\alpha_{f l e x}, \alpha_{\text {axial }}$ and $\alpha_{w}$ are three dimensionless parameters defined respectively by:

$$
\alpha_{f l e x}=\frac{(E I)_{f i p, c}-(E I)_{0, c}}{(E I)_{0, c}}, \alpha_{\text {axial }}=\frac{E_{f r p} t_{f r p}}{E_{c} d}, \alpha_{w}=\frac{b}{b_{f r p}}, \frac{b}{b_{f r p}} \leq 3
$$

where $(E I)_{c, f r p}$ and $(E I)_{c, 0}$ are the flexural rigidities of the cracked section with and without a strengthening plate, respectively and $M_{u, 0}$ is the theoretical ultimate moment of the unplated section which is also the upper bound of the flexural debonding moment $M_{d b, f}$. The limitation imposed on the width ratio reflects the limitation of the test data used by Teng and Yao [22,23]. Eq. (8) is a best-fit expression of the results of eighteen tests.

The shear debonding strength is the sum of different values which represent the contributions of the concrete $V_{c}$, the strengthening plate $V_{\text {frp }}$, and the internal reinforcement $V_{s}$ :

$$
V_{d b, s}=V_{c}+V_{f r p}+\varepsilon_{v, e} \bar{V}_{s}
$$

where $\bar{V}_{s}=A_{s v} E_{s v} d_{e} / s_{v} . \varepsilon_{v, e}$ is the strain in the steel shear reinforcement, referred to here as the effective strain, and this effective strain may be well below the yield strain of the steel shear reinforcement at debonding failure.

The best-fit expression for $\varepsilon_{v, e}$ is given by

$$
\varepsilon_{v, e}=\frac{10}{\left(\alpha_{f l e x} \alpha_{E} \alpha_{t} \alpha_{w}\right)^{1 / 2}}
$$

where $\alpha_{E}=\frac{E_{f r p}}{E_{c}}, \alpha_{t}=\left(\frac{t_{f r p}}{d}\right)^{1,3}$

$\alpha_{E}$ represents the elastic moduli ratio and $\alpha_{t}$ the ratio between the plate thickness and the effective depth of the section.

As done by Oehlers [21], an interaction between plate end shear and bending has been proposed as follows: 


$$
\left(\frac{V_{d b, \text { end }}}{0.85 V_{d b, s}}\right)^{2}+\left(\frac{M_{d b, \text { end }}}{0.85 M_{d b, f}}\right)^{2}=1.0
$$

Teng and Yao [22,23] explain that for design purposes, the shear capacity of concrete beams, $V_{c}$, to be used in Eq. (10) can be obtained from current code specified equations. The contributions of $V_{f r p}$ are usually small enough to be ignored. These simplifications yield conservative predictions of the debonding load when compared to most test results. In their study, three different codes were used to calculate the shear capacity of the concrete, $V_{c}$ : the British code (BS8110), the Australian code (AS600) and the American code (ACI318).

\section{Jansze's model}

Another model originally developed for steel plated beams but has been proposed for application to RC beams was developed by Jansze (cited in [5]). The model considers that shear cracking starts in the RC beam, but does not account for the contribution of shear reinforcement. The critical shear force in the $\mathrm{RC}$ beam at the plate end that causes debonding $\mathrm{V}_{\mathrm{db} \text {,end }}$ is given as a function of the shearing stress, $\tau_{P E S}$, by:

$$
V_{d b, \text { end }}=\tau_{P E S} b d=0.18 \sqrt[3]{3 \frac{d}{B_{\text {mod }}}}\left(1+\sqrt{\frac{200}{d}}\right) \sqrt[3]{100 \rho_{s} f_{c}^{\prime}} b d
$$

where $B_{\text {mod }}$ is a modified shear span, equal to:

$$
B_{\text {mod }}=\sqrt[4]{\frac{\left(1-\sqrt{\rho_{s}}\right)^{2}}{\rho_{s}} d a^{3}}
$$

If $B_{\text {mod }}$ is greater than the actual shear span, $\mathrm{B}$, then the average value of both should be used $\left(B_{\text {mod }}+B\right) / 2$. Jansze model (cited in [5]) appears to be invalid for plates that extend all the way to the support as $B_{\text {mod }}$ becomes zero and Eq.(15) predicts that debonding will never take place.

\section{Ahmed and van Germert's model}

Ahmed and van Germert (cited in [5]) modified Jansze's model to make it more suitable for use with FRP-plated RC beams by introducing corrections to account for the differences in the FRP and steel material properties. The critical shear force is given as follows:

$$
V_{d b, e n d}=\left(\tau_{P E S}+\Delta \tau_{\text {mod }}\right) b d
$$

with

$$
\begin{aligned}
& \Delta \tau_{\text {mod }}=\tau_{P E S} b d\left(\frac{S_{s}}{I_{s, c} b_{f r p}}-\frac{S_{f r p}}{I_{f r p, c} b_{a}}\right)+6188.5\left(\frac{\tau-4.121}{b d}\right) \\
& \tau=\left(0.15776 \sqrt{f^{\prime}{ }_{c}}+\frac{11.2366 \rho_{s} d}{B}\right)+0.9 \frac{A_{s v} f_{s v}}{s b}
\end{aligned}
$$


where $\tau_{P E S}$ is the same shearing stress defined by Jansze, $S_{f r p}$ and $S_{S}$ are the first moments of the FRP plate area, and that of an equivalent steel plate about the neutral axis of a cracked plated section transformed to concrete. The equivalent steel plate is one that has the same total tensile capacity and width as that of the FRP plate, but with an equivalent thickness determined assuming that the yield stress of steel is $550 \mathrm{MPa}, I_{f r p, c}$ and $I_{s, c}$ are the moments of inertia of a cracked plated section transformed to concrete with a FRP plate and an equivalent steel plate respectively. The increase in shear strength offered by the shear reinforcement is also included as seen in Eq.(14).

\section{Colotti et al.'s model}

Colotti et al. [19] proposed a model based on truss analogy. The actual load-carrying capacity of a plated beam is then determined as the minimum value obtained from four different shear strength expressions corresponding to: (a) plate-debonding failure; (b) shear failure; (c) tension/concrete crushing failure; and (d) plate rupture.

The ultimate load for the bond failure mode:

$$
\left.V_{d b, \text { end }}=p_{y} d \mid \phi+\alpha-\sqrt{(\phi+\alpha)^{2}-2 \phi \beta}\right], p_{y}>0
$$

where the terms $\alpha, \beta$ and $\phi$ are defined by $\alpha=a / d$, ratio of shear span to beam effective depth; $\beta=l_{a} / d$, ratio of plate length in shear to beam effective depth; and $\phi=U_{y} / p_{y}$, ratio of bond strength to stirrup strength. The limiting bond strength is given by, $U_{y}=b_{m}\left[2.77+0.06\left(f_{c}^{\prime}{ }_{c}-20\right)\right]$ for $f^{\prime}>20 \mathrm{MPa}$. The effective width of the plate-adhesive interface, $b_{m}$, is assumed to be the average of the beam and plate widths such that: $b_{m}=\left(b+b_{f r p}\right) / 2$.

Shear failure mode in the concrete web or yielding of the steel stirrups are assumed to occur when:

$$
\begin{aligned}
& V=\frac{b d f_{c}}{2}\left[\sqrt{1+\alpha^{2}}-\alpha\right]+p_{y} d \alpha \text { for } 0 \leq \frac{p_{y}}{b f_{c}} \leq \frac{\sqrt{1+\alpha^{2}}-\alpha}{2 \sqrt{1+\alpha^{2}}} \\
& V=\sqrt{p_{y} b d^{2} f_{c}\left(1-\frac{p_{y}}{b f_{c}}\right)} \text { for } \frac{\sqrt{1+\alpha^{2}}-\alpha}{2 \sqrt{1+\alpha^{2}}} \leq \frac{p_{y}}{b f_{c}} \leq 0.5 \\
& V=\frac{b d f_{c}}{2} \text { for } \frac{p_{y}}{b f_{c}}>0.5
\end{aligned}
$$

The failure of the concrete web or the failure of the longitudinal reinforcement occurs when the shearing force is:

$$
\begin{aligned}
& V=p_{y} d\left[\sqrt{\frac{2 T_{y}}{p_{y} d}+\alpha^{2}}-\alpha\right] \text { for } \frac{p_{y}}{b f_{c}}>\frac{\sqrt{1+\alpha^{2}}-\alpha}{2 \sqrt{1+\alpha^{2}}} \\
& V=\frac{b d f_{c}}{2}\left[\sqrt{\frac{4 T_{y}}{b d f_{c}}\left(1-\frac{T_{y}}{b d f_{c}}\right)+\alpha^{2}}-\alpha\right] \text { for } \frac{p_{y}}{b f_{c}} \leq \frac{\sqrt{1+\alpha^{2}}-\alpha}{2 \sqrt{1+\alpha^{2}}}, T_{y} \leq 0.5 b d f_{c}
\end{aligned}
$$




$$
V=\frac{b d f_{c}}{2}\left[\sqrt{1+\alpha^{2}}-\alpha\right] \text { for } \frac{p_{y}}{b f_{c}} \leq \frac{\sqrt{1+\alpha^{2}}-\alpha}{2 \sqrt{1+\alpha^{2}}}, T_{y} \leq 0.5 b d f_{c}
$$

FRP tensile rupture, failure of the longitudinal steel reinforcement or concrete crushing in compression occurs when:

$$
V=\frac{M_{u}}{a}
$$

where the flexural capacity of the cross section is calculated as specified in ACI440 Guide [11], with $\varepsilon_{p}=\varepsilon_{c u}(d / c)-\varepsilon_{b i} \leq k_{m} \varepsilon_{p u}$.

The term $k_{m}$, defined to limit the strain in the FRP reinforcement to prevent debonding or delamination, is defined as follows

$$
k_{m}\left\{\begin{array}{cc}
1-\frac{n E_{f r p} t_{f r p 1}}{428000} \text { for } & n E_{f r p} t_{f r p 1} \leq 214000 \mathrm{~N} / \mathrm{mm} \\
\frac{107000}{n E_{f r p} t_{f r p 1}} \text { for } & n E_{f r p} t_{f r p 1}>214000 \mathrm{~N} / \mathrm{mm}
\end{array}\right.
$$

where $n$ is the number of plies of FRP reinforcement; $t_{\text {frp } 1}$ is the nominal thickness of one ply.

In the numerical investigation, the authors made the following assumptions: $d=0.9 \mathrm{~h}, v=0.7$, $s_{c}=l_{c} / 5$. Furthermore, the tensile strength of concrete $\mathrm{f}_{\mathrm{t}}{ }_{\mathrm{t}}$ and the crack spacing size $l_{c}$, according to Eurocode2 [29] were assumed to be $f_{t c}=1.3 x 0 ., 3 f_{c}^{2 / 3}(\mathrm{MPa}), l_{c}=50+0.25 k_{1} k_{2} \varphi_{1} / \rho_{r}$, with $k_{l}=0.8$, $k_{2}=0.5, \rho_{r}=A_{s} /(2.5 b d)$ and $\varphi_{1}$ is the diameter of longitudinal bars.

\section{Raoof and Zhang's model}

Zhang et al. [28] and Raoof and Zhang [24] developed a strength model for simply-supported $\mathrm{RC}$ beams reinforced by steel plates subject to three or four point bending that also could be used for FRP sheets. They base their model on the shear strength of a single concrete "tooth". To prevent the debonding failure mode, the proposed limiting value for the stress should be compared to the stress in the plate directly under a point load. Elastic behavior and no-interaction between adjacent cracks were assumed. The critical point in the concrete "tooth" is assumed to be at the point of contact between the concrete and the longitudinal steel reinforcement. The tensile stress at this point is represented by:

$$
\sigma=\frac{M}{I}\left(\frac{l_{\min }}{2}\right)
$$

where $M=\tau l_{\text {min }} b_{f r p} d^{\prime}$ and $I=b\left(l_{\text {min }}\right)^{3} / 12$. Here, $l_{\text {min }}$ represents the minimum crack spacing, $\tau$ the shear stress at the interface between the concrete and the plate, $I$ the moment of inertia of the tooth, and $M$ the moment at the base of the tooth. Substituting $M$ and $I$ into Eq.(25) and assuming $\sigma=f_{c t}$, the shear stress at the interface between the concrete and the strengthening plate based on a minimum stabilized crack spacing can be determined as follows. 


$$
\tau_{\min }=\frac{f_{c l} l_{\min }}{6 h^{\prime}} \frac{b}{b_{f r p}}
$$

The authors assumed the simultaneous failure of all end anchorage teeth at debonding. The minimum width of a crack $l_{m i n}$, termed the minimum stabilized crack spacing, is given by:

$$
l_{\min }=\frac{A_{c} f_{c t}}{u\left(\Sigma O_{b a r s}+b_{f r p}\right)}
$$

where $A_{c}$ is the area of concrete in tension, $u$ the strengthening plate -to-concrete average bond strength, $\Sigma \mathrm{O}_{\text {bars }}$ the total perimeter of the tension reinforcing bars. It is assumed that $u=0.28 \sqrt{f_{c u}}$ (in $\mathrm{MPa}$ ) and $f_{c t}=0.36 \sqrt{f_{c u}}$ (in $\mathrm{MPa}$ ). Considering a $\mathrm{RC}$ beam reinforced by a single plate, $A_{e}$ is twice the distance from the centroid of the tension reinforcement to the base of the $\mathrm{RC}$ beam multiplied by the width of the RC beam.

The minimum stress in the strengthening plate $\sigma_{s, \min }$ required to cause flexural cracking and failure of a tooth covering the minimum stabilized crack spacing can then be determined as follows:

$$
\sigma_{s(\min )}=0.154 \frac{L_{a} h_{1} b^{2} \sqrt{f_{c u}}}{h^{\prime} b_{f r p} t_{f r p}\left(\Sigma O_{b a r s}+b_{f r p}\right)}
$$

where $L_{a}$ is an effective length of the plate for end anchorage, and $h_{1}$ is the distance from the centroid of the tension reinforcement to the base of the $\mathrm{RC}$ beam.

In Zhang et al. [28], the effective length for end anchorage was taken as the length of the plate in the shear span. Raoof and Zhang [24] assumed that the anchorage length is equal to the smaller value between the length given in [28] and $l_{a}$, defined as follows:

$$
\begin{aligned}
& l_{a}=l_{\text {min }}\left(21-0.25 l_{\text {min }}\right), l_{\text {min }} \leq 72 \mathrm{~mm} \\
& l_{a}=3 l_{\text {min }}, l_{\text {min }}>72 \mathrm{~mm}
\end{aligned}
$$

This effective length model was calibrated to match test data of steel plated RC beams that failed by plate end debonding.

Once the stress in the plate is known, the moment that causes the separation of the plate, at the location where the stress is calculated, can be obtained using a conventional section analysis with the assumption that plane sections remain plane during bending and taking into account the tensile strength of the concrete. The higher bending moment is used assuming a minimum $\left(l_{\min }\right)$ and a maximum $\left(l_{\max }=2 l_{\min }\right)$ stabilized crack spacing. If the end of the plate does not reach the shear span zone, the effective length should be obtained from Eq. (28).

\section{Wang and Ling's model}

Wang and Ling (cited in [5]) modified the previous model [28] to adapt it to match the results for FRP strengthened beams. They modified the definition of the minimum width of a crack, proposed by Raoof and Zang in Eq.(26) by the following expression: 


$$
l_{\min }=\frac{A_{c} f_{c t}}{u_{s} \Sigma O_{b a r s}+u_{f r p} b_{f r p}}
$$

where $u_{s}=0.313 \sqrt{f^{\prime}}$ is the average bond strength between the steel tension reinforcement and the concrete, while $u_{f r p}$ is the average bond shear strength between the FRP and the concrete which was taken as $1.96 \mathrm{MPa}$.

\section{Raoof and Hassanen's models}

Raoof and Hassanen [25] tried to improve Zhang et al. model [28] proposing two expressions for the effective anchorage length of the FRP plate. These models will be called model I and model II.

In the first model [25], Eq. (30) is used to calculate the minimum stabilized crack spacing. The effective length of the FRP plate for end anchorage is taken to be the smaller of the plate length in the shear span and the following lengths which were calibrated based on the authors' experimental test data:

$$
\begin{aligned}
& l_{a}=l_{\text {min }}\left(24-0.5 l_{\text {min }}\right), l_{\text {min }} \leq 40 \mathrm{~mm} \\
& l_{a}=4 l_{\text {min }}, l_{\text {min }}>40 \mathrm{~mm}
\end{aligned}
$$

In Raoof and Hassanen model II [25], $u_{f r p}$ is equal to $0.8 \mathrm{MPa}$, as defined by Wang and Ling (cited in [5]), while $\mathrm{u}_{\mathrm{s}}$ is equal to $0.28 \sqrt{f_{c u}}$, as defined by Zhang model [28]. The effective length of the FRP plate for end anchorage is calculated as done in the Raoof and Hassanen model I [25], using the new value of FRP to concrete bond strength:

$$
\begin{aligned}
& L_{p 2}=l_{\text {min }}\left(11.6-0.17 l_{\min }\right), l_{\min } \leq 56.5 \mathrm{~mm} \\
& L_{p 2}=2 l_{\min }, \quad l_{\min }>56.5 \mathrm{~mm}
\end{aligned}
$$

Once the stabilized crack spacing and the effective length of FRP plate for end anchorage are determined, the remainder of the analysis follows the same steps given by Zhang et al.

\section{Ziraba et al. models}

Two debonding strength models were proposed by Ziraba et al. [26] for steel plated RC beams. Model I is used to predict plate end interfacial debonding, while Model II is used for predicting concrete cover separation.

Model I proposes an expression for the shear capacity of an RC beam, at the plate end, to cause plate end interfacial debonding:

$$
V_{b d, \text { end }}=\frac{f_{c}^{\prime}}{C_{R 1}}\left[\frac{C}{\alpha_{1} f_{c t}\left(1+\alpha_{2} C_{R 2} \tan \phi\right)}\right]^{4 / 5}
$$

where 


$$
\begin{aligned}
& C_{R 1}=\left[1+\left(\frac{K_{a}}{E_{f r p} b_{f r p} t_{f r p}}\right)^{1 / 2} \frac{M_{0}}{V_{0}}\right] \frac{b_{f r p} t_{f r p}}{I_{t r c, f r p} b_{a}}\left(d_{f r p}-x_{t r c, f r p}\right), \\
& C_{R 2}=t_{f r p}\left(\frac{K_{n}}{4 E_{f r p} I_{f r p}}\right)^{1 / 4}
\end{aligned}
$$

while $\alpha_{1}$ and $\alpha_{2}$ are empirical multipliers calibrated from numerical studies for RC beams retrofitted with steel plates. $\mathrm{C}$ is the coefficient of cohesion and $\varphi$ the angle of internal friction. This is the first known model that takes into account the adhesive layer properties where the shear stiffness $K_{a}$ and the normal stiffness $K_{n}$ of the adhesive layer are defined as:

$$
K_{a}=\frac{G_{a} b_{a}}{t_{a}}, K_{n}=\frac{E_{a} b_{a}}{t_{a}}
$$

with $G_{a}$ being the shear modulus of the adhesive layer respectively. $I_{t r c, f r p}$ is the moment of inertia of the cracked plated section transformed into FRP, $x_{t r c, f r p}$ is the neutral axis depth of this transformed cracked section (distance from the compression face to the neutral axis), $I_{f r p}$ the second moment of area of the FRP plate alone, $d_{f r p}$ the distance from the compression face of the RC beam to the centroid of the FRP plate, and $M_{0}$ and $V_{0}$ the bending moment and shear force respectively at the plate end.

This relationship is subject to the constraint of $a / h<3$. The following values for $\alpha_{1}, \alpha_{2}$ and $\varphi$ were specified in [26]: $\alpha_{1}=35, \alpha_{1}=1.1$ and $\phi=28$. For the present study $C$ has been taken as $7.15 \mathrm{MPa}$ which is an average of the values given in [26].

In Model II, Ziraba et al. [26] defined the shear beam capacity by modifying the ACI code equation; the contribution of steel reinforcement to the shear strength, $V_{s}$, is multiplied by a coefficient, $k$, which is empirically derived to account for the stirrup efficiency and is related to the peak interfacial normal stress at the plate end.

$$
V_{d b, \text { end }}=\left(V_{c}+k V_{s}\right)=1 / 6\left(\sqrt{f^{\prime}{ }_{c}}+100 \rho_{s}\right) b d+k\left(A_{s v} f_{y v} d\right) / s
$$

where $V_{c}$ and $V_{s}$ are respectively the contributions of concrete and steel shear reinforcement to the shear capacity of an $\mathrm{RC}$ beam. The $k$ value is based on a regression analysis of the test results of fourteen steel plated RC beams which failed by concrete cover separation:

$$
k=2.4 e^{n} \text { and } n=-0.08 C_{R 1} C_{R 2} \times 10^{6}
$$

\section{Wu and Niu model}

$\mathrm{Wu}$ and $\mathrm{Niu}$ [3] proposed a methodology for predicting the debonding failure caused by intermediate flexural cracks in flexural strengthening of RC beams with epoxy-bonded FRP sheets. The validity of the model was verified by comparing to an assembled database. The model based on fracture mechanics principles compares the maximum tensile force in the FRP to $P_{\max }$ which represents the maximum transferable load, derived from a pull-push or pull-pull shear tests. $P_{\max }$ can be expressed as follows: 


$$
P_{\max }=b_{f r p} \sqrt{2 G_{f} E_{f r p} t_{f r p}}
$$

where $G_{f}$ is the interfacial fracture energy consumed during debonding.

Taking into account a cracked FRP-strengthened beam, $P_{\max }$ represents the maximum stress value which the FRP can transfer at the beam without failing due to intermediate-crack (IC) debonding. This value is measured as difference between the FRP tension at maximum moment point and a $L_{e}^{\prime}$ spacing section.

The equivalent transfer length, $L_{e}{ }_{e}$ is twice of the effective transfer length determined from the simple bond tests; it requires to develop the maximum transferable FRP tensile stress $P_{\max }$, and can be computed as:

$$
L_{e}^{\prime}=2 L_{e}=\frac{1,3 \sqrt{E_{f r p} t_{f r p}}}{f_{c}^{\prime 0,095}}
$$

\section{Casas and Pascual's model}

Casas and Pascual [27] proposed a new, easy to apply model for the end debonding and the intermediate crack induced debonding of FRP-strengthened concrete beams. Debonding occurs when the nominal average shear stress reaches the allowable stress value $\tau_{\text {max }}$. Then, the tensile force per unit width in the FRP sheet, $\mathrm{T}_{\mathrm{u}}$, depends on the compressive strength of concrete, $f_{c}$, and the effective bond length $L_{e}$.

$$
T_{u}=\tau_{\max } L_{e}=0.996 \sqrt{f^{\prime}} L_{e}
$$

when the stiffness of the strengthened concrete element is much higher than the FRP stiffness, $L_{e}$ is defined as:

$$
L_{e}=\sqrt{\frac{k_{f r p}}{g_{b}}}
$$

where $k_{f r p}=E_{f r p} t_{f r p}$ is the axial stiffness per unit length of the FRP. $g_{b}$ is the shear joint stiffness of concrete plus adhesive resin, expressed as

$$
g_{b}=\frac{g_{a} g_{c}}{g_{a}+g_{c}} \quad \text { where } \quad g_{a}=\frac{G_{a}}{t_{a}}, g_{c}=\frac{G_{c}}{t_{c e}}
$$

$G_{a}$ and $G_{c}$ are the shear modulus of the resin and concrete. Poisson ratios for concrete and resin are taken as 0.50 and 0.38 respectively for the case where the concrete is in the plastic range as explained in [30]. $t_{a}$ is the resin thickness used in the application of the repair and $t_{c e}$ is the concrete thickness that can be estimated as :

$$
t_{c e}=b_{f r p}+50,8 \leq h / 2
$$

where $b_{f r p}$ and $h$ are expressed in mm. 
The failure criteria in the case of beams with two or more consecutive cracks spaced at a distance of $s(s \cong d / 2)$ can be found using an adjusted ultimate capacity expression by applying a coefficient $\beta$. Then, the ultimate force per unit width in the FRP is:

$$
T_{u}=\beta \tau_{\max } L_{e} \text { where } \beta=\frac{\xi_{1}}{1-\xi_{2} \xi_{3}}
$$

where the coefficients $\xi_{1}$ and $\xi_{2}$ are defined by the following functions:

$$
\xi_{1}=\frac{e^{s / L_{e}}-e^{-s / L_{e}}}{e^{s / L_{e}}+e^{-s / L_{e}}}, \xi_{2}=\frac{2}{e^{s / L_{e}}+e^{-s / L_{e}}}
$$

The simplified model is based on the moment-tension interaction M-T curve which relates the moments in the beam and the tension forces in the FRP characterized by the parameter $\xi_{3}$ defined as:

$$
\xi_{3}=1-\theta \frac{k}{k^{\prime}}\left(1-\frac{M_{2}}{M_{1}}\right)
$$

Assuming a bilinear behavior, the M-T curve is characterized by the parameters $k$ and $k$ ' which represent the slope of the linear elastic and post-yielding lines, respectively. The value of $\theta$ was demonstrated to be approximately equal to $2 / 3$. The ratio between the bending moment $M_{2}$ at a distance $d / 2$ from the section of interest and the bending moment at this section $M_{l}$ is obtained from a linear-elastic analysis.

\section{ACI 440.2R-08}

For sections away from the section where externally bonded FRP terminates, ACI 440.2R-08 [11] indicates that intermediate crack induced debonding can be prevented if the effective strain in the FRP remains below $\varepsilon_{\mathrm{fd}}$, defined as:

$$
\varepsilon_{f d}=0.41 \sqrt{\frac{f_{c}^{\prime}}{n E_{f r p} t_{f r p}}} \leq 0.9 \varepsilon_{f u}
$$

Where $\varepsilon_{f u}$ is the design rupture strain in the FRP.

\section{Analysis of end dedonding models}

In a first step of the analysis of the models, the shear force that led to the debonding of the FRP as obtained from the experimental data base $V_{\text {exp }}$, is compared to the shear value $V_{\text {an }}$, predicted by each of the models. To be consistent with the way the results of experimental investigations on end debonding are reported, $\mathrm{V}_{\mathrm{an}}$ is calculated at the end of the beam. On the other hand, for crack induced debonding, $\mathrm{V}_{\text {an }}$ is calculated in the maximum moment region. The ratio of $\mathrm{V}_{\exp } / \mathrm{V}_{\text {an }}$ is obtained for each applicable test result and the average ratio for each model is defined as the model's bias. A model's Coefficient of Variation (COV) is defined as the standard deviation of the ratios divided by the bias. The results for all the models studied in this paper are summarized in Table 4. In addition to finding the mean bias and COV, the ratios for each model are plotted on 
Normal and Lognormal probability scales to identify which of these two probability distributions can best describe the scatter around the bias. The regression coefficient $\mathrm{R}^{2}$ for the regression analysis performed on the probability scale plot is used as a measure of the goodness of the probability distribution. Thus, when the $\mathrm{R}^{2}$ approaches 1.0 on the Normal probability plot, the bias is considered to be well represented by the Normal distribution.

In Table 4, the comparison of the results of the end debonding considering only carbon FRP sheets is divided into two groups based on the installation type: (i) carbon wet lay-up (C-W) and (ii) carbon prepeg plates (C-P). The very low number of beams reinforced by glass or aramid FRP sheets does not allow for a realistic analysis of the models. Also, in each case, the number of valid tests that could be used in the comparison was limited for various reasons. In many cases, the models require as input specific detailed information about material properties that were not reported by the experimentalists. In other cases, the geometric and other conditions under which the models are applicable were not satisfied. These conditions and requirements have vastly limited the number of usable experimental test results. For instance, it was found that many tested specimens did not satisfy the flexural strength ratio range for which the Smith and Teng model [6] is applicable. In many cases, the Colotti et al. model [19] predicts a different failure mode than the one observed from test results. Casas and Pascual's model [27] as well as Ziraba's model [26] base their predictions on the resin's properties which have been reported by only a few experimental investigators. A large number of tested specimens have extended the FRP sheets all the way to the end supports which meant that these could not be used to verify Janze's model nor that of Ahmed and van Gemert The number of valid test results for each model is provided in Table 4. For wet lay-up installations that failed by end debonding, the maximum number of usable tests is as high as 90 for the Teng and Yao model and as low as 19 for the Casas and Pascual or the Ziraba models. For prepeg sheet installations that failed by end debonding, the number of usable tests ranged from 59 down to 38 for the Casas and Pascual and the Ziraba models.

The bias values and COV's in Table 4 show large differences in the results between the models. Most models were developed to provide conservative envelopes to the experimental results for the specific objective of using the models for design purposes. These models show various levels of conservatism expressed in terms of bias ratios ranging from just above 1.0 (1.09) for the Colotti et al. model [19] applied to CP sheets up to 3.1 for the Raoof and Hassanen Model II [25] applied to the CP sheets. On the other hand, the models of Jansze and Ahmed and van Germert overpredict the experimental results for both the wet lay-up and prepeg installations by a considerable margin, yielding bias values varying between 0.64 and 0.82 . This makes these two models less likely to be useful for application as predictive models or design models unless augmented by high safety factors.

The model by Colotti et al. seems to provide on the average results that are the closest to those from the tests with an average bias of 0.90 for wet layups and a bias of 1.09 for prepeg beams respectively. This gives an indication that Colotti is the closest to being used as a predictive model. It is noted however that in many instances, this model, which was developed to not only estimate the load at failure but also the failure mode, did not predict the correct failure mode even when the predicted load at failure was close to the reported experimental value. Applying the model to the database, it is observed that only in $56.7 \%$ of the cases was the analytically predicted failure mode consistent with the observed mode.

Several models, particularly, those of Ahmed, Raoof and Hassanen, Colotti and Ziraba I, show considerable differences exceeding $10 \%$ between the biases obtained for the wet lay-up specimens and the pre-peg specimens. Although differences in the variability in the results may be expected due to the difficulty of controlling the resin's thickness in the different installations procedures, none of the models distinguishes between installations methods. Therefore, good models should provide similar biases independent of the installation method, even though the standard deviations may be different to reflect the variability in the resin thickness associated with the different installation methods. 
The standard deviation and the Coefficient of Variation (COV) provide a means to evaluate the consistency of the models. The models showing very high variability, with standard deviations on the ratios of $\mathrm{V}_{\text {exp }} / \mathrm{V}_{\text {an }}$ exceeding 1.0, include those of Raoof and Zhang [24], Raoof and Hassanen [25], and Ziraba I [26]. A normalized measure of the variability in the model accuracy is expressed in terms of the Coefficient of Variation. Table 4 shows that most models give very high COV's emphasizing the difficulties associated with predicting the debonding strength of FRP-strengthened concrete beams. In particular, the models by Raoof and Hasannen, Raoof and Zhang, Ziraba, Jansze and Ahmed and van Germert are associated with COV's exceeding 40\%.

The models showing the lowest COV values are those of Smith and Teng for both CP and wet lay-up installations and Casas and Pascual tested with the 19 data points that provided all the necessary input parameters as well as that of Colotti for wet lay-up.

The plots of $\mathrm{V}_{\text {exp }} / \mathrm{V}_{\text {an }}$ on Normal and Lognormal scale help associate the variability of each model with a probability distribution type. As an example, Figure 2 shows the plot of the ratios obtained for the Casas and Pascual model for wet lay-up on Normal probability scale. When the data points lie on a straight line, they give an indication that the data follow a Normal probability distribution. The regression coefficient of determination $\mathrm{R}^{2}$ of the linear fit on this normal probability scale provides a measure of how well the probability distribution will predict future outcomes. Also, the regression equation provides an approach to obtain the mean and standard deviation of the Normal distribution that best describe the variation in the data. Specifically, the mean of the Normal distribution is obtained by setting the ordinate " $y$ " of the regression equation equal to zero and solving for $x$. In this example of the Casas and Pascual model, the mean ratio or the bias is obtained as 2.2 which is the same value obtained from the point estimation procedure of the bias. The standard deviation is obtained by setting the ordinate " $y=1$ " and solving for $\mathrm{x}$ which in this case is the sum of the mean plus the standard deviation. In this case, the standard deviation is found to be 0.52 which is higher than the 0.46 value obtained from the point estimates as shown in Table 4, but still reasonably close given the relatively large variability in the data. Thus, the Normal probability plot with a coefficient of determination $\mathrm{R}^{2}=0.96$ indicates that $96 \%$ of the variation in the data can be explained by describing the ratio of $\mathrm{V}_{\exp } / \mathrm{V}_{\text {an }}$ as a random variable that follows a Normal probability distribution with a mean $=2.21$ and a standard deviation $=0.52$ or a $\mathrm{COV}=24 \%$. The plot on the Lognormal scale (Figure 3) shows a lower $\mathrm{R}^{2}=0.94$ value indicating that the Normal distribution gives a better description of the variability of the data.

Because the number of valid tests for the Casas and Pascual model was relatively small with only 19 valid tests, more tests were fitted to this model by assuming that the properties of the resin are known and equal to the average properties from the 19 tests for which such data is available. This approach is similar to the one used by Smith and Teng [6]. In this case, the thickness of the resin is assumed to be $t_{a}=2 \mathrm{~mm}$ for C-P and $0.42 \mathrm{~mm}$ for C-W. The modulus of elasticity for the resin is $\mathrm{E}_{\mathrm{a}}=8500 \mathrm{MPa}$. This increased the number of valid tests to 90 for $\mathrm{C}-\mathrm{W}$ tests and to 59 for prepeg test beams. Applying the model to all $90 \mathrm{C}-\mathrm{W}$ data points, the mean of the bias is slightly reduced to 1.89 from the original 2.21, while the standard deviation increases from the original 0.46 to 0.57 . The range of the tests however is widely increased to range from $186 \mathrm{kN}$ to $6.70 \mathrm{kN}$. The same coefficient of determination $\mathrm{R}^{2}$ is reported. For the C-P beams, using 59 data points instead of the original 38 data for which all the information is provided the bias changes from 2.27 to 2.13 while the COV remains practically the same at $24 \%$.

Table 4 also lists which of the Normal or Lognormal probability distributions can best describe the variability in each of the models based on the $\mathrm{R}^{2}$ values which are also provided in the table. For example, the table shows that the variability in the results of the model of Teng and Yao [22] applied using the ACI equations for the shear capacity of concrete beams can very well be described using a Normal probability distribution whereas the application of the Colotti model [19] for prepeg installations shows the least good fit on either the Normal or Lognormal plots. It should be noted that during the plotting on the probability scale when occasionally a single data point 
would clearly shift the linear regression, this point was designated as an outlier and removed from the linear regression analysis.

In summary, the results of this first set of statistical analyses can be used to relate the actual load that is expected to lead to the debonding of an FRP strengthened concrete beam to the analytically predicted load using an equation of the form:

$$
V_{\text {actual }}=\lambda V_{\text {analytical }}
$$

where the analytically predicted load that causes failure $\mathrm{V}_{\text {an }}$ is calculated using as input the basic geometric and material parameters relevant to the model being used, $\lambda$ is a random variable with a mean equal to the bias and a COV as given in Table 4 for each model and installation type and $\lambda$ would follow the appropriate probability distribution for the model being used. It should be noted that the variability in $\lambda$ as expressed in the COV values of Table 4 does not account for the variability in the input material and geometric parameters in actual installations where these parameters are not carefully controlled.

The use of Eq. (50) to represent the bias and the variability in the analytical model imply that the same bias is applicable for the whole range of loads and beam sizes and that the tests were performed on beams having geometries that adequately represent the geometries on which the models will apply. Unfortunately, as observed in the data presented in Appendix A and B, the range of beam sizes for the test specimens is relatively small and is not necessarily representative of the dimensions expected in engineering applications such as for bridges. Furthermore, most of the tests were performed on very small scale beams and few of the tests are performed on medium or full scale beams. The value of $\lambda$ that is obtained from the average of the beams tested will be mostly influenced by the large number of small scale tests as compared to the fewer medium or full scale tests. A good representation of $\lambda$, must be obtained when the tested beam sizes are adequately distributed over the applicable dimension range. An approach is used next in an attempt to account for the fewer number of medium scale tests. The approach consists of applying a regression analysis rather than the point estimation method described above to study the relationship between experimental results and predicted analytical results.

A second set of statistical analyses performed as part of this study consists of plotting the experimental results expressed as $\mathrm{V}_{\exp }$ versus the model prediction $\mathrm{V}_{\text {an }}$ and performing a linear regression fit of the data. The best linear expression that describes the relationship between $\mathrm{V}_{\text {an }}$ and $\mathrm{V}_{\text {exp }}$ is thus obtained. The regression is executed such that the line goes through the origin $(0,0)$. The analysis of the regression residuals consists of a plot of the residuals (differences between $V_{\exp }$ and $\mathrm{V}_{\mathrm{an}}$ ) to verify their distribution around zero and the calculation of the residuals' standard deviation. In addition, the standard error of the regression's coefficient is also calculated. Figures 4, through 9 provide examples of the regression analysis performed for a number of the models. Specifically, the figures illustrate the regression results for the wet lay-up and pre-peg installations of beams that were compared to the Smith and Teng [6], Colotti [19] and Casas and Pascual model [27] for the end debonding of FRP. These results are selected for illustration because they showed relatively good relationship between the experimental and analytical as expressed in regression coefficients of determination $\mathrm{R}^{2}$ which are higher than 0.90 for both types of installation. The results of the analyses for the plotted data and all the other models are also summarized in Table 4.

The regression analysis shows how well the relation between the experimental results and the analytical results can be represented by an equation of the form:

$$
\mathrm{V}_{\mathrm{exp}}=\mathrm{a} \mathrm{V}_{\mathrm{an}}+\varepsilon
$$


where the regression error $\varepsilon$ follows a Normal probability distribution with an average value of zero and a standard deviation $\sigma_{\varepsilon}$. The coefficient $a$ or the slope of the linear relationship can also be considered to be a random variable with a standard deviation, $\sigma_{a}$. Table 4 gives a listing of the regression coefficient, a, the regression coefficient standard error, $\sigma_{\mathrm{a}}$, the regression error, $\sigma_{\varepsilon}$ and regression coefficient of determination $\mathrm{R}^{2}$. These data can be used to obtain the $95 \%$ confidence intervals on the regression equation as well as the $95 \%$ prediction intervals which are respectively shown in red and blue dashed lines in Figures 4 through 9 for the cases with relatively high $\mathrm{R}^{2}$ values.

The results summarized in Table 4 indicate that all the slopes of the best fit line, "a", have very narrow bounds with standard errors of less than 0.10. On the other hand, large variations in the overall standard error expressed as $\sigma_{\varepsilon}$ are observed where $\sigma_{\varepsilon}$ varies between a low of $\sigma_{\varepsilon}=5.91$ for the Casas and Pascual model [27] for wet lay-up installations and $\sigma_{\varepsilon}>35$ for the Wang and Ling (cited in [5]), Raoof and Hassanen [25] and Zhang models [28]. These same models have also very low regression coefficients $\mathrm{R}^{2}$.

In most cases, the value of the regression slope of Eq. (51) is quite similar to the bias obtained from Eq. (50) highlighting the robustness of the statistical analysis process for the given range of beam sizes and beam capacities. The cases where the difference between $a$ and the bias $\lambda$ is significant are those for which the regression analysis produced low $\mathrm{R}^{2}$ values indicating that the variability in $\mathrm{V}_{\text {exp }}$ is not well described by the expression of Eq. (50) or for those in which the regression equation of Eq. (51) was driven by a few points at high values of $V_{\text {an }}$ and where the residuals are not evenly distributed around zero. This problem may be explained by the scaling effect since most of the available test results have been performed on small scale laboratory specimens. More tests need to be executed on full scale beams to verify the consistency of the current models for all pertinent scale levels.

The plots shown in Figures 4 to 9 are for the models that showed the highest $\mathrm{R}^{2}$ values. These models also happen to have among the lowest regression standard errors. The figures show the plots of the $\mathrm{V}_{\text {exp }}$ versus $\mathrm{V}_{\text {an }}$ as well as the regression line. Also, shown in the figure are the upper and lower $95 \%$ confidence intervals of the regression line as well as the upper and lower $95 \%$ prediction intervals. The plots are shown at the same scale varying between $0 \mathrm{kN}$ to $200 \mathrm{kN}$ to highlight the limitations in the applicable ranges for each of the models. For example while the Smith and Teng [6] and the Colotti [19] models show a wider range for the upper and lower 95\% intervals than the Casas and Pascual model [27] for wet lay-up tests analyzed with the 19 data for which all the information is provided. The limited range for which the applicability of the Casas model can be tested is readily noticed. Increasing the number of valid tests for the Casas and Pascual model from 19 to 90 by using average values for the resin material increased the range of valid test results to $186 \mathrm{kN}$. This reduced the slope of the regression line from the original 2.18 to 1.65 . The standard error however increases from the original 5.91 to 20.92. It should however be noted that some of the increase in the error may reflect the deviation of the true resin properties from those assumed by taking average values.

For the prepeg tests, the range of applicability of all models is approximately the same with a high shear force of $80.10 \mathrm{kN}$. The data plots in Figure 9 show the regression results of the Casas and Pascual model. If the number of valid tests is increased from 38 to 59 by using the average properties of the resin, a smaller drop in the slope from the original 2.14 to 1.99 for the Casas and Pascual model is observed for the C-P samples as compared to the C-W samples. These results serve to further emphasize the importance of performing large scale tests for obtaining higher confidence levels in our ability to predict the strength of FRP strengthened beams and have more confidence in the design of such strengthening schemes. 


\section{Analysis of IC induced debonding strength models}

The results shown in Table 4 for the intermediate crack-induced debonding case compare the analytical results from the Casas and Pascual Model [27], the $\mathrm{Wu}$ and Niu model [3] and the ACI model [11] for different subgroups of the experimental database. Different numbers of specimens are used in each comparison because the different models require different input that may not have been made available in the published test results. For example, the Casas and Pascual model requires the properties of the adhesive layer as input, whereas they are not required for the other models. Only 24 tests in Appendix B out of which 20 are reinforced concrete beams strengthened with CFRP, reported the values of the resin's thickness. The second comparison made for the Casas and Pascual model adds two large scale experiments of two beams that had been previously damaged under static loading and then strengthened using FRP sheets as reported by Casas et al. [27,31]. The third comparison of the Casas and Pascual model includes the whole set of experimental data including the tests for which no resin properties were available. In these cases, as done for the end debonding when necessary, a resin thickness $t_{a}$ is assumed to be equal to $2 \mathrm{~mm}$ for pultruded installations and according to equations (2) and (3) for wet lay-up installations. The modulus of elasticity, $E_{a}$, is set equal to the average of the available values $(7389 \mathrm{MPa})$. A parametric analysis has shown that the final results are not very sensitive to changes in this assumed value as demonstrated by Ceci [20]. For example, if $\mathrm{E}_{\mathrm{a}}$ is changed to $3000 \mathrm{MPa}$ the values of $\mathrm{V}_{\mathrm{an}}$, increase by a maximum of $+7.0 \%$. When $\mathrm{E}_{\mathrm{a}}$ is set at $12000 \mathrm{MPa}$, the values of $\mathrm{V}_{\text {an }}$ decrease by about $2.2 \%$. Due to the low number of tests performed on beams with wet lay-up installations, the analysis of intermediate crack induced debonding does not distinguish between the method of installation and the data includes pre-peg as well as wet lay-up installations.

$\mathrm{Wu}$ and Niu model is based on a fracture mechanics approach to study if the crack would progress along the interface between the FRP and the concrete. The model does not require input on the resin characteristics. This model considers the possibility that the beam fails due to either concrete crushing or FRP rupture. In 5 of the 20 tests considered, the model predicted the wrong failure mode ( 3 FRP rupture and 2 concrete crushing). For this reason, only 15 of the 20 beams for which all the properties are provided are compared for the $\mathrm{Wu}$ and Niu model in the IC group of Table 4. Subsequently, all the experimental data for which the $\mathrm{Wu}$ and Niu predicted the correct failure mode were included in the analysis.

Similarly, the ACI method does not require the resin's properties and it only requires as input the FRP properties and the concrete strength. IC debonding occurs before concrete crushing which for design purposes, and according to ACI, is assumed to take place when the maximum concrete strain $\varepsilon_{\mathrm{cu}}$ reaches 0.003 . However, it is well known that in actual situations concrete may exceed this nominal design strain value. Therefore, three cases are considered for the evaluation of the ACI model. Case 1 compares the ACI equations to experimental results where the maximum strain in the concrete remains below 0.003 and for which all the resin properties are known. Thirteen specimens satisfied these requirements. This Case 1 is checked to compare the ACI results to those of the Casas and Pascual model even though the ACI equations do not require the resin properties as input. Case 2 performs the statistical analysis for all the 68 specimens where the concrete strain, according to ACI equations, remains below 0.003. Case 3 performs the statistical analysis for 183 specimens for which the concrete strain may have exceeded the 0.003 design limit, yet the actual test failure was reported to be caused by IC debonding rather than concrete crushing.

The results of the statistical analysis summarized in Table 4 show that the $\mathrm{Wu}$ and Niu model [3] vastly over-predicts the failure load. This is reflected by a point estimation of the bias $\lambda$ and a regression slope, a, significantly less than 1.0. The regression analysis results for the $\mathrm{Wu}$ and Niu model [3] are shown in Figure 10. The results of the Casas and Pascual model [27] for the original 
20 beam tests are shown in Figure 11. The results of the Casas and Pascual model [27] show a point estimated bias value of 1.88 and a slope for the regression line of 1.76 which although slightly different are nevertheless within a close range. However, both figures 10 and 11 highlight the low range of values for which the $\mathrm{Wu}$ and Niu [3] as well as the Casas and Pascual models [27] were tested when only the beams with known resin properties were analyzed. In order to increase the range, two additional tests obtained from [27,31] have been added to the database. The inclusion of these two additional tests into the results of the Intermediate debonding database labeled Casas IC + Casas D in Table 4, show how the inclusion of a few large scale tests will alter the results of the regression analysis. As a matter of fact as noted in Table 4, the point estimation of the bias changes very little from 1.88 to 1.80 when the two large scale tests are added. These values are similar to the regression coefficient of 1.76 obtained for the original data set. On the other hand, the lack of sufficient test data along the whole range of application has meant that the point estimation of the bias becomes inconsistent with the regression fit of Eq. (50) when the additional tests are included. In this case, the regression line slope of 1.08 is significantly different from the point estimated bias. The reasons for this discrepancy are illustrated in Figure 12 that shows how the large number of data points in the lower load ranges controls the point estimation statistics, while the regression analysis provides what seems to be a more balanced evaluation of the relationship between $V_{\exp }$ and $\mathrm{V}_{\mathrm{an}}$ in the whole range of the tests. It should be noted that the addition of the two large scale tests have led to a higher regression standard error $\sigma_{\varepsilon}$ of 8.34 as compared to the original standard error of 2.78. More large scale tests are needed in order to further verify the relationship between the predicted values and experimental test results. Significant differences are observed in the bias and the regression coefficients as well as in the COV's and regression errors when the data for which no resin properties are provided are included with the assumed resin properties. These differences are due to both the increase in the database as well as the assumptions on the resin properties.

The inclusion of the additional experimental data for the analysis of the $\mathrm{Wu}$ and Niu model gives a lower bias value which changes from 0.60 to 0.50 increasing the gap between the model results and the experimental results. This difference is only due to the increase in the database and is not related to the resin properties since the $\mathrm{Wu}$ and Niu model does not require the resin properties as input.

The results of the ACI440.2R model demonstrate the importance of having a large database that extends to the whole range of practical beam dimensions. The results show that when applied as intended for only the cases where concrete strain remains below 0.003 (Case 2), the ACI model shows a bias of 1.22 and a COV 0.45 . While a bias above 1.0 indicates that on the average the ACI equation is conservative, the high $\mathrm{COV}$ of $45 \%$ would indicate that many beams will fail at lower loads than anticipated by the ACI equations. This is further confirmed when looking at the regression coefficient for case 2 which falls to 0.91 with a regression error of 36.73 . The high COV and regression error are practically similar to those of the Casas and Pascual model although in the latter case, the required resin properties have to be assumed while no such properties are needed for the ACI model. When all the data are considered including those for which the concrete strain exceeds the nominal limit of 0.003 (Case 3) the value of the ACI bias drops back to 0.87 and the regression coefficient is 0.77 which are both significantly lower than 1.0 .

The large differences between the regression coefficient and the bias between cases 2 and 3, reflect the fact that the regression analysis puts some additional weighting on the few large scale tests as compared to the bias which is an average value that may be more influenced by the many tests on small scale specimens. This phenomenon may be visualized in the plot of Figure 13.

One reason for the inconsistencies between the predicted load and the experimental failure load may be due to the fact that the Wu and Niu and the ACI models were calibrated based on tests performed on prisms rather than on beam tests. The use of the prism tests means that these two 
models are applicable for type-1 IC debonding, where there are no other cracks between the crack where the delamination process initiates and the end of the FRP sheet. In prism tests, the tension at the end of the FRP sheet is zero, which is not the case when there are other cracks in between the initiating crack and the end of the FRP sheet. Also, the effect of the curvature in the beam is ignored in the prism tests. While the Casas and Pascual model takes these factors into account, the $\mathrm{Wu}$ and Niu fracture mechanics-based model considers only type-1 IC debonding. Similarly, the ACI model is based on the bond-strength model proposed by Chen and Teng, which was calibrated with a large data base of shear tests, and verified with a limited number of tests of RC beams in flexure. However, a significant number of additional tests have been used in the present analysis. This may explain why the ACI and Wu and Niu models over-predict the resistance of beams in IC debonding where a combination of type-1 and type-2 IC debonding is observed.

As expected for all IC models, the inclusion of the additional data set increases the COV associated with the point estimation of the bias by a significant amount. For the Casas and Pascual model one reason for the increase in the COV is due to the possible differences between the assumed resin properties and the real values which are not known. The COV of the Casas model increases from $18 \%$ to a very high $65 \%$, while the $\mathrm{Wu}$ and Niu COV increases from $32 \%$ to $46 \%$. The COV associated with the ACI bias also increases from $29 \%$ with the limited data set to $55 \%$ with the full data set. Figure 13 shows the plot for the ACI comparison with the full data set. The larger range of the loads that cause failure is reflected by the larger scale used. The increase in the COV with the larger database may be due to the scale effects when the models are developed based on small scale specimens as well as the preponderance of type- 2 debonding in the additional beam tests included.

Similar observations to those noted above for the bias can be made for the regression coefficients. The trends in the regression standard error are also similar to those observed for the COV.

\section{Conclusions}

In this paper, two experimental databases were assembled to study the debonding failure mechanism of concrete beams reinforced in flexure using FRP sheets. One database is for beams that failed due to end debonding and the second database is for beams that failed due to intermediate-crack induced debonding. The database for beams that failed by end debonding includes 34 testing programs, consisting of 161 tests performed on beams of various dimensions. The 184 beams that failed in intermediate crack induced debonding were collected from 37 different experimental investigations. The databases assembled in this study build up on the data bases previously assembled by Smith and Teng [6]and Colotti [19].

The two databases were used to evaluate the suitability of existing analytical models for designing FRP strengthening schemes that resist debonding or for predicting the debonding failure mode. The goal of the analysis is to asses the applicability of existing models for calibrating design criteria and proposing reliability-based safety factors which would produce uniform levels of safety during the design of FRP strengthening schemes for concrete beams in bending. Twelve models were investigated for end debonding and three models for intermediate crack induced debonding. Based on the comparative study, the following conclusions can be drawn:

1. Many models were verified or calibrated to match the results of specific databases and may not produce similar results when the test conditions or scales are different than those of the 
tests that generated the models. For example, the $\mathrm{Wu}$ and Niu model [3] was found to overpredict the test results reported by other investigators.

2. The objective of many model authors was not necessarily to predict correctly the load of failure, but to provide a model that will lead to safe lower bounds on the failure loads for design purposes. For example, this is the approach taken by Smith and Teng [6] and Teng and Yao [22] whose models show large values for the bias of the model which gives the average ratio of the experimental results to the analytical results. Also, the ACI model for IC debonding was developed to prevent this mode of failure and not to predict it. However, even when the average bias for the design equation may exceed 1.0 by a significant margin, the high variability in the test results may show that in many cases, the proposed equations may overpredict the load carrying capacity of FRP strengthened beams. Therefore, it is important to calibrate design equations for FRP debdonding using structural reliability criteria that ensure that the design equations produce acceptable levels of safety that are consistent with those of other structural failure modes.

3. Colotti et al. proposed a model [19] based on strength of materials criteria to not only predict the failure load but also the mode of failure of strengthened RC beams and came closest to providing a predictive model rather than a safe design model.

4. The design models which gave the lowest coefficients of variation (COV) while showing consistent results for end debonding for both pre-peg and wet lay-up installations are the Smith and Teng [6] and the Casas and Pascual model [27]. The Casas and Pascual model takes into consideration the interaction between FRP, the resin and the concrete which all other models except for Ziraba [26] ignored.

5. One clear advantage of the Casas and Pascual model [27] is that it can be used for end debonding and also for intermediate crack-induced debonding.

6. The results show that many models give good predictions for wet lay-up installations but few models give the same level of accuracy for prepeg plates. Very few models take into account the difference in behavior due to the installation process.

7. Most models ignored the effect of the FRP-concrete interface and did not take the resin properties into account although recent studies have shown that the debdonding process does initiate at the interface.

8. As previously reported in [27], it is noted that the scale effect is very important for the debonding mode of failure and that more tests need to be executed on full scale beams to verify the consistency of the current models for all pertinent scale levels.

The conclusions presented in this paper provide a statistical analysis of the response of FRP flexurally strengthened beams and, therefore, they are the first step on the way to developing a set of reliability-based partial safety factors to use during the design of FRP strengthening schemes for bridge decks and beams. This will be the subject of a companion paper.

\section{Acknowledgements}

The financial support provided by the Spanish Ministry of Education through the Research Project BIA2010-16332 is greatly acknowledged. The third author also acknowledges the financial support provided by the Spanish Ministry of Education during his sabbatical leave at the Technical University of Catalonia (UPC) under the scholarship SAB2009-0164. 


\section{References}

[1] Hollaway LC, Teng JG (2008). Strengthening and rehabilitation of civil infrastructures using fiber-reinforced polymer (FRP) composites. Cambridge (England): Woodhead Publishing Limited.

[2] Arduini M, Nanni A (1997). Parametric study of beams with externally bonded FRP reinforcement. ACI Struct J; 94(5): 493-501.

[3] Wu Z, Niu H (2007). Prediction of crack-induced debonding failure in R/C structures flexurally strengthened with externally bonded FRP composites. Doboku Gakkai Ronbunshuu E; 63(4):620-639.

[4] Karbhari VM, Niu H, Sikorsky C (2006). Review and comparison of fracture mechanics-based bond strength models for FRP-strengthened structures. J Reinforced Plastics and Composites; 25:1757-1794.

[5] Smith ST, Teng JG (2002). FRP-strengthened RC beams. I: review of debonding strength models. Eng Struct; 24:385-395.

[6] Smith ST, Teng JG (2002). FRP-strengthened RC beams. II: assessment of debonding strength models. Eng Struct; 24:397-417.

[7] Yao J, Teng JG, Lam L (2002). Debonding in RC cantilever slabs strengthened with FRP strips. Proc Int Conf on Advanced Polymer Composite for Structural Applications in Construction, Southampton University, UK; 125-133.

[8] Chajes MJ, Finch Jr WW, Januska TF, Thomson Jr TA (1996). Bond and force transfer of composite material plates bonded to concrete. ACI Struct J; 93(2):208-217.

[9] Ross CA, Jerome DM, Tedesco JW, Hughes ML (1999). Strengthening of reinforced concrete beams with externally bonded composite laminates. ACI Struct J; 96(2):212-220.

[10] Rahimi H and Hutchinson A (2001). Concrete beams strengthened with externally bonded FRP plates. J Comp Construct; 5(1):44-56.

[11] ACI440.2R-08 (2008). Guide for the design and construction of externally bonded. FRP systems for strengthening concrete structures. Farmington Hills: American Concrete Institute.

[12] CNR-DT 200/2004 (2004). Guide for design and construction of externally bonded FRP systems for strengthening concrete structures. National Research Council.

[13] Federation Internationale du Béton, FIB (2001). Externally bonded FRP reinforcement for RC structures. Fib bulletin 14, Lusanne, Switzerland.

[14] JSCE (2001). Recommendations for upgrading of concrete structures with use of continuous fibre sheets. Japan Society of Civil Engineers, Japan.

[15] TR55 (2004). Design guidance for strengthening concrete structures using fibre composite material. Technical Report no. 55. $2^{\text {nd }}$ edition. London: The Concrete Society.

[16] Triantafillou TC, Plevris (1992). Strengthening of RC beams with epoxy-bonded fibrecomposite materials. Mat and Struct; 25:201-211.

[17] Atadero RA, Karbhari VM (2008). Calibration of resistance factors for reliability based design of externally-bonded FRP composites. Composites: Part B; 39: 665-679.

[18] Atadero RA, Karbhari VM (2009). Sources of uncertainty and design values for fieldmanufactured FRP. Comp Struct; 89:83-93.

[19] Colotti V, Spadea G, Swamy RN (2004). Structural model to predict the failure behavior of plated reinforced concrete beams. J Comp Construct; 8(2):104-122.

[20] Ceci AM (2009). Development of Design Specifications for Strengthening Deteriorated Concrete Bridge Elements using Externally Applied FRP Sheets. Master Thesis, Technical University of Catalonia (UPC), Barcelona, Spain.

[21] Oehlers DJ (1992). Reinforced concrete beams with plates glued to their soffits. J Struct Eng; 118(8):2023-2039. 
[22] Teng JG, Yao J (2007). Plate end debonding in FRP-plated RC beams I: Experiments. Eng Struct; 29:2457-2471.

[23] Teng JG, Yao J (2007). Plate end debonding in FRP-plated RC beams II: Strength model. Eng Struct; 29:2472-2486.

[24] Raoof M, Zhang S(1997). An insight into the structural behaviour of reinforced concrete beams with externally bonded plates. Proc Inst Civil Eng, Struct and Build; 122:477-492.

[25] Raoof M, Hassanen MAH (2000). Peeling failure of reinforced concrete beams with fibrereinforced plastic or steel plates glued to their soffits. Proc Inst Civil Eng, Struct and Build; 140(3):291-305.

[26] Ziraba YN, Baluch, Basunbul IA, Azad AK, Al-Sulaimanu GJ, Sharif AM (1995). Combined experimental-numerical approach to characterization of steel-glue-concrete interface. Mat and Struct; 28(9):518-525.

[27] Casas JR, Pascual J (2007). Debonding of FRP in bending: Simplified model and experimental validation. Constr and Build Mat; 21:1940-1949.

[28] Zhang S, Raoof M, Wood LA (1995). Prediction of peeling failure of reinforced concrete beams with externally bonded steel plates. Proc Inst Civil Eng, Struct and Build; 110:257-268.

[29] EN1992 (1992). Design of concrete structures. European Commitee for Strandardization (CEN).

[30] Martinez, J., Ortiz, J. (1978). Construccion Mixta: Hormigon-Acero. Editorial Rueda. (in Spanish)

[31] Ramos G, Casas JR, Alarcón A (2004). Repair and strengthening of segmental bridges using carbon fibers. Eng Struct; 26: 609-618.

[32] Benjeddou O, Ouezdou MB, Bedday A (2007). Damaged RC beams repaired by bonding of CFRP laminates. Constr and Build Mat; 21:1301-1310.

[33] Breña SF, Macri BM (2004). Effect of carbon-fiber-reinforced polymer laminate configuration on the behavior of strengthened reinforced concrete beams. J Comp Construct; 8(3):229-240.

[34] Esfahani MR, Kianoush MR, Tajari AR (2007). Flexural behavior of reinforced concrete beams strengthened by CFRP sheets. Eng Struct; 29:2428-2444.

[35] Fanning P, Kelly O (2000). Smeared crack models of RC beams with externally bonded CFRP plates. Computational Mechanics; 26:325-332.

[36] Garden HN, Quantrill RJ, Hollaway LC, Thorne AM, Parke GAR (1998). An experimental study of the anchorage length of carbon fibre composite plates used to strengthen reinforced concrete beams. Constr and Build Mat; 12:203-219.

[37] Grace NF, Singh SB (2005). Durability evaluation of carbon fiber-reinforced polymer strengthened concrete beams: Experimental study and design. ACI Struct J; 102(1):40-48.

[38] Matthys S (2000). Structural behavior and design of concrete members strengthened with externally bonded FRP reinforcement. PhD thesis, Ghent University. Brussels.

[39] Nguyen DM, Chan TK, Cheong HK (2001). Brittle failure and bond development length of CFRP-concrete beams. J Comp Construct; 5(1):12-17.

[40] Pham HB, Al-Mahaidi R (2006). Prediction models for debonding failure loads of carbon fiber reinforced polymer retrofitted reinforced concrete beams. J Comp Construct; 10(1):48-59.

[41] Ritchie PA, Thomas DA, Lu LW, Conelly GM (1991). External reinforcement of concrete beams using fiber reinforced plastics. ACI Struct J; 88(4):490-499.

[42] Saadatmanesh H, Ehsani MR (1991). RC beams strenghtened with GFRP plates.I: Experimental study. J Struct Eng; 117(11):3417-3433.

[43] Sharif A, Al-Sulaimani GJ, Basunbul A, Baluch MH, Ghaleb BN (1994). Strengthening of initially loaded reinforced concrete beams using FRP plates. ACI Struct J; 91(2):160-168.

[44] Spadea G, Bencardino F, Swamy RN (1998). Structural behavior of composite RC beams with externally bonded CFRP. J Comp Construct; 2(3):132-137. 
[45] Täljsten B (1997). Defining anchor lengths of steel and CFRP plates bonded to concrete. Int J Adhesion and Adhesives; 17:319-327.

[46] Bonacci JF, Maalej M (2000). Externally bonded fiber-reinforced polymer for rehabilitation of corrosion damaged concrete beams. ACI Struct J; 97(5):703-711.

[47] Yao J, Teng JG, Chen JF (2005). Experimental study on FRP-to-concrete bonded joints. Comp Part B: Eng; 36:99-113.

[48] Gao B, Kim JK, Leung CKY (2004). Experimental study on RC beams with FRP strips bonded with rubber modified resins. Comp Science and Technology; 64: 2557-2564.

[49] Niu HD, Vasquez A, Karbhari VM (2006). Effect of material configuration on strengthening of concrete slabs by CFRP composites. Comp Part B: Eng; 37(2-3):226-226.

[50] Seim W, Hörmann M, Karbhari V, Seible F (2001). External FRP post-strengthening of scaled concrete slab. J Comp Construct; 5(2):67-75. 


\begin{tabular}{|c|c|c|c|c|c|c|c|}
\hline Reference & $\begin{array}{l}\text { n. of } \\
\text { tests }\end{array}$ & $\begin{array}{c}\mathrm{L} \\
{[\mathrm{mm}]}\end{array}$ & $\begin{array}{l}\mathrm{h} / \mathrm{b} \\
{[-]}\end{array}$ & $\begin{array}{l}\text { Type of } \\
\text { FRP }\end{array}$ & $\begin{array}{c}t_{\text {frp }} \\
{[\mathrm{mm}]}\end{array}$ & $\begin{array}{l}\mathrm{V}_{\text {exp }} \\
{[\mathrm{kN}]}\end{array}$ & $\begin{array}{c}\text { Type of } \\
\text { test }\end{array}$ \\
\hline $\begin{array}{l}\text { Ahmed et al. } \\
(1999-2000)\end{array}$ & 7 & 1500 & 2.00 & C-W & $0.33-0.67$ & $41.5-70.1$ & f.p.b.t. \\
\hline $\begin{array}{l}\text { Arduini et al. } \\
\text { (1997) }\end{array}$ & 4 & - & $1.00-1.30$ & C-W & $0.20-1.30$ & $114.0-45.0$ & f.p.b.t. \\
\hline $\begin{array}{l}\text { Berber et al. } \\
\text { (1999) }\end{array}$ & 6 & 2350 & 2.08 & C-P & 0.22 & $50.3-68.5$ & f.p.b.t. \\
\hline $\begin{array}{l}\text { Benjeddou et al. } \\
(2007)\end{array}$ & 6 & 1800 & 1.25 & $C-P$ & 1.20 & $15.1-20.1$ & f.p.b.t. \\
\hline $\begin{array}{l}\text { Breña et al. } \\
(2004)\end{array}$ & 11 & 812 & 1.00 & C-W / C-P & $0.16-1.19$ & $13.9-26.20$ & f.p.b.t. \\
\hline $\begin{array}{l}\text { David et al. } \\
\text { (1999) }\end{array}$ & 4 & 2800 & 2.00 & C-P & $1.20-2-40$ & $68.0-79.5$ & f.p.b.t. \\
\hline $\begin{array}{l}\text { Esfahani et al. } \\
(2007)\end{array}$ & 2 & 1600 & 1.30 & C-W & 0.18 & $35.5-37.2$ & f.p.b.t. \\
\hline $\begin{array}{l}\text { Fanning et al. } \\
(2000)\end{array}$ & 6 & 2800 & 1.56 & C-P & 1.20 & $31.0-51.5$ & f.p.b.t. \\
\hline $\begin{array}{l}\text { Garden et al. } \\
\text { (1997) }\end{array}$ & 17 & 2200 & $1.00-1.77$ & C-W / C-P & $0.50-1.30$ & $15.4-30.0$ & f.p.b.t. \\
\hline $\begin{array}{l}\text { Grace et al. } \\
(2005)\end{array}$ & 4 & 2540 & 1.67 & C-W / C-P & $0.40-1.20$ & $66.7-68.3$ & f.p.b.t. \\
\hline $\begin{array}{l}\text { Hau et al. } \\
(1999)\end{array}$ & 5 & 1500 & $1.30-2.60$ & G-W & 1.66 & $53.0-79.4$ & f.p.b.t. \\
\hline $\begin{array}{l}\text { Juvandes et al. } \\
\text { (1998) }\end{array}$ & 2 & 1500 & 2.00 & C-W / C-P & 1.20 & $6.7-12.5$ & f.p.b.t. \\
\hline $\begin{array}{l}\text { Matthys } \\
(2000)\end{array}$ & 6 & - & 2.25 & C-W & $1.20-0.20$ & $95.8-186.0$ & f.p.b.t. \\
\hline $\begin{array}{l}\text { Nguyen et al. } \\
(2001)\end{array}$ & 4 & 1330 & 1.25 & C-P & 1.20 & $28.1-65.1$ & f.p.b.t. \\
\hline $\begin{array}{l}\text { Pham et al. } \\
(2006)\end{array}$ & 11 & 2300 & 1.86 & C-W & $1.06-1.58$ & $25.7-37.3$ & f.p.b.t. \\
\hline $\begin{array}{l}\text { Quantrill et al. } \\
\text { (1996) }\end{array}$ & 4 & 900 & 1.00 & G-P / C-P & $1.20-1.60$ & $20.4-12.3$ & f.p.b.t. \\
\hline $\begin{array}{l}\text { Rahimi et al. } \\
(2001)\end{array}$ & 8 & 2742 & 1.33 & C-W & $0.80-1.20$ & $35.3-29.7$ & f.p.b.t. \\
\hline $\begin{array}{l}\text { Ritchie et al. } \\
\text { (1991) }\end{array}$ & 5 & 2438 & 2.00 & G-P & $1.27-4.76$ & $50.6-72.1$ & f.p.b.t. \\
\hline $\begin{array}{l}\text { Ross et al. } \\
\text { (1999) }\end{array}$ & 11 & 2742 & 1.00 & C-P & 0.50 & $35.6-84.5$ & f.p.b.t. \\
\hline $\begin{array}{l}\text { Saadatmanesh et } \\
\text { al. (1991) }\end{array}$ & 1 & 4575 & 2.22 & G-P & 6.00 & 125.0 & f.p.b.t. \\
\hline Sharif et al. (1994) & 2 & 1180 & 1.00 & G-W & $2.00-3.00$ & $33.0-34.0$ & f.p.b.t. \\
\hline $\begin{array}{l}\text { Spadea et al. } \\
\text { (1998) }\end{array}$ & 2 & - & 1.00 & C-W & $1.20-1.20$ & $37.4-43.4$ & f.p.b.t. \\
\hline $\begin{array}{l}\text { Tan et al. } \\
\text { (1999) }\end{array}$ & 7 & - & 1.50 & C-W & 0.20 & $19.8-27.5$ & f.p.b.t. \\
\hline $\begin{array}{l}\text { Täljsten et al. } \\
\text { (1997) }\end{array}$ & 6 & 3600 & 1.50 & C-W / C-P & $1.40-2.40$ & $71.4-80.1$ & f.p.b.t. \\
\hline $\begin{array}{l}\text { Teng and Yao } \\
(2007)\end{array}$ & 5 & 1500 & 1.66 & C-W / C-P & $1.20-2.63$ & $76.0-99.4$ & f.p.b.t. \\
\hline $\begin{array}{l}\text { Triantafillou et al. } \\
(1992-1998)\end{array}$ & 8 & $1220-2130$ & $1.67-2.00$ & C-W & $0.49-1.90$ & $12.8-98.2$ & f.p.b.t. \\
\hline
\end{tabular}

Table 1: Experimental tests collected in end debonding database. f.p.b.t. $=$ four point bending test. $C=$ carbon, $G=$ glass, $\mathrm{W}=$ wet lay-up, $\mathrm{P}=$ pultruded. 


\begin{tabular}{|c|c|c|c|c|c|c|c|}
\hline Reference & $\begin{array}{l}\text { n. of } \\
\text { tests }\end{array}$ & $\begin{array}{c}\mathrm{L} \\
{[\mathrm{mm}]}\end{array}$ & $\begin{array}{l}\mathrm{h} / \mathrm{b} \\
{[-]}\end{array}$ & $\begin{array}{l}\text { Type of } \\
\text { FRP }\end{array}$ & $\begin{array}{c}t_{\text {frp }} \\
{[\mathrm{mm}]}\end{array}$ & $\begin{array}{l}\mathrm{V}_{\text {exp }} \\
{[\mathrm{kN}]}\end{array}$ & $\begin{array}{c}\text { Type of } \\
\text { test }\end{array}$ \\
\hline $\begin{array}{l}\text { Beber et al. } \\
\text { (1999) }\end{array}$ & 6 & 2349 & 2.08 & C & $0.44-1.10$ & $50.3-68.5$ & f.p.b.t. \\
\hline $\begin{array}{l}\text { Benjamin } \\
\text { (2005) }\end{array}$ & 8 & 4537 & 1.67 & C & 1.4 & $37.7-51.8$ & 3.p.b.t. \\
\hline $\begin{array}{l}\text { Bonacci and } \\
\text { Maalej (2000) }\end{array}$ & 1 & 3650 & 1.48 & C & 0.3 & 250.0 & f.p.b.t. \\
\hline $\begin{array}{l}\text { Chan et al. } \\
(2001)\end{array}$ & 4 & 4600 & 1.88 & C & 1.2 & $129.0-220$. & f.p.b.t. \\
\hline $\begin{array}{l}\text { Delaney } \\
\text { (2006) }\end{array}$ & 4 & 1800 & 1.50 & C & 1.4 & $44.4-49.5$ & f.p.b.t. \\
\hline $\begin{array}{l}\text { Esfahani et al. } \\
\text { (2007) }\end{array}$ & 1 & 1600 & 1.33 & C & 0.18 & 54.5 & f.p.b.t. \\
\hline $\begin{array}{l}\text { Gao et al. } \\
\text { (2004) }\end{array}$ & 3 & 1500 & 1.33 & C & 0.2 & $39.3-43.9$ & f.p.b.t. \\
\hline $\begin{array}{l}\text { Kishi et al. } \\
(1998-2003)\end{array}$ & 11 & 2600 & $1.67-2.66$ & $A / C$ & $0.1-0.6$ & $37.0-80.0$ & f.p.b.t. \\
\hline $\begin{array}{l}\text { Kotynia } \\
\text { (2005) }\end{array}$ & 6 & $3000-4200$ & 2.00 & C & $0.4-1.4$ & $90.0-46.0$ & $\begin{array}{l}\text { f.p.b.t. } \\
\text { 3.p.b.t }\end{array}$ \\
\hline $\begin{array}{l}\text { Kurihashi et al. } \\
(1999-2000)\end{array}$ & 8 & $1800-3400$ & 1.66 & $A / C$ & $0.2-0.6$ & $34.9-77.5$ & f.p.b.t. \\
\hline $\begin{array}{l}\text { Leung } \\
\text { (2004) }\end{array}$ & 16 & $7200-1800$ & 2.66 & C & $0.2-1.8$ & $32.1-548.5$ & f.p.b.t. \\
\hline $\begin{array}{l}\text { Maleej and Leung } \\
\text { (2005) }\end{array}$ & 10 & $4800-1500$ & 1.27 & C & $0.2-0.7$ & $37.7-334.7$ & f.p.b.t. \\
\hline $\begin{array}{l}\text { Maeda et al. } \\
(2001)\end{array}$ & 2 & 1800 & 1.00 & C & $0.2-0.3$ & $39.2-54.5$ & f.p.b.t. \\
\hline $\begin{array}{l}\text { M'Bazza et al. } \\
(1996)\end{array}$ & 1 & 3000 & 1.5 & C & 0.9 & 49.9 & f.p.b.t. \\
\hline $\begin{array}{l}\text { Mikami et al. } \\
\text { (1999) }\end{array}$ & 1 & 3000 & 1.66 & C & 0.3 & 40.2 & 3.p.b.t. \\
\hline $\begin{array}{l}\text { Niu et al. } \\
(2006)\end{array}$ & 12 & 4200 & 0.21 & C & $1.2-2.6$ & $54.2-133.8$ & $\begin{array}{l}\text { f.p.b.t. } \\
\text { 3.p.b.t. }\end{array}$ \\
\hline $\begin{array}{l}\text { Seim et al. } \\
\text { (2001) }\end{array}$ & 6 & 2030 & 0.25 & $\mathrm{G} / \mathrm{C}$ & $1.1-1.2$ & $40.8-80.8$ & 3.p.b.t. \\
\hline $\begin{array}{l}\text { Spadea et al. } \\
(1998)\end{array}$ & 2 & 4800 & 2.14 & $\mathrm{G} / \mathrm{C}$ & 1.2 & $37.4-43.4$ & f.p.b.t. \\
\hline $\begin{array}{l}\text { Takahashi and } \\
\text { Sato } \\
\text { (2003) }\end{array}$ & 5 & 1600 & 1.5 & C & $0.2-0.5$ & $\begin{array}{l}113.5- \\
155.5\end{array}$ & f.p.b.t. \\
\hline $\begin{array}{l}\text { Takeo et al. } \\
\text { (1999) }\end{array}$ & 6 & 2000 & 1.62 & C & 0.2 & $33.8-85.6$ & $\begin{array}{l}\text { f.p.b.t. } \\
\text { 3.p.b.t. }\end{array}$ \\
\hline $\begin{array}{l}\text { Teng and Yao } \\
\text { (2007) }\end{array}$ & 2 & 1500 & 1.67 & $\mathrm{G} / \mathrm{C}$ & $1.67-2.01$ & $71.3-82.0$ & f.p.b.t. \\
\hline $\begin{array}{l}\text { Wu et al. } \\
(1999-2000)\end{array}$ & 5 & 1800 & 1.33 & C & $0.1-0.3$ & $65.0-78.4$ & f.p.b.t. \\
\hline $\begin{array}{l}\text { Yao et al. } \\
\text { (2005) }\end{array}$ & 10 & 1100 & 0.5 & C & $0.2-1.2$ & $7.2-21.4$ & $\begin{array}{l}\text { c.b.t. } \\
\text { 3.p.b.t. }\end{array}$ \\
\hline $\begin{array}{l}\text { Zarniç et al. } \\
\text { (1999) }\end{array}$ & 2 & 2900 & $0.15-1.5$ & C & 1.2 & $31.5-58.4$ & f.p.b.t. \\
\hline $\begin{array}{l}\text { Zhang et al. } \\
\text { (2005) }\end{array}$ & 20 & $1800-3500$ & $1.66-2.66$ & $A / C$ & $0.2-0.6$ & $34.0-78.1$ & f.p.b.t. \\
\hline
\end{tabular}

Table 2: Experimental tests collected in I-C induced debonding database. f.p.b.t. $=$ four point bending test; 3.p.b.t. = three point bending test; c.b.t $=$ cantilever beam test. 


\begin{tabular}{|c|c|c|c|c|c|c|c|}
\hline \multirow{2}{*}{ Model } & \multirow{2}{*}{$\begin{array}{c}\text { Mechanism } \\
\text { criteria }\end{array}$} & \multicolumn{5}{|c|}{ Parameter addressed } & Limitations \\
\hline & & R.C. & $\mathrm{S}_{\mathrm{l}}$ & $\mathrm{S}_{\mathrm{t}}$ & FRP & Rs & \multirow{15}{*}{$\begin{array}{l}1.4-(\mathrm{d} / 200) \geq 1.1 \\
\mathrm{M}_{\mathrm{db}, \text { end }} / \mathrm{M}_{\mathrm{u}} \leq 0.61 \\
\mathrm{~b} / \mathrm{b}_{\mathrm{frp}} \leq 3 \\
\mathrm{~B}_{\text {mod }}>0\end{array}$} \\
\hline Oehlers & S.M.- E.F. & $\checkmark$ & $\checkmark$ & & $\checkmark$ & & \\
\hline Smith and Teng & S.M. & $\checkmark$ & $\checkmark$ & & $\checkmark$ & & \\
\hline Teng and Yao & S.M.- E.F. & $\checkmark$ & $\checkmark$ & $\checkmark$ & $\checkmark$ & & \\
\hline Jansze et al. & S.M. & $\checkmark$ & $\checkmark$ & & & & \\
\hline Ahmed and van Germert & S.M. & $\checkmark$ & $\checkmark$ & $\checkmark$ & $\checkmark$ & & \\
\hline Colotti et al. & S.M. & $\checkmark$ & $\checkmark$ & $\checkmark$ & $\checkmark$ & & \\
\hline Raoof and Zhang & F.M.- E.F. & $\checkmark$ & $\checkmark$ & & $\checkmark$ & & \\
\hline Wang and Ling & F.M.- E.F. & $\checkmark$ & $\checkmark$ & & $\checkmark$ & & \\
\hline Raoof and Hassanen I & F.M.- E.F. & $\checkmark$ & $\checkmark$ & & $\checkmark$ & & \\
\hline Raoof and Hassanen II & F.M.- E.F. & $\checkmark$ & $\checkmark$ & & $\checkmark$ & & \\
\hline Ziraba I & S.M.- F.M. & $\checkmark$ & $\checkmark$ & & $\checkmark$ & $\checkmark$ & \\
\hline Ziraba II & S.M.- F.M. & $\checkmark$ & $\checkmark$ & & $\checkmark$ & $\checkmark$ & \\
\hline Wu and Niu & F.M. & $\checkmark$ & $\checkmark$ & & $\checkmark$ & & \\
\hline Casas and Pascual & F.M. & $\checkmark$ & $\checkmark$ & & $\checkmark$ & $\checkmark$ & \\
\hline
\end{tabular}

Table 3: Summary of principal methods used to predict the end-debonding and intermediate crack induced debonding. S.M. = strength materials, F.M. = fracture mechanics. E.F. = experimental data fitting.

R.C. $=$ reinforced concrete. $\mathrm{S}_{1}=$ longitudinal reinforcement steel. $\mathrm{S}_{\mathrm{t}}=$ Stirrups. FRP $=$ fiber reinforced polymers. Rs $=$ resin. 


\begin{tabular}{|c|c|c|c|c|c|c|c|c|c|c|c|c|}
\hline Model & $\begin{array}{l}\text { Regression } \\
\text { coefficient }\end{array}$ & $\begin{array}{c}\text { Regression } \\
\text { coefficient } \\
\text { standard } \\
\text { error }\end{array}$ & $\begin{array}{c}\text { Regression } \\
\text { standard } \\
\text { error }\end{array}$ & $\mathrm{R} 2$ & $\begin{array}{c}\text { Number of } \\
\text { observations }\end{array}$ & Bias & $\begin{array}{l}\text { Standard } \\
\text { deviation }\end{array}$ & COV & $\begin{array}{l}\text { Probability } \\
\text { distribution }\end{array}$ & $\mathrm{R} 2$ & $\mathrm{~V}_{\max }$ & $\mathrm{V}_{\min }$ \\
\hline CW & \multicolumn{12}{|c|}{ END DEBONDING } \\
\hline Smith and Teng & 1.64 & 0.05 & 16.32 & 0.94 & 69 & 1.66 & 0.45 & 0.27 & Lognormal & 0.97 & 186.00 & 6.70 \\
\hline Teng and $\mathrm{Yao} \mathrm{ACl}$ & 1.34 & 0.06 & 22.74 & 0.87 & 90 & 1.45 & 0.50 & 0.34 & Normal & 0.99 & 186.00 & 6.70 \\
\hline Teng and Yao AS600 & 1.83 & 0.07 & 21.67 & 0.88 & 90 & 1.96 & 0.72 & 0.37 & Lognormal & 0.99 & 186.00 & 6.70 \\
\hline Teng and Yao BS & 1.55 & 0.06 & 22.63 & 0.87 & 90 & 1.57 & 0.61 & 0.39 & Lognormal & 0.99 & 186.00 & 6.70 \\
\hline Jansze & 0.55 & 0.03 & 24.41 & 0.85 & 83 & 0.65 & 0.32 & 0.49 & Lognormal & 0.97 & 186.00 & 6.70 \\
\hline Ahmed & 0.53 & 0.02 & 23.60 & 0.86 & 83 & 0.65 & 0.30 & 0.46 & Lognormal & 0.95 & 186.00 & 6.70 \\
\hline Raoof and Zhang & 0.90 & 0.09 & 41.87 & 0.55 & 89 & 1.42 & 0.86 & 0.61 & Lognormal & 0.95 & 186.00 & 6.70 \\
\hline Wang & 0.90 & 0.08 & 40.89 & 0.57 & 89 & 1.45 & 0.87 & 0.61 & Lognormal & 0.94 & 186.00 & 6.70 \\
\hline Raoof and Hassanen I & 1.05 & 0.08 & 36.72 & 0.66 & 89 & 1.57 & 1.03 & 0.66 & Lognormal & 0.97 & 186.00 & 6.70 \\
\hline Raoof and Hassanen II & 1.43 & 0.11 & 37.67 & 0.64 & 89 & 2.29 & 1.91 & 0.84 & Lognormal & 0.97 & 186.00 & 6.70 \\
\hline Colotti & 0.99 & 0.02 & 12.01 & 0.97 & 55 & 0.90 & 0.21 & 0.24 & Normal & 0.96 & 186.00 & 6.70 \\
\hline Ziraba I & 1.44 & 0.08 & 7.45 & 0.95 & 19 & 1.63 & 0.52 & 0.32 & Normal & 0.96 & 74.40 & 13.95 \\
\hline Ziraba II & 0.89 & 0.06 & 8.46 & 0.93 & 19 & 1.17 & 0.21 & 0.18 & Normal & 0.95 & 74.40 & 13.95 \\
\hline Casas and Pascual & 2.18 & 0.10 & 5.91 & 0.97 & 19 & 2.21 & 0.46 & 0.21 & Normal & 0.96 & 74.40 & 13.95 \\
\hline $\begin{array}{l}\text { Casas and Pascual } \\
\text { (with additional data) }\end{array}$ & 1.65 & 0.06 & 20.92 & 0.89 & 90 & 1.89 & 0.57 & 0.37 & Normal & 0.96 & 186.00 & 6.70 \\
\hline CP & & & & & END DEBC & DING & & & & & & \\
\hline Smith and Teng & 1.47 & 0.06 & 13.57 & 0.93 & 39 & 1.62 & 0.44 & 0.27 & Lognormal & 0.91 & 80.10 & 12.50 \\
\hline Teng and $\mathrm{Yao} \mathrm{ACl}$ & 1.15 & 0.05 & 16.09 & 0.89 & 59 & 1.41 & 0.54 & 0.38 & Normal & 0.97 & 80.10 & 12.50 \\
\hline Teng and Yao AS600 & 1.60 & 0.07 & 15.30 & 0.90 & 59 & 1.84 & 0.65 & 0.35 & Lognormal & 0.98 & 80.10 & 12.50 \\
\hline Teng and Yao BS & 1.31 & 0.06 & 15.57 & 0.90 & 59 & 1.44 & 0.52 & 0.36 & Lognormal & 0.98 & 80.10 & 12.50 \\
\hline Jansze & 0.66 & 0.03 & 16.02 & 0.89 & 50 & 0.64 & 0.28 & 0.44 & Lognormal & 0.95 & 80.10 & 12.50 \\
\hline Ahmed & 0.67 & 0.04 & 18.89 & 0.87 & 50 & 0.82 & 0.56 & 0.69 & Lognormal & 0.95 & 80.10 & 12.50 \\
\hline Raoof and Zhang & 1.31 & 0.09 & 22.96 & 0.78 & 59 & 1.68 & 1.19 & 0.71 & Lognormal & 0.96 & 80.10 & 12.50 \\
\hline Wang and Ling & 1.29 & 0.08 & 21.79 & 0.80 & 59 & 1.61 & 1.17 & 0.76 & Lognormal & 0.95 & 80.10 & 12.50 \\
\hline Raoof and Hassanen I & 1.36 & 0.09 & 22.28 & 0.79 & 59 & 2.22 & 1.96 & 0.88 & Lognormal & 0.92 & 80.10 & 12.50 \\
\hline Raoof and Hassanen II & 1.79 & 0.12 & 22.67 & 0.78 & 59 & 3.14 & 3.27 & 1.04 & Lognormal & 0.92 & 80.10 & 12.50 \\
\hline Colotti & 1.02 & 0.06 & 13.65 & 0.90 & 34 & 1.09 & 0.44 & 0.40 & Normal & 0.91 & 79.50 & 12.50 \\
\hline Ziraba I & 1.06 & 0.10 & 23.51 & 0.77 & 38 & 2.09 & 1.32 & 0.63 & Normal & 0.95 & 80.10 & 12.50 \\
\hline
\end{tabular}


Pag. 32

\begin{tabular}{|c|c|c|c|c|c|c|c|c|c|c|c|c|}
\hline Ziraba II & 0.77 & 0.05 & 17.94 & 0.86 & 38 & 1.26 & 0.52 & 0.41 & Normal & 0.91 & 80.10 & 12.50 \\
\hline Casas and Pascual & 2.14 & 0.07 & 8.94 & 0.97 & 38 & 2.27 & 0.54 & 0.24 & Normal & 0.97 & 80.10 & 12.50 \\
\hline $\begin{array}{l}\text { Casas and Pascual } \\
\text { (with additional data) }\end{array}$ & 1.99 & 0.06 & 10.94 & 0.95 & 59 & 2.13 & 0.54 & 0.24 & Lognormal & 0.95 & 80.10 & 12.50 \\
\hline
\end{tabular}

\begin{tabular}{|c|c|c|c|c|c|c|c|c|c|c|c|c|}
\hline$C W+C P$ & \multicolumn{12}{|c|}{ INTERMEDIATE DEBONDING } \\
\hline Casas IC & 1.76 & 0.05 & 2.78 & 0.98 & 20 & 1.88 & 0.35 & 0.18 & Lognormal & 0.96 & 34.90 & 8.51 \\
\hline Casas IC + CasasD & 1.08 & 0.05 & 8.34 & 0.96 & 22 & 1.80 & 0.42 & 0.23 & Normal & 0.97 & 135.45 & 8.51 \\
\hline $\begin{array}{c}\text { Casas IC + CasasD } \\
\text { (all data) }\end{array}$ & 1.48 & 0.03 & 31.95 & 0.92 & 188 & 2.23 & 1.45 & 0.65 & Lognormal & 0.96 & 548.5 & 6.90 \\
\hline Wu and Niu & 0.57 & 0.03 & 3.82 & 0.96 & 15 & 0.60 & 0.19 & 0.32 & Normal & 0.93 & 34.90 & 10.00 \\
\hline $\begin{array}{l}\text { Wu and Niu } \\
\text { (all data) }\end{array}$ & 0.37 & 0.02 & 39.59 & 0.86 & 78 & 0.50 & 0.23 & 0.46 & Lognormal & 0.98 & 548.5 & 10.00 \\
\hline $\begin{array}{l}\text { ACl440.2R } \\
\text { Case } 1\end{array}$ & 0.70 & 0.03 & 3.63 & 0.97 & 13 & 0.73 & 0.22 & 0.29 & Lognormal & 0.88 & 34.90 & 10 \\
\hline $\begin{array}{c}\mathrm{ACl} 440.2 \mathrm{R} \\
\text { Case } 2\end{array}$ & 0.91 & 0.03 & 36.73 & 0.94 & 68 & 1.22 & 0.56 & 0.45 & Normal & 0.94 & 548.5 & 10 \\
\hline $\begin{array}{c}\text { ACl440.2R } \\
\text { (all data, case 3) }\end{array}$ & 0.77 & 0.02 & 34.08 & 0.90 & 183 & 0.87 & 0.48 & 0.55 & Lognormal & 0.97 & 548.5 & 6.9 \\
\hline
\end{tabular}

Table 4: Statistical results of existing models compared to experimental database 
Appendix A: Database of beams failed by end debonding 
Pag. 34

\begin{tabular}{|c|c|c|c|c|c|c|c|c|c|c|c|c|c|c|c|c|}
\hline & Beam & $\begin{array}{c}\mathrm{b} \\
{[\mathrm{mm}]}\end{array}$ & $\begin{array}{c}\mathrm{h} \\
{[\mathrm{mm}]}\end{array}$ & $\begin{array}{c}\mathrm{d} \\
{[\mathrm{mm}]}\end{array}$ & $\begin{array}{c}\mathrm{d}^{\prime} \\
{[\mathrm{mm}]}\end{array}$ & $\begin{array}{c}\mathrm{a} \\
{[\mathrm{mm}]}\end{array}$ & $\begin{array}{c}\mathrm{B} \\
{[\mathrm{mm}]} \\
\end{array}$ & $\begin{array}{c}\mathrm{L} \\
{[\mathrm{mm}]}\end{array}$ & $\begin{array}{c}\mathrm{f}_{\mathrm{c}}^{\prime} \\
{[\mathrm{MPa}]}\end{array}$ & $\begin{array}{c}\mathrm{E}_{\mathrm{s}} \\
{[\mathrm{GPa}]}\end{array}$ & $\begin{array}{c}\mathrm{f}_{\mathrm{ys}} \\
{[\mathrm{MPa}]}\end{array}$ & $\begin{array}{c}\mathrm{A}_{\mathrm{s}} \\
{\left[\mathrm{mm}^{2}\right]}\end{array}$ & $\begin{array}{c}\text { Reo } \\
\text { [tension] }\end{array}$ & $\begin{array}{c}\mathrm{E}_{\mathrm{s}}^{\prime} \\
{[\mathrm{GPa}]}\end{array}$ & $\begin{array}{c}\mathrm{f}_{\mathrm{y}} \\
{[\mathrm{MPa}]}\end{array}$ & $\begin{array}{c}\mathrm{A}_{\mathrm{s}}^{\prime} \\
{\left[\mathrm{mm}^{2}\right]}\end{array}$ \\
\hline \multirow[t]{7}{*}{ Ahmed et al. (1999) } & AF3 & 125 & 225 & 193 & 32 & 100 & 2500 & 21500 & 246.0 & 185 & 2568 & 101 & $2-8$ & 195 & $\overline{553}$ & 257 \\
\hline & CF2-1 & 125 & 225 & 193 & 32 & 100 & 500 & 1500 & 46.0 & 185 & 568 & 129 & $2-8,1-6$ & 195 & 553 & 57 \\
\hline & CF3-1 & 125 & 225 & 193 & 32 & 100 & 500 & 1500 & 46.0 & 185 & 568 & 151 & $3-8$ & 195 & 553 & 57 \\
\hline & CF4-1 & 125 & 225 & 193 & 32 & 100 & 500 & 1500 & 46.0 & 183 & 586 & 207 & $2-10,1-8$ & 195 & 553 & 57 \\
\hline & DF.2 & 125 & 225 & 193 & 32 & 50 & 500 & 1500 & 46.0 & 185 & 568 & 151 & $3-8$ & 195 & 553 & 57 \\
\hline & DF.3 & 125 & 225 & 193 & 32 & 50 & 500 & 1500 & 46.0 & 185 & 568 & 151 & $3-8$ & 195 & 553 & 57 \\
\hline & DF.4 & 125 & 225 & 193 & 32 & 50 & 500 & 1500 & 46.0 & 185 & 568 & 151 & $3-8$ & 195 & 553 & 57 \\
\hline \multirow[t]{10}{*}{ Ahmed et al. (2000) } & AF.2 & 125 & 225 & 196 & 25 & 200 & 500 & - & 41.0 & 200 & 568 & 101 & -8 & 200 & 568 & 57 \\
\hline & AF.2-1 & 125 & 225 & 196 & 25 & 150 & 500 & - & 41.0 & 200 & 568 & 101 & -8 & 200 & 568 & 57 \\
\hline & AF.4 & 125 & 225 & 196 & 25 & 50 & 500 & - & 41.0 & 200 & 568 & 101 & -8 & 200 & 568 & 57 \\
\hline & DF.1 & 125 & 225 & 196 & 25 & 50 & 500 & - & 42.0 & 200 & 568 & 151 & -8 & 200 & 568 & 57 \\
\hline & BF.2-1 & 125 & 225 & 196 & 25 & 50 & 500 & - & 41.0 & 200 & 568 & 101 & -8 & 200 & 568 & 57 \\
\hline & BF.3-1 & 125 & 225 & 196 & 25 & 50 & 500 & - & 41.0 & 200 & 568 & 101 & -8 & 200 & 568 & 57 \\
\hline & EF.1-1 & 125 & 225 & 196 & 25 & 50 & 500 & - & 46.0 & 200 & 568 & 151 & -8 & 200 & 568 & 57 \\
\hline & EF.3-1 & 125 & 225 & 196 & 25 & 50 & 500 & - & 38.0 & 200 & 568 & 151 & -8 & 200 & 568 & 57 \\
\hline & EF.4-1 & 125 & 225 & 196 & 25 & 50 & 500 & - & 33.0 & 200 & 568 & 151 & -8 & 200 & 568 & 57 \\
\hline & FF.2-3 & 125 & 225 & 196 & 25 & 70 & 700 & - & 39.5 & 200 & 568 & 151 & -8 & 200 & 568 & 57 \\
\hline \multirow[t]{4}{*}{ Arduini et al. (1997) } & A4 & 200 & 200 & 163 & 30 & 150 & 700 & - & 33.0 & 200 & 540 & 308 & -14 & 200 & 540 & 308 \\
\hline & A5 & 200 & 200 & 163 & 30 & 150 & 700 & - & 33.0 & 200 & 540 & 308 & -14 & 200 & 540 & 308 \\
\hline & $\mathrm{B} 2$ & 300 & 400 & 349.5 & 44 & 100 & 1100 & - & 30.0 & 200 & 340 & 398 & -13 & 200 & 340 & 266 \\
\hline & B3 & 300 & 400 & 349.5 & 44 & 100 & 1100 & - & 30.0 & 200 & 340 & 398 & -13 & 200 & 340 & 266 \\
\hline \multirow[t]{6}{*}{ Beber et al. (1999) } & VR5 & 120 & 250 & 214 & 34 & 75 & 783 & 2350 & 33.6 & 200 & 565 & 157 & $2-10$ & 200 & 738 & 57 \\
\hline & VR6 & 120 & 250 & 214 & 34 & 75 & 783 & 2350 & 33.6 & 200 & 565 & 157 & $2-10$ & 200 & 738 & 57 \\
\hline & VR7 & 120 & 250 & 214 & 34 & 75 & 783 & 2350 & 33.6 & 200 & 565 & 157 & $2-10$ & 200 & 738 & 57 \\
\hline & VR8 & 120 & 250 & 214 & 34 & 75 & 783 & 2350 & 33.6 & 200 & 565 & 157 & $2-10$ & 200 & 738 & 57 \\
\hline & VR9 & 120 & 250 & 214 & 34 & 75 & 783 & 2350 & 33.6 & 200 & 565 & 157 & $2-10$ & 200 & 738 & 57 \\
\hline & VR10 & 120 & 250 & 214 & 34 & 75 & 783 & 2350 & 33.6 & 200 & 565 & 157 & $2-10$ & 200 & 738 & 57 \\
\hline \multirow[t]{6}{*}{ Benjeddou et al. (2007) } & RB1 & 120 & 150 & 120 & 30 & 50 & 600 & 1800 & 21.0 & 200 & 400 & 157 & $2-10$ & 200 & 400 & 157 \\
\hline & RB2 & 120 & 150 & 120 & 30 & 50 & 600 & 1800 & 21.0 & 200 & 400 & 157 & $2-10$ & 200 & 400 & 157 \\
\hline & RB3 & 120 & 150 & 120 & 30 & 50 & 600 & 1800 & 21.0 & 200 & 400 & 157 & $2-10$ & 200 & 400 & 157 \\
\hline & RB4 & 120 & 150 & 120 & 30 & 50 & 600 & 1800 & 21.0 & 200 & 400 & 157 & $2-10$ & 200 & 400 & 157 \\
\hline & RB5 & 120 & 150 & 120 & 30 & 50 & 600 & 1800 & 21.0 & 200 & 400 & 157 & $2-10$ & 200 & 400 & 157 \\
\hline & RB6 & 120 & 150 & 120 & 30 & 50 & 600 & 1800 & 38.0 & 200 & 400 & 157 & $2-10$ & 200 & 400 & 157 \\
\hline
\end{tabular}

Table A. 1: Database of beams failed by end debonding. Ahmed et al. (cited in [6]), Ahmed et al. (cited in [19]), Arduini et al. (cited in [19]), Beber et al. (cited in [6]), Benjeddou et al. [32]. 
Pag. 35

\begin{tabular}{|c|c|c|c|c|c|c|c|c|c|c|c|c|c|}
\hline & Beam & $\begin{array}{c}\mathrm{E}_{\mathrm{yv}} \\
{[\mathrm{GPa}]}\end{array}$ & $\begin{array}{c}\mathrm{f}_{\mathrm{yv}} \\
{[\mathrm{MPa}]}\end{array}$ & $\begin{array}{c}\mathrm{A}_{\mathrm{sv}} \\
{\left[\mathrm{mm}^{2}\right]}\end{array}$ & $\begin{array}{c}\mathrm{s} \\
{[\mathrm{mm}]}\end{array}$ & $\begin{array}{c}\mathrm{E}_{\mathrm{a}} \\
{[\mathrm{MPa}]}\end{array}$ & $\begin{array}{c}\mathrm{t}_{\mathrm{a}} \\
{[\mathrm{mm}]}\end{array}$ & $\begin{array}{c}\text { Type } \\
{[-]} \\
\end{array}$ & $\begin{array}{c}\mathrm{E}_{\text {frp }} \\
{[\mathrm{GPa}]}\end{array}$ & $\begin{array}{c}\mathrm{f}_{\text {frp }} \\
{[\mathrm{MPa}]}\end{array}$ & $\begin{array}{c}\mathrm{t}_{\text {frp }} \\
{[\mathrm{mm}]}\end{array}$ & $\begin{array}{c}\mathrm{b}_{\mathrm{frp}} \\
{[\mathrm{mm}]}\end{array}$ & $\begin{array}{r}\mathrm{V}_{\exp } \\
{[\mathrm{kN}]}\end{array}$ \\
\hline \multirow[t]{7}{*}{ "Ahmed et al. (1999) } & AF3 & 195 & 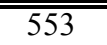 & 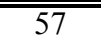 & $\overline{771}$ & 7200 & - & C-W & 240.00 & 3500 & 0.334 & $\overline{775}$ & 488.30 \\
\hline & CF2-1 & 195 & 553 & 57 & 71 & 7200 & - & $\mathrm{C}-\mathrm{W}$ & 240.00 & 3500 & 0.334 & 75 & 52.40 \\
\hline & CF3-1 & 195 & 553 & 57 & 71 & 7200 & - & $\mathrm{C}-\mathrm{W}$ & 240.00 & 3500 & 0.334 & 75 & 59.10 \\
\hline & CF4-1 & 195 & 553 & 57 & 71 & 7200 & - & $\mathrm{C}-\mathrm{W}$ & 240.00 & 3500 & 0.334 & 75 & 70.10 \\
\hline & DF. 2 & 195 & 553 & 57 & 100 & 7200 & - & $\mathrm{C}-\mathrm{W}$ & 240.00 & 3500 & 0.334 & 75 & 60.30 \\
\hline & DF. 3 & 195 & 553 & 57 & 100 & 7200 & - & $\mathrm{C}-\mathrm{W}$ & 240.00 & 3500 & 0.501 & 75 & 60.00 \\
\hline & DF.4 & 195 & 553 & 57 & 100 & 7200 & - & $\mathrm{C}-\mathrm{W}$ & 240.00 & 3500 & 0.668 & 75 & 62.80 \\
\hline \multirow[t]{10}{*}{ Ahmed et al. (2000) } & AF.2 & 200 & 553 & 57 & 71 & - & - & C-W & 240.00 & 3500 & 0.3 & 75 & 41.50 \\
\hline & AF.2-1 & 200 & 553 & 57 & 71 & - & - & C-W & 240.00 & 3500 & 0.3 & 75 & 42.90 \\
\hline & AF.4 & 200 & 553 & 57 & 71 & - & - & $\mathrm{C}-\mathrm{W}$ & 240.00 & 3500 & 0.3 & 75 & 55.50 \\
\hline & DF.1 & 200 & 553 & 57 & 100 & - & - & C-W & 240.00 & 3500 & 0.2 & 75 & 59.00 \\
\hline & BF.2-1 & 200 & 553 & 57 & 167 & - & - & C-W & 240.00 & 3500 & 0.3 & 75 & 45.00 \\
\hline & BF.3-1 & 200 & 553 & 57 & 100 & - & - & C-W & 240.00 & 3500 & 0.3 & 75 & 52.00 \\
\hline & EF.1-1 & 200 & 553 & 57 & 100 & - & - & C-W & 240.00 & 3500 & 0.3 & 75 & 65.90 \\
\hline & EF.3-1 & 200 & 553 & 57 & 100 & - & - & C-W & 240.00 & 3500 & 0.3 & 75 & 59.50 \\
\hline & EF.4-1 & 200 & 553 & 57 & 100 & - & - & C-W & 240.00 & 3500 & 0.3 & 75 & 60.30 \\
\hline & FF.2-3 & 200 & 553 & 57 & 100 & - & - & $\mathrm{C}-\mathrm{W}$ & 240.00 & 3500 & 0.5 & 75 & 53.00 \\
\hline \multirow[t]{4}{*}{ Arduini et al. (1997) } & A4 & 200 & 540 & 57 & 150 & - & - & $\mathrm{C}-\mathrm{W}$ & 167.00 & 2906 & 1.3 & 150 & 55.00 \\
\hline & A5 & 200 & 540 & 57 & 150 & - & - & $\mathrm{C}-\mathrm{W}$ & 167.00 & 2906 & 2.6 & 150 & 45.00 \\
\hline & B2 & 200 & 340 & 101 & 100 & - & - & $\mathrm{C}-\mathrm{W}$ & 400.00 & 3000 & 0.2 & 300 & 85.00 \\
\hline & B3 & 200 & 340 & 101 & 100 & - & - & $\mathrm{C}-\mathrm{W}$ & 400.00 & 3000 & 0.5 & 300 & 114.00 \\
\hline \multirow[t]{6}{*}{ Beber et al. (1999) } & VR5 & 200 & 738 & 57 & 110 & 8500 & - & $\mathrm{C}-\mathrm{P}$ & 230.00 & 3400 & 0.22 & 120 & 51.10 \\
\hline & VR6 & 200 & 738 & 57 & 110 & 8500 & - & C-P & 230.00 & 3400 & 0.22 & 120 & 50.30 \\
\hline & VR7 & 200 & 738 & 57 & 110 & 8500 & - & C-P & 230.00 & 3400 & 0.22 & 120 & 62.10 \\
\hline & VR8 & 200 & 738 & 57 & 110 & 8500 & - & C-P & 230.00 & 3400 & 0.22 & 120 & 62.00 \\
\hline & VR9 & 200 & 738 & 57 & 110 & 8500 & - & C-P & 230.00 & 3400 & 0.22 & 120 & 64.80 \\
\hline & VR10 & 200 & 738 & 57 & 110 & 8500 & - & $\mathrm{C}-\mathrm{P}$ & 230.00 & 3400 & 0.22 & 120 & 68.50 \\
\hline \multirow[t]{6}{*}{ Benjeddou et al. (2007) } & RB1 & 200 & 235 & 28 & 10 & 12800 & - & C-P & 165.00 & 2800 & 1.2 & 100 & 20.06 \\
\hline & RB2 & 200 & 235 & 28 & 10 & 12800 & - & C-P & 165.00 & 2800 & 1.2 & 100 & 18.83 \\
\hline & RB3 & 200 & 235 & 28 & 10 & 12800 & - & C-P & 165.00 & 2800 & 1.2 & 100 & 16.05 \\
\hline & RB4 & 200 & 235 & 28 & 10 & 12800 & - & C-P & 165.00 & 2800 & 1.2 & 100 & 15.38 \\
\hline & RB5 & 200 & 235 & 28 & 10 & 12800 & - & C-P & 165.00 & 2800 & 1.2 & 50 & 15.05 \\
\hline & RB6 & 200 & 235 & 28 & 10 & 12800 & - & C-P & 165.00 & 2800 & 1.2 & 100 & 18.69 \\
\hline
\end{tabular}

Table A. 1 (cont): Database of beams failed by end debonding. Ahmed et al. (cited in [6]), Ahmed et al. (cited in [19]), Arduini et al. (cited in [19]), Beber et al. (cited in [6]), Benjeddou et al. (cited in [32]). 
Pag. 36

\begin{tabular}{|c|c|c|c|c|c|c|c|c|c|c|c|c|c|c|c|c|}
\hline & Beam & $\begin{array}{c}\mathrm{b} \\
{[\mathrm{mm}]} \\
\end{array}$ & $\begin{array}{c}\mathrm{h} \\
{[\mathrm{mm}]}\end{array}$ & $\begin{array}{c}\mathrm{d} \\
{[\mathrm{mm}]} \\
\end{array}$ & $\begin{array}{c}\mathrm{d}^{\prime} \\
{[\mathrm{mm}]}\end{array}$ & $\begin{array}{c}\mathrm{a} \\
{[\mathrm{mm}]}\end{array}$ & $\begin{array}{c}\mathrm{B} \\
{[\mathrm{mm}]} \\
\end{array}$ & $\begin{array}{c}\mathrm{L} \\
{[\mathrm{mm}]} \\
\end{array}$ & $\begin{array}{c}\mathrm{f}_{\mathrm{c}}^{\prime} \\
{[\mathrm{MPa}]} \\
\end{array}$ & $\begin{array}{c}\mathrm{E}_{\mathrm{s}} \\
{[\mathrm{GPa}]}\end{array}$ & $\begin{array}{c}\mathrm{f}_{\mathrm{ys}} \\
{[\mathrm{MPa}]}\end{array}$ & $\begin{array}{c}\mathrm{A}_{\mathrm{s}} \\
{\left[\mathrm{mm}^{2}\right]}\end{array}$ & $\begin{array}{c}\text { Reo } \\
\text { [tension] }\end{array}$ & $\begin{array}{c}\mathrm{E}_{\mathrm{s}}^{\prime} \\
{[\mathrm{GPa}]}\end{array}$ & $\begin{array}{c}\mathrm{f}_{\mathrm{y}} \\
{[\mathrm{MPa}]}\end{array}$ & $\begin{array}{r}\mathrm{A}_{\mathrm{s}}^{\prime} \\
{\left[\mathrm{mm}^{2}\right.} \\
\end{array}$ \\
\hline \multirow[t]{11}{*}{ Breña et al. (2004) } & 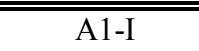 & 102 & 102 & $\overline{89}$ & 13 & 25 & 330 & 812 & 42.2 & 200 & 4435 & $\overline{771}$ & $101-9,5$ & 200 & 4435 & $\overline{771}$ \\
\hline & A1-II & 102 & 102 & 89 & 13 & 25 & 330 & 812 & 42.2 & 200 & 435 & 142 & $2-9,5$ & 200 & 435 & 142 \\
\hline & A2-I & 102 & 102 & 89 & 13 & 25 & 330 & 812 & 42.2 & 200 & 435 & 71 & $1-9,5$ & 200 & 435 & 71 \\
\hline & A2-II & 102 & 102 & 89 & 13 & 25 & 330 & 812 & 42.2 & 200 & 435 & 142 & $2-9,5$ & 200 & 435 & 142 \\
\hline & A3-I & 102 & 102 & 89 & 13 & 25 & 330 & 812 & 53.3 & 200 & 435 & 71 & $1-9,5$ & 200 & 435 & 71 \\
\hline & A3-II & 102 & 102 & 89 & 13 & 25 & 330 & 812 & 53.3 & 200 & 435 & 142 & $2-9,5$ & 200 & 435 & 142 \\
\hline & A4-I & 102 & 102 & 89 & 13 & 25 & 330 & 812 & 53.3 & 200 & 435 & 71 & $1-9,5$ & 200 & 435 & 71 \\
\hline & A4-II & 102 & 102 & 89 & 13 & 25 & 330 & 812 & 53.3 & 200 & 435 & 142 & $2-9,5$ & 200 & 435 & 142 \\
\hline & A5-I & 102 & 102 & 89 & 13 & 25 & 330 & 812 & 53.3 & 200 & 435 & 71 & $1-9,5$ & 200 & 435 & 71 \\
\hline & A5-II & 102 & 102 & 89 & 13 & 25 & 330 & 812 & 53.3 & 200 & 435 & 142 & $2-9,5$ & 200 & 435 & 142 \\
\hline & A6-I & 102 & 102 & 89 & 13 & 25 & 330 & 812 & 47.7 & 200 & 435 & 71 & $1-9,5$ & 200 & 435 & 71 \\
\hline \multirow[t]{4}{*}{ David et al. (1999) } & $\overline{\mathrm{P}_{2}}$ & 150 & 300 & 257 & - & 200 & 933 & 2800 & 40.0 & 200 & 500 & 308 & $2-14$ & - & - & - \\
\hline & $\mathrm{P}_{3}$ & 150 & 300 & 257 & - & 200 & 933 & 2800 & 40.0 & 200 & 500 & 308 & $2-14$ & - & - & - \\
\hline & $\mathrm{P}_{4}$ & 150 & 300 & 257 & - & 200 & 933 & 2800 & 40.0 & 200 & 500 & 308 & $2-14$ & - & - & - \\
\hline & $\mathrm{P}_{5}$ & 150 & 300 & 257 & - & 200 & 933 & 2800 & 40.0 & 200 & 500 & 308 & $2-14$ & - & - & - \\
\hline \multirow[t]{2}{*}{ Esfahani et al. (2007) } & B3-12D-2L15 & 150 & 200 & 166 & 25 & 100 & 600 & 1600 & 25.2 & 200 & 400 & 226 & $2-12$ & 200 & 365 & 157 \\
\hline & B3-12D-3L15 & 150 & 200 & 166 & 25 & 100 & 600 & 1600 & 25.2 & 200 & 400 & 226 & $2-12$ & 200 & 365 & 157 \\
\hline \multirow[t]{6}{*}{ Fanning et al. (2000) } & F5 & 155 & 240 & 209 & 31 & 385 & 1100 & 2800 & 66.4 & 204 & 460 & 339 & $3-12$ & 204 & 460 & 226 \\
\hline & F6 & 155 & 240 & 209 & 31 & 385 & 1100 & 2800 & 66.4 & 204 & 460 & 339 & $3-12$ & 204 & 460 & 226 \\
\hline & F7 & 155 & 240 & 209 & 31 & 462 & 1100 & 2800 & 66.4 & 204 & 460 & 339 & $3-12$ & 204 & 460 & 226 \\
\hline & F8 & 155 & 240 & 209 & 31 & 462 & 1100 & 2800 & 66.4 & 204 & 460 & 339 & $3-12$ & 204 & 460 & 226 \\
\hline & F9 & 155 & 240 & 209 & 31 & 550 & 1100 & 2800 & 66.4 & 204 & 460 & 339 & $3-12$ & 204 & 460 & 226 \\
\hline & $\mathrm{F} 10$ & 155 & 240 & 209 & 31 & 550 & 1100 & 2800 & 66.4 & 204 & 460 & 339 & $3-12$ & 204 & 460 & 226 \\
\hline \multirow[t]{7}{*}{ Garden et al. (1997) } & $1 \mathrm{~A}_{\mathrm{u}}$ & 100 & 100 & 84 & 16 & 20 & 300 & 900 & 47.3 & 215 & 350 & 85 & $3-6$ & 215 & 350 & 57 \\
\hline & $2 \mathrm{~A}_{\mathrm{u}}$ & 100 & 100 & 84 & 16 & 20 & 340 & 900 & 47.3 & 215 & 350 & 85 & $3-6$ & 215 & 350 & 57 \\
\hline & $3 \mathrm{~A}_{\mathrm{u}}$ & 100 & 100 & 84 & 16 & 20 & 400 & 900 & 47.3 & 215 & 350 & 85 & $3-6$ & 215 & 350 & 57 \\
\hline & $1 \mathrm{~B}_{\mathrm{u}}$ & 100 & 100 & 84 & 16 & 20 & 300 & 900 & 47.3 & 215 & 350 & 85 & $3-6$ & 215 & 350 & 57 \\
\hline & $2 \mathrm{~B}_{\mathrm{u}}$ & 100 & 100 & 84 & 16 & 20 & 340 & 900 & 47.3 & 215 & 350 & 85 & $3-6$ & 215 & 350 & 57 \\
\hline & $3 \mathrm{~B}_{\mathrm{u}}$ & 100 & 100 & 84 & 16 & 20 & 400 & 900 & 47.3 & 215 & 350 & 85 & $3-6$ & 215 & 350 & 57 \\
\hline & $1 \mathrm{~B}_{2 \mathrm{u}}$ & 100 & 100 & 84 & 16 & 20 & 300 & 900 & 47.3 & 215 & 350 & 85 & $3-6$ & 215 & 350 & 57 \\
\hline
\end{tabular}

Table A. 2: Database of beams failed by end debonding. Breña et al. [33], David et al. (cited in [6]), Esfahani et al. [34], Fanning et al. [35], Garden et al. (cited in [6]). 


\begin{tabular}{|c|c|c|c|c|c|c|c|c|c|c|c|c|c|}
\hline & Beam & $\begin{array}{c}\mathrm{E}_{\mathrm{yv}} \\
{[\mathrm{GPa}]}\end{array}$ & $\begin{array}{c}\mathrm{f}_{\mathrm{yv}} \\
{[\mathrm{MPa}]}\end{array}$ & $\begin{array}{c}\mathrm{A}_{\mathrm{sv}} \\
{\left[\mathrm{mm}^{2}\right]}\end{array}$ & $\begin{array}{c}\mathrm{s} \\
{[\mathrm{mm}]}\end{array}$ & $\begin{array}{c}\mathrm{E}_{\mathrm{a}} \\
{[\mathrm{MPa}]}\end{array}$ & $\begin{array}{c}\mathrm{t}_{\mathrm{a}} \\
{[\mathrm{mm}]}\end{array}$ & $\begin{array}{c}\text { Type } \\
{[-]}\end{array}$ & $\begin{array}{c}\mathrm{E}_{\text {frp }} \\
{[\mathrm{GPa}]}\end{array}$ & $\begin{array}{c}\mathrm{f}_{\text {frp }} \\
{[\mathrm{MPa}]}\end{array}$ & $\begin{array}{c}\mathrm{t}_{\text {frp }} \\
{[\mathrm{mm}]}\end{array}$ & $\begin{array}{c}\mathrm{b}_{\mathrm{frp}} \\
{[\mathrm{mm}]}\end{array}$ & $\begin{array}{r}\mathrm{V}_{\text {exp }} \\
{[\mathrm{kN}]}\end{array}$ \\
\hline \multirow[t]{11}{*}{ Breña et al. (2004) } & A1-I & 200 & 420 & 28 & 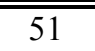 & 3035 & 0.4 & C-W & 230.00 & 3790 & 0.165 & 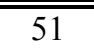 & 13.95 \\
\hline & A1-II & 200 & 420 & 28 & 51 & 3035 & 0.4 & $\mathrm{C}-\mathrm{W}$ & 230.00 & 3790 & 0.165 & 51 & 20.10 \\
\hline & A2-I & 200 & 420 & 28 & 51 & 3035 & 0.8 & $\mathrm{C}-\mathrm{W}$ & 230.00 & 3790 & 0.33 & 51 & 15.70 \\
\hline & A2-II & 200 & 420 & 28 & 51 & 3035 & 0.8 & $\mathrm{C}-\mathrm{W}$ & 230.00 & 3790 & 0.33 & 51 & 22.25 \\
\hline & A3-I & 200 & 420 & 28 & 51 & 3035 & 1.2 & $\mathrm{C}-\mathrm{W}$ & 230.00 & 3790 & 0.495 & 51 & 19.50 \\
\hline & A3-II & 200 & 420 & 28 & 51 & 3035 & 1.2 & $\mathrm{C}-\mathrm{W}$ & 230.00 & 3790 & 0.495 & 51 & 24.00 \\
\hline & A4-I & 200 & 420 & 28 & 51 & 3035 & 0.8 & $\mathrm{C}-\mathrm{W}$ & 230.00 & 3790 & 0.33 & 76 & 18.40 \\
\hline & A4-II & 200 & 420 & 28 & 51 & 3035 & 0.8 & C-W & 230.00 & 3790 & 0.33 & 76 & 26.25 \\
\hline & A5-I & 200 & 420 & 28 & 51 & 3035 & 0.4 & $\mathrm{C}-\mathrm{W}$ & 230.00 & 3790 & 0.165 & 102 & 17.60 \\
\hline & A5-II & 200 & 420 & 28 & 51 & 3035 & 0.4 & C-W & 230.00 & 3790 & 0.165 & 102 & 24.45 \\
\hline & A6-I & 200 & 420 & 28 & 51 & 4480 & 1.6 & C-P & 155.00 & 2400 & 1.19 & 51 & 17.40 \\
\hline \multirow[t]{4}{*}{ David et al. (1999) } & $\mathrm{P}_{2}$ & 200 & 500 & 57 & 140 & 8500 & 1.0 & C-P & 150.00 & 2400 & 1.2 & 100 & 68.00 \\
\hline & $\mathrm{P}_{3}$ & 200 & 500 & 57 & 140 & 8500 & 1.0 & C-P & 150.00 & 2400 & 1.2 & 100 & 71.10 \\
\hline & $\mathrm{P}_{4}$ & 200 & 500 & 57 & 140 & 8500 & 1.0 & C-P & 150.00 & 2400 & 2.4 & 100 & 78.00 \\
\hline & $\mathrm{P}_{5}$ & 200 & 500 & 57 & 140 & 8500 & 1.0 & C-P & 150.00 & 2400 & 2.4 & 100 & 79.50 \\
\hline \multirow[t]{2}{*}{ Esfahani et al. (2007) } & B3-12D-2L15 & 200 & 350 & 50 & 80 & - & - & $\mathrm{C}-\mathrm{W}$ & 237.00 & 2845 & 0.176 & 150 & 35.47 \\
\hline & B3-12D-3L15 & 200 & 350 & 50 & 80 & - & - & $\mathrm{C}-\mathrm{W}$ & 237.00 & 2845 & 0.176 & 150 & 37.22 \\
\hline \multirow[t]{6}{*}{ Fanning et al. (2000) } & F5 & 198 & 250 & 28 & 125 & - & - & C-P & 155.00 & 2400 & 1.2 & 120 & 50.00 \\
\hline & F6 & 198 & 250 & 28 & 125 & - & - & C-P & 155.00 & 2400 & 1.2 & 120 & 51.50 \\
\hline & F7 & 198 & 250 & 28 & 125 & - & - & C-P & 155.00 & 2400 & 1.2 & 120 & 48.75 \\
\hline & F8 & 198 & 250 & 28 & 125 & - & - & C-P & 155.00 & 2400 & 1.2 & 120 & 32.00 \\
\hline & F9 & 198 & 250 & 28 & 125 & - & - & $\mathrm{C}-\mathrm{P}$ & 155.00 & 2400 & 1.2 & 120 & 31.00 \\
\hline & F10 & 198 & 250 & 28 & 125 & - & - & $\mathrm{C}-\mathrm{P}$ & 155.00 & 2400 & 1.2 & 120 & 41.00 \\
\hline \multirow[t]{7}{*}{ Garden et al. (1997) } & $1 \mathrm{~A}_{\mathrm{u}}$ & 215 & 350 & 14 & 51 & 11560 & 2.0 & $\mathrm{C}-\mathrm{P}$ & 111.00 & 1273 & 0.5 & 90 & 19.80 \\
\hline & $2 \mathrm{~A}_{\mathrm{u}}$ & 215 & 350 & 14 & 51 & 11560 & 2.0 & C-P & 111.00 & 1273 & 0.5 & 90 & 19.30 \\
\hline & $3 \mathrm{~A}_{\mathrm{u}}$ & 215 & 350 & 14 & 51 & 11560 & 2.0 & C-P & 111.00 & 1273 & 0.5 & 90 & 19.50 \\
\hline & $1 \mathrm{~B}_{\mathrm{u}}$ & 215 & 350 & 14 & 51 & 11560 & 2.0 & $\mathrm{C}-\mathrm{P}$ & 111.00 & 1273 & 0.7 & 65 & 18.30 \\
\hline & $2 \mathrm{~B}_{\mathrm{u}}$ & 215 & 350 & 14 & 51 & 11560 & 2.0 & C-P & 111.00 & 1273 & 0.7 & 65 & 17.00 \\
\hline & $3 \mathrm{~B}_{\mathrm{u}}$ & 215 & 350 & 14 & 51 & 11560 & 2.0 & C-P & 111.00 & 1273 & 0.7 & 65 & 17.30 \\
\hline & $1 B_{2 u}$ & 215 & 350 & 14 & 51 & 11560 & 2.0 & C-P & 111.00 & 1273 & 0.7 & 65 & 18.20 \\
\hline
\end{tabular}

Table A. 2 (cont): Database of beams failed by end debonding. Breña et al. [33], David et al. (cited in [6]), Esfahani et al. [34], Fanning et al. [35], Garden et al. (cited in [6]). 
Pag. 38

\begin{tabular}{|c|c|c|c|c|c|c|c|c|c|c|c|c|c|c|c|c|}
\hline & Beam & $\begin{array}{c}\mathrm{b} \\
{[\mathrm{mm}]}\end{array}$ & $\begin{array}{c}\mathrm{h} \\
{[\mathrm{mm}]} \\
\end{array}$ & $\begin{array}{c}\mathrm{d} \\
{[\mathrm{mm}]} \\
\end{array}$ & $\begin{array}{c}\mathrm{d}^{\prime} \\
{[\mathrm{mm}]} \\
\end{array}$ & $\begin{array}{c}\mathrm{a} \\
{[\mathrm{mm}]} \\
\end{array}$ & $\begin{array}{c}\mathrm{B} \\
{[\mathrm{mm}]} \\
\end{array}$ & $\begin{array}{c}\mathrm{L} \\
{[\mathrm{mm}]} \\
\end{array}$ & $\begin{array}{c}\mathrm{f}_{\mathrm{c}}{ }^{\prime} \\
{[\mathrm{MPa}]}\end{array}$ & $\begin{array}{c}\mathrm{E}_{\mathrm{s}} \\
{[\mathrm{GPa}]}\end{array}$ & $\begin{array}{c}\mathrm{f}_{\mathrm{ys}} \\
{[\mathrm{MPa}]}\end{array}$ & $\begin{array}{c}\mathrm{A}_{\mathrm{s}} \\
{\left[\mathrm{mm}^{2}\right]}\end{array}$ & $\begin{array}{c}\text { Reo } \\
\text { [tension] } \\
\end{array}$ & $\begin{array}{c}\mathrm{E}_{\mathrm{s}}^{\prime} \\
{[\mathrm{GPa}]}\end{array}$ & $\begin{array}{c}\mathrm{f}_{\mathrm{y}} \\
{[\mathrm{MPa}]}\end{array}$ & $\begin{array}{c}\mathrm{A}_{\mathrm{s}}^{\prime} \\
{\left[\mathrm{mm}^{2}\right]} \\
\end{array}$ \\
\hline \multirow[t]{3}{*}{ Garden et al. (1997) } & $1 \mathrm{C}_{\mathrm{u}}$ & 100 & 100 & 84 & 16 & 20 & 300 & 900 & 47.3 & 215 & 350 & 85 & $3-6$ & 215 & 350 & 57 \\
\hline & $2 \mathrm{C}_{\mathrm{u}}$ & 100 & 100 & 84 & 16 & 20 & 340 & 900 & 47.3 & 215 & 350 & 85 & $3-6$ & 215 & 350 & 57 \\
\hline & $3 \mathrm{C}_{\mathrm{u}}$ & 100 & 100 & 84 & 16 & 20 & 400 & 900 & 47.3 & 215 & 350 & 85 & $3-6$ & 215 & 350 & 57 \\
\hline \multirow[t]{7}{*}{ Garden et al. (1998) } & B1u, 1.0 & 100 & 100 & 84 & 16 & 20 & 300 & 900 & 43.2 & 215 & 350 & 85 & $3-6$ & 215 & 350 & 57 \\
\hline & $\mathrm{B} 2 \mathrm{u}, 1.0$ & 100 & 100 & 84 & 16 & 20 & 300 & 900 & 43.2 & 215 & 350 & 85 & $3-6$ & 215 & 350 & 57 \\
\hline & $\mathrm{B} 1 \mathrm{u}, 2.3$ & 130 & 230 & 206 & 25 & 20 & 844 & 2200 & 37.6 & 220 & 556 & 236 & $3-10$ & 220 & 556 & 101 \\
\hline & B3U1.0 & 100 & 100 & 87 & 10 & 20 & 340 & - & 44.8 & 215 & 350 & 85 & -6 & 215 & 350 & 57 \\
\hline & B4U1.0 & 100 & 100 & 87 & 10 & 20 & 400 & - & 44.8 & 215 & 350 & 85 & -6 & 215 & 350 & 57 \\
\hline & B5U1.0 & 100 & 100 & 87 & 10 & 20 & 400 & - & 44.8 & 215 & 350 & 85 & -6 & 215 & 350 & 57 \\
\hline & B1U4.5 & 145 & 230 & 214 & 15 & 40 & 1525 & - & 39.0 & 220 & 556 & 236 & -12 & 220 & 556 & 111 \\
\hline \multirow[t]{4}{*}{ Grace et al. (2005) } & $\mathrm{Bb} 1$ & 152 & 254 & 228.6 & 25.4 & 152.5 & 864 & 2540 & 31.0 & 200 & 414 & 397 & $3-15,9$ & 200 & 414 & 142 \\
\hline & $\mathrm{Bb} 2$ & 152 & 254 & 228.6 & 25.4 & 152.5 & 864 & 2540 & 31.0 & 200 & 414 & 397 & $3-15,9$ & 200 & 414 & 142 \\
\hline & $\mathrm{Bb} 3$ & 152 & 254 & 228.6 & 25.4 & 152.5 & 864 & 2540 & 31.0 & 200 & 414 & 397 & $3-15,9$ & 200 & 414 & 142 \\
\hline & $\mathrm{Bb} 4$ & 152 & 254 & 228.6 & 25.4 & 152.5 & 864 & 2540 & 31.0 & 200 & 414 & 397 & $3-15,9$ & 200 & 414 & 142 \\
\hline \multirow{5}{*}{ Hau et al. (1999) } & 2 & 150 & 250 & 205 & 45 & 350 & 500 & 1500 & 35.4 & 231 & 537 & 157 & $2-10$ & 231 & 537 & 157 \\
\hline & 4 & 150 & 250 & 205 & 45 & 200 & 500 & 1500 & 36.2 & 231 & 537 & 157 & $2-10$ & 231 & 537 & 157 \\
\hline & 5 & 150 & 250 & 205 & 45 & 50 & 500 & 1500 & 40.6 & 231 & 537 & 157 & $2-10$ & 231 & 537 & 157 \\
\hline & 6 & 150 & 250 & 205 & 45 & 200 & 500 & 1500 & 39.9 & 231 & 537 & 157 & $2-10$ & 231 & 537 & 157 \\
\hline & 7 & 150 & 250 & 205 & 45 & 350 & 500 & 1500 & 37.6 & 231 & 537 & 157 & $2-10$ & 231 & 537 & 157 \\
\hline \multirow[t]{2}{*}{ Juvandes et al. (1998) } & B7 & 75 & 150 & 131 & 22 & 10 & 650 & 1500 & 37.0 & 200 & 190 & 14 & $2-3$ & 200 & 470 & 151 \\
\hline & B.11 & 75 & 150 & 128.5 & 20 & 200 & 650 & - & 36.0 & 200 & 190 & 14 & -3 & 200 & 190 & 151 \\
\hline \multirow[t]{6}{*}{ Matthys (2000) } & BF2 & 200 & 450 & 409 & - & 70 & 1250 & - & 36.5 & 200 & 590 & 804 & -16 & 200 & 590 & - \\
\hline & $\mathrm{BF} 3$ & 200 & 450 & 409 & - & 70 & 1250 & - & 34.9 & 200 & 590 & 804 & -16 & 200 & 590 & - \\
\hline & BF4 & 200 & 450 & 409 & - & 70 & 1250 & - & 30.8 & 200 & 590 & 804 & -16 & 200 & 590 & - \\
\hline & BF5 & 200 & 450 & 409 & - & 70 & 1250 & - & 37.4 & 200 & 590 & 804 & -16 & 200 & 590 & - \\
\hline & BF8 & 200 & 450 & 409 & - & 71 & 1251 & - & 39.4 & 200 & 590 & 402 & -16 & 200 & 590 & - \\
\hline & BF9 & 200 & 450 & 409 & - & 71 & 1251 & - & 33.7 & 200 & 590 & 402 & -16 & 200 & 590 & - \\
\hline \multirow[t]{4}{*}{ Nguyen et al. (2001) } & A950 & 120 & 150 & 120 & 34 & 190 & 440 & 1330 & 25.7 & 200 & 384 & 236 & $3-10$ & 200 & 400 & 57 \\
\hline & A1100 & 120 & 150 & 120 & 34 & 115 & 440 & 1330 & 25.7 & 200 & 384 & 236 & $3-10$ & 200 & 400 & 57 \\
\hline & A1150 & 120 & 150 & 120 & 34 & 90 & 440 & 1330 & 25.7 & 200 & 384 & 236 & $3-10$ & 200 & 400 & 57 \\
\hline & $\mathrm{B} 2$ & 120 & 150 & 120 & 34 & 115 & 440 & 1330 & 25.7 & 200 & 384 & 236 & $3-10$ & 200 & 400 & 57 \\
\hline Pham et al. (2006) & E1a & 140 & 260 & 220 & 40 & 150 & 700 & 2300 & 53.7 & 205 & 551 & 339 & $3-12$ & 205 & 551 & 226 \\
\hline
\end{tabular}

Table A. 3: Database of beams failed by end debonding. Garden et al. (cited in [6]), Garden et al. [36], Grace et al. [37], Hau et al. (cited in [6]), Juvandes et al. (cited in [22]), Matthys [38], Nguyen et al. [39], Pham et al. [40]. 
Pag. 39

\begin{tabular}{|c|c|c|c|c|c|c|c|c|c|c|c|c|c|}
\hline & Beam & $\begin{array}{c}\mathrm{E}_{\mathrm{yv}} \\
{[\mathrm{GPa}]}\end{array}$ & $\begin{array}{c}\mathrm{f}_{\mathrm{yv}} \\
{[\mathrm{MPa}]}\end{array}$ & $\begin{array}{c}\mathrm{A}_{\mathrm{sv}} \\
{\left[\mathrm{mm}^{2}\right]}\end{array}$ & $\begin{array}{c}\mathrm{s} \\
{[\mathrm{mm}]}\end{array}$ & $\begin{array}{c}\mathrm{E}_{\mathrm{a}} \\
{[\mathrm{MPa}]}\end{array}$ & $\begin{array}{c}\mathrm{t}_{\mathrm{a}} \\
{[\mathrm{mm}]}\end{array}$ & $\begin{array}{c}\text { Type } \\
{[-]} \\
\end{array}$ & $\begin{array}{c}\mathrm{E}_{\text {frp }} \\
{[\mathrm{GPa}]}\end{array}$ & $\begin{array}{c}\mathrm{f}_{\text {frp }} \\
{[\mathrm{MPa}]}\end{array}$ & $\begin{array}{c}\mathrm{t}_{\text {frp }} \\
{[\mathrm{mm}]}\end{array}$ & $\begin{array}{c}\mathrm{b}_{\mathrm{frp}} \\
{[\mathrm{mm}]}\end{array}$ & $\begin{array}{r}\mathrm{V}_{\exp } \\
{[\mathrm{kN}]}\end{array}$ \\
\hline \multirow[t]{3}{*}{ Garden et al. (1997) } & $1 \mathrm{C}_{\mathrm{u}}$ & 215 & 350 & 14 & 51 & 11560 & 2.0 & C-P & 111.00 & 1273 & 1 & 45 & 16.00 \\
\hline & $2 \mathrm{C}_{\mathrm{u}}$ & 215 & 350 & 14 & 51 & 11560 & 2.0 & C-P & 111.00 & 1273 & 1 & 45 & 17.80 \\
\hline & $3 \mathrm{C}_{\mathrm{u}}$ & 215 & 350 & 14 & 51 & 11560 & 2.0 & C-P & 111.00 & 1273 & 1.0 & 45 & 15.40 \\
\hline \multirow[t]{7}{*}{ Garden et al. (1998) } & B1u, 1.0 & 215 & 350 & 14 & 51 & 8600 & 2.0 & C-P & 111.00 & 1414 & 0.82 & 67 & 18.30 \\
\hline & $\mathrm{B} 2 \mathrm{u}, 1.0$ & 215 & 350 & 14 & 51 & 8600 & 2.0 & C-P & 111.00 & 1414 & 0.82 & 67 & 16.00 \\
\hline & $\mathrm{B} 1 \mathrm{u}, 2.3$ & 215 & 350 & 57 & 150 & 8600 & 2.0 & C-P & 115.00 & 1284 & 1.28 & 90 & 50.20 \\
\hline & B3U1.0 & 215 & 350 & 14 & 50 & - & - & $\mathrm{C}-\mathrm{W}$ & 111.00 & 1414 & 0.8 & 67 & 17.00 \\
\hline & B4U1.0 & 215 & 350 & 14 & 50 & - & - & $\mathrm{C}-\mathrm{W}$ & 111.00 & 1414 & 0.8 & 67 & 17.30 \\
\hline & B5U1.0 & 215 & 350 & 14 & 50 & - & - & $\mathrm{C}-\mathrm{W}$ & 111.00 & 1414 & 0.8 & 67 & 17.30 \\
\hline & B1U4.5 & 220 & 350 & 57 & 150 & - & - & $\mathrm{C}-\mathrm{W}$ & 115.00 & 1284 & 1.3 & 90 & 30.00 \\
\hline \multirow[t]{4}{*}{ Grace et al. (2005) } & $\mathrm{Bb} 1$ & 200 & 414 & 142 & 102 & 2140 & - & $\mathrm{C}-\mathrm{W}$ & 138.00 & 2070 & 1.2 & 152 & 68.30 \\
\hline & $\mathrm{Bb} 2$ & 200 & 414 & 142 & 102 & 2140 & - & $\mathrm{C}-\mathrm{W}$ & 138.00 & 2070 & 1.2 & 152 & 68.30 \\
\hline & $\mathrm{Bb} 3$ & 200 & 414 & 142 & 102 & 2140 & - & $\mathrm{C}-\mathrm{P}$ & 227.00 & 2758 & 0.4 & 152 & 66.75 \\
\hline & $\mathrm{Bb} 4$ & 200 & 414 & 142 & 102 & 2140 & - & $\mathrm{C}-\mathrm{P}$ & 227.00 & 2758 & 0.4 & 152 & 66.75 \\
\hline \multirow[t]{5}{*}{ Hau et al. (1999) } & 2 & 231 & 537 & 157 & 100 & 3260 & 0.4 & G-W & 19.72 & 259 & 1.32 & 150 & 53.00 \\
\hline & 4 & 231 & 537 & 157 & 100 & 3260 & 0.4 & $\mathrm{G}-\mathrm{W}$ & 19.72 & 259 & 1.3 & 150 & 65.40 \\
\hline & 5 & 231 & 537 & 157 & 100 & 3260 & 0.4 & G-W & 19.72 & 259 & 2.6 & 150 & 79.40 \\
\hline & 6 & 231 & 537 & 157 & 100 & 3260 & 0.4 & G-W & 19.72 & 259 & 1.32 & 150 & 63.10 \\
\hline & 7 & 231 & 537 & 157 & 100 & 3260 & 0.4 & $\mathrm{G}-\mathrm{W}$ & 19.72 & 259 & 1.32 & 150 & 53.90 \\
\hline \multirow[t]{2}{*}{ Juvandes et al. (1998) } & B7 & 200 & 190 & 14 & 60 & 10250 & 2.5 & C-P & 150.00 & 2400 & 1.2 & 50 & 12.50 \\
\hline & B.11 & 200 & 190 & 14 & 60 & - & - & $\mathrm{C}-\mathrm{W}$ & 150.00 & 2400 & 1.2 & 50 & 6.70 \\
\hline \multirow[t]{6}{*}{ Matthys (2000) } & BF2 & 200 & 560 & 101 & 100 & - & - & $\mathrm{C}-\mathrm{W}$ & 159.00 & 3200 & 1.2 & 100 & 185.00 \\
\hline & BF3 & 200 & 560 & 101 & 100 & - & - & $\mathrm{C}-\mathrm{W}$ & 159.00 & 3200 & 1.2 & 100 & 186.00 \\
\hline & $\mathrm{BF} 4$ & 200 & 560 & 101 & 100 & - & - & $\mathrm{C}-\mathrm{W}$ & 159.00 & 3200 & 1.2 & 100 & 184.20 \\
\hline & BF5 & 200 & 560 & 101 & 100 & - & - & $\mathrm{C}-\mathrm{W}$ & 159.00 & 3200 & 1.2 & 100 & 177.00 \\
\hline & BF8 & 200 & 560 & 101 & 100 & - & - & $\mathrm{C}-\mathrm{W}$ & 159.00 & 3200 & 1.2 & 100 & 111.30 \\
\hline & BF9 & 200 & 560 & 101 & 100 & - & - & $\mathrm{C}-\mathrm{W}$ & 159.00 & 3200 & 0.2 & 100 & 95.80 \\
\hline \multirow[t]{4}{*}{ Nguyen et al. (2001) } & A950 & 200 & 400 & 57 & 50 & 12800 & 1.5 & C-P & 181.00 & 3140 & 1.2 & 80 & 28.10 \\
\hline & A1 100 & 200 & 400 & 57 & 50 & 12800 & 1.5 & C-P & 181.00 & 3140 & 1.2 & 80 & 28.70 \\
\hline & A1150 & 200 & 400 & 57 & 50 & 12800 & 1.5 & C-P & 181.00 & 3140 & 1.2 & 80 & 29.50 \\
\hline & B2 & 200 & 400 & 57 & 50 & 12800 & 1.5 & C-P & 181.00 & 3140 & 1.2 & 80 & 65.10 \\
\hline Pham et al. (2006) & E1a & 204 & 334 & 79 & 125 & 3500 & - & $\mathrm{C}-\mathrm{W}$ & 209.00 & 3900 & 1.056 & 100 & 35.35 \\
\hline
\end{tabular}

Table A.3 (cont): Database of beams failed by end debonding. Garden et al. (cited in [6]), Garden et al. [36], Grace et al. [37], Hau et al. (cited in [6]), Juvandes et al. (cited in [22]), Matthys [38], Nguyen et al. [39], Pham et al. [40]. 
Pag. 40

\begin{tabular}{|c|c|c|c|c|c|c|c|c|c|c|c|c|c|c|c|c|}
\hline & Beam & $\begin{array}{c}\mathrm{b} \\
{[\mathrm{mm}]}\end{array}$ & $\begin{array}{c}\mathrm{h} \\
{[\mathrm{mm}]} \\
\end{array}$ & $\begin{array}{c}\mathrm{d} \\
{[\mathrm{mm}]} \\
\end{array}$ & $\begin{array}{c}\mathrm{d}^{\prime} \\
{[\mathrm{mm}]}\end{array}$ & $\begin{array}{c}\mathrm{a} \\
{[\mathrm{mm}]} \\
\end{array}$ & $\begin{array}{c}\mathrm{B} \\
{[\mathrm{mm}]} \\
\end{array}$ & $\begin{array}{c}\mathrm{L} \\
{[\mathrm{mm}]} \\
\end{array}$ & $\begin{array}{c}\mathrm{f}_{\mathrm{c}}{ }^{\prime} \\
{[\mathrm{MPa}]}\end{array}$ & $\begin{array}{c}\mathrm{E}_{\mathrm{s}} \\
{[\mathrm{GPa}]}\end{array}$ & $\begin{array}{c}\mathrm{f}_{\mathrm{ys}} \\
{[\mathrm{MPa}]}\end{array}$ & $\begin{array}{c}\mathrm{A}_{\mathrm{s}} \\
{\left[\mathrm{mm}^{2}\right]}\end{array}$ & $\begin{array}{c}\text { Reo } \\
\text { [tension] }\end{array}$ & $\begin{array}{c}\mathrm{E}_{\mathrm{s}}^{\prime} \\
{[\mathrm{GPa}]}\end{array}$ & $\begin{array}{c}\mathrm{f}_{\mathrm{y}} \\
{[\mathrm{MPa}]}\end{array}$ & $\begin{array}{c}\mathrm{A}_{\mathrm{s}}^{\prime} \\
{\left[\mathrm{mm}^{2}\right]} \\
\end{array}$ \\
\hline \multirow[t]{10}{*}{ Pham et al. (2006) } & 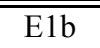 & 140 & 260 & 220 & 40 & 150 & 700 & 2300 & 53.7 & 205 & 551 & 339 & $3-12$ & 205 & 551 & 226 \\
\hline & E2a & 140 & 260 & 220 & 40 & 350 & 700 & 2300 & 53.7 & 205 & 551 & 339 & $3-12$ & 205 & 551 & 226 \\
\hline & $\mathrm{E} 2 \mathrm{~b}$ & 140 & 260 & 220 & 40 & 350 & 700 & 2300 & 53.7 & 205 & 551 & 339 & $3-12$ & 205 & 551 & 226 \\
\hline & E3a & 140 & 260 & 220 & 40 & 150 & 700 & 2300 & 53.7 & 205 & 551 & 339 & $3-12$ & 205 & 551 & 226 \\
\hline & E3b & 140 & 260 & 220 & 40 & 150 & 700 & 2300 & 53.7 & 205 & 551 & 339 & $3-12$ & 205 & 551 & 226 \\
\hline & $\mathrm{E} 4 \mathrm{a}$ & 140 & 260 & 220 & 40 & 150 & 700 & 2300 & 53.7 & 205 & 551 & 339 & $3-12$ & 205 & 551 & 226 \\
\hline & $\mathrm{E} 4 \mathrm{~b}$ & 140 & 260 & 220 & 40 & 150 & 700 & 2300 & 53.7 & 205 & 551 & 339 & $3-12$ & 205 & 551 & 226 \\
\hline & E5a & 140 & 260 & 220 & 40 & 150 & 700 & 2300 & 53.7 & 205 & 551 & 339 & $3-12$ & 205 & 551 & 226 \\
\hline & $\mathrm{E} 5 \mathrm{~b}$ & 140 & 260 & 220 & 40 & 150 & 700 & 2300 & 53.7 & 205 & 551 & 339 & $3-12$ & 205 & 551 & 226 \\
\hline & $\mathrm{E} 3 \mathrm{~b} 2$ & 140 & 260 & 220 & 40 & 150 & 700 & 2300 & 53.7 & 205 & 551 & 226 & $2-12$ & 205 & 551 & 226 \\
\hline \multirow[t]{4}{*}{ Quantrill el al. (1996) } & $\mathrm{B} 2$ & 100 & 100 & 84 & 16 & 20 & 300 & 900 & 42.4 & 215 & 350 & 85 & $3-6$ & 215 & 350 & 57 \\
\hline & B3 & 100 & 100 & 84 & 16 & 20 & 300 & 900 & 42.4 & 215 & 350 & 85 & $3-6$ & 210 & 350 & 57 \\
\hline & B4 & 100 & 100 & 84 & 16 & 20 & 300 & 900 & 42.4 & 215 & 350 & 85 & $3-6$ & 215 & 350 & 57 \\
\hline & B6 & 100 & 100 & 84 & 16 & 20 & 300 & 900 & 42.4 & 215 & 350 & 85 & $3-6$ & 215 & 350 & 57 \\
\hline \multirow[t]{8}{*}{ Rahimi et al. (2001) } & A4 & 200 & 150 & 120 & 30 & 85 & 750 & 2100 & 41.5 & 210 & 575 & 157 & $2-10$ & 210 & 575 & 101 \\
\hline & A5 & 200 & 150 & 120 & 30 & 85 & 750 & 2100 & 41.5 & 210 & 575 & 157 & $2-10$ & 210 & 575 & 101 \\
\hline & A6 & 200 & 150 & 120 & 30 & 85 & 750 & 2100 & 41.5 & 210 & 575 & 157 & $2-10$ & 210 & 575 & 101 \\
\hline & A7 & 200 & 150 & 120 & 30 & 85 & 750 & 2100 & 41.5 & 210 & 575 & 157 & $2-10$ & 210 & 575 & 101 \\
\hline & $\mathrm{A} 8$ & 200 & 150 & 120 & 30 & 85 & 750 & 2100 & 41.5 & 210 & 575 & 157 & $2-10$ & 210 & 575 & 101 \\
\hline & A9 & 200 & 150 & 120 & 30 & 85 & 750 & 2100 & 41.5 & 210 & 575 & 157 & $2-10$ & 210 & 575 & 101 \\
\hline & $\mathrm{A} 10$ & 200 & 150 & 120 & 30 & 85 & 750 & 2100 & 41.5 & 210 & 575 & 157 & $2-10$ & 210 & 575 & 101 \\
\hline & A11 & 200 & 150 & 120 & 30 & 85 & 750 & 2100 & 41.5 & 210 & 575 & 157 & $2-10$ & 210 & 575 & 101 \\
\hline \multirow[t]{5}{*}{ Ritchie et al (1991) } & $\mathrm{C}$ & 152 & 305 & 251 & - & 203 & 914 & 2438 & 39.8 & 200 & 414 & 253 & $2-12.7$ & - & - & - \\
\hline & $\mathrm{D}$ & 152 & 305 & 251 & - & 203 & 914 & 2438 & 39.8 & 200 & 414 & 253 & $2-12.7$ & - & - & - \\
\hline & G & 152 & 305 & 251 & - & 0 & 914 & 2438 & 43.0 & 200 & 414 & 253 & $2-12.7$ & - & - & - \\
\hline & I & 152 & 305 & 251 & - & 203 & 914 & 2438 & 39.8 & 200 & 414 & 253 & $2-12.7$ & - & - & - \\
\hline & $\mathrm{M}$ & 152 & 305 & 251 & - & 0 & 914 & 2438 & 43.0 & 200 & 414 & 253 & $2-12.7$ & - & - & - \\
\hline \multirow[t]{5}{*}{ Ross et al. (1999) } & $1 \mathrm{~B}$ & 200 & 200 & 152 & 48 & 1 & 914 & 2742 & 54.8 & 200 & 410 & 143 & $2-9,5$ & 200 & 410 & 143 \\
\hline & $1 \mathrm{C}$ & 200 & 200 & 152 & 48 & 1 & 914 & 2742 & 54.8 & 200 & 410 & 143 & $2-9,5$ & 200 & 410 & 143 \\
\hline & $2 \mathrm{~B}$ & 200 & 200 & 152 & 48 & 1 & 914 & 2742 & 54.8 & 200 & 410 & 253 & $2-12,7$ & 200 & 410 & 143 \\
\hline & $2 \mathrm{C}$ & 200 & 200 & 152 & 48 & 1 & 914 & 2742 & 54.8 & 200 & 410 & 253 & $2-12,7$ & 200 & 410 & 143 \\
\hline & $2 \mathrm{D}$ & 200 & 200 & 152 & 48 & 1 & 914 & 2742 & 54.8 & 200 & 410 & 253 & $2-12,7$ & 200 & 410 & 143 \\
\hline
\end{tabular}

Table A. 4: Database of beams failed by end debonding. Pham et al. [40], Quantrill et al. (cited in [6]), Rahimi et al. [10], Ritchie et al. [41], Ross et al. [9]. 


\begin{tabular}{|c|c|c|c|c|c|c|c|c|c|c|c|c|c|}
\hline & Beam & $\begin{array}{c}\mathrm{E}_{\mathrm{yv}} \\
{[\mathrm{GPa}]}\end{array}$ & $\begin{array}{c}\mathrm{f}_{\mathrm{yv}} \\
{[\mathrm{MPa}]}\end{array}$ & $\begin{array}{c}\mathrm{A}_{\mathrm{sv}} \\
{\left[\mathrm{mm}^{2}\right]}\end{array}$ & $\begin{array}{c}\mathrm{s} \\
{[\mathrm{mm}]}\end{array}$ & $\begin{array}{c}\mathrm{E}_{\mathrm{a}} \\
{[\mathrm{MPa}]}\end{array}$ & $\begin{array}{c}\mathrm{t}_{\mathrm{a}} \\
{[\mathrm{mm}]}\end{array}$ & $\begin{array}{c}\text { Type } \\
{[-]} \\
\end{array}$ & $\begin{array}{c}\mathrm{E}_{\text {frp }} \\
{[\mathrm{GPa}]}\end{array}$ & $\begin{array}{c}\mathrm{f}_{\text {frp }} \\
{[\mathrm{MPa}]}\end{array}$ & $\begin{array}{c}\mathrm{t}_{\text {frp }} \\
{[\mathrm{mm}]}\end{array}$ & $\begin{array}{c}\mathrm{b}_{\mathrm{frp}} \\
{[\mathrm{mm}]}\end{array}$ & $\begin{array}{r}\mathrm{V}_{\text {exp }} \\
{[\mathrm{kN}]}\end{array}$ \\
\hline \multirow[t]{10}{*}{ Pham et al. (2006) } & $\overline{\text { E1b }}$ & 204 & 334 & $\overline{799}$ & 125 & 3500 & - & C-W & 209.00 & 3900 & 1.056 & 100 & 37.30 \\
\hline & E2a & 204 & 334 & 79 & 125 & 3500 & - & $\mathrm{C}-\mathrm{W}$ & 209.00 & 3900 & 1.056 & 100 & 25.70 \\
\hline & $\mathrm{E} 2 \mathrm{~b}$ & 204 & 334 & 79 & 125 & 3500 & - & $\mathrm{C}-\mathrm{W}$ & 209.00 & 3900 & 1.056 & 100 & 26.70 \\
\hline & E3a & 204 & 334 & 79 & 125 & 3500 & - & $\mathrm{C}-\mathrm{W}$ & 209.00 & 3900 & 1.056 & 100 & 33.00 \\
\hline & $\mathrm{E} 3 \mathrm{~b}$ & 204 & 334 & 79 & 125 & 3500 & - & $\mathrm{C}-\mathrm{W}$ & 209.00 & 3900 & 1.056 & 100 & 32.60 \\
\hline & $\mathrm{E} 4 \mathrm{a}$ & 204 & 334 & 79 & 125 & 3500 & - & $\mathrm{C}-\mathrm{W}$ & 209.00 & 3900 & 1.056 & 100 & 39.50 \\
\hline & $\mathrm{E} 4 \mathrm{~b}$ & 204 & 334 & 79 & 125 & 3500 & - & $\mathrm{C}-\mathrm{W}$ & 209.00 & 3900 & 1.056 & 100 & 30.60 \\
\hline & E5a & 204 & 334 & 79 & 125 & 3500 & - & $\mathrm{C}-\mathrm{W}$ & 209.00 & 3900 & 1.584 & 100 & 31.65 \\
\hline & $\mathrm{E} 5 \mathrm{~b}$ & 204 & 334 & 79 & 125 & 3500 & - & $\mathrm{C}-\mathrm{W}$ & 209.00 & 3900 & 1.584 & 100 & 31.60 \\
\hline & E3b2 & 204 & 334 & 79 & 125 & 3500 & - & $\mathrm{C}-\mathrm{W}$ & 209.00 & 3900 & 1.056 & 100 & 30.00 \\
\hline \multirow[t]{4}{*}{ Quantrill el al. (1996) } & $\mathrm{B} 2$ & 215 & 350 & 14 & 50 & 11560 & 2.0 & G-P & 49.00 & 1078 & 1.2 & 80 & 17.00 \\
\hline & B3 & 215 & 350 & 14 & 50 & 11560 & 2.0 & G-P & 49.00 & 1078 & 1.2 & 30 & 12.30 \\
\hline & B4 & 215 & 350 & 14 & 50 & 11560 & 2.0 & G-P & 49.00 & 1078 & 1.6 & 60 & 17.50 \\
\hline & B6 & 215 & 350 & 14 & 50 & 11560 & 2.0 & C-P & 118.50 & 987 & 1.2 & 80 & 20.40 \\
\hline \multirow[t]{8}{*}{ Rahimi et al. (2001) } & A4 & 210 & 575 & 28 & 150 & 7000 & 2.0 & $\mathrm{C}-\mathrm{W}$ & 127.00 & 1532 & 0.8 & 150 & 30.95 \\
\hline & A5 & 210 & 575 & 28 & 150 & 7000 & 2.0 & $\mathrm{C}-\mathrm{W}$ & 127.00 & 1532 & 0.8 & 150 & 31.60 \\
\hline & A6 & 210 & 575 & 28 & 150 & 7000 & 2.0 & $\mathrm{C}-\mathrm{W}$ & 127.00 & 1532 & 1.2 & 150 & 29.70 \\
\hline & A7 & 210 & 575 & 28 & 150 & 7000 & 2.0 & $\mathrm{C}-\mathrm{W}$ & 127.00 & 1532 & 1.2 & 150 & 35.30 \\
\hline & A8 & 210 & 575 & 28 & 150 & 7000 & 2.0 & $\mathrm{C}-\mathrm{W}$ & 127.00 & 1532 & 0.8 & 150 & 32.60 \\
\hline & A9 & 210 & 575 & 28 & 150 & 7000 & 2.0 & $\mathrm{C}-\mathrm{W}$ & 127.00 & 1532 & 0.8 & 150 & 31.95 \\
\hline & A10 & 210 & 575 & 28 & 150 & 7000 & 2.0 & $\mathrm{C}-\mathrm{W}$ & 127.00 & 1532 & 0.8 & 150 & 33.75 \\
\hline & A11 & 210 & 575 & 28 & 150 & 7000 & 2.0 & $\mathrm{C}-\mathrm{W}$ & 127.00 & 1532 & 0.8 & 150 & 34.70 \\
\hline \multirow[t]{5}{*}{ Ritchie et al (1991) } & $\mathrm{C}$ & 200 & 414 & 99 & 102 & 8500 & 2.0 & G-P & 11.72 & 161 & 4.76 & 152 & 55.40 \\
\hline & $\mathrm{D}$ & 200 & 414 & 99 & 102 & 8500 & 2.0 & G-P & 11.72 & 161 & 4.76 & 151 & 59.60 \\
\hline & $\mathrm{G}$ & 200 & 414 & 99 & 102 & 8500 & 2.0 & G-P & 10.34 & 184 & 4.19 & 152 & 62.90 \\
\hline & I & 200 & 414 & 99 & 102 & 8500 & 2.0 & C/G-P & 27.58 & 319 & 4.06 & 150 & 50.60 \\
\hline & M & 200 & 414 & 99 & 102 & 8500 & 2.0 & C-P & 117.91 & 1489 & 1.27 & 152 & 72.10 \\
\hline \multirow[t]{5}{*}{ Ross et al. (1999) } & $1 \mathrm{~B}$ & 200 & 410 & 143 & 102 & 8500 & 2.0 & C-P & 138.00 & 2206 & 0.5 & 200 & 40.10 \\
\hline & $1 \mathrm{C}$ & 200 & 410 & 143 & 102 & 8500 & 2.0 & C-P & 138.00 & 2206 & 0.5 & 200 & 35.60 \\
\hline & $2 \mathrm{~B}$ & 200 & 410 & 143 & 102 & 8500 & 2.0 & C-P & 138.00 & 2206 & 0.5 & 200 & 49.00 \\
\hline & $2 \mathrm{C}$ & 200 & 410 & 143 & 102 & 8500 & 2.0 & C-P & 138.00 & 2206 & 0.5 & 200 & 35.60 \\
\hline & $2 \mathrm{D}$ & 200 & 410 & 143 & 102 & 8500 & 2.0 & C-P & 138.00 & 2206 & 0.5 & 200 & 40.10 \\
\hline
\end{tabular}

Table A. 4 (cont):Database of beams failed by end debonding. Pham et al. [40], Quantrill et al. (cited in [6]), Rahimi et al. [10], Ritchie et al. [41], Ross et al. [9]. 
Pag. 42

\begin{tabular}{|c|c|c|c|c|c|c|c|c|c|c|c|c|c|c|c|c|}
\hline & Beam & $\begin{array}{c}\mathrm{b} \\
{[\mathrm{mm}]}\end{array}$ & $\begin{array}{c}\mathrm{h} \\
{[\mathrm{mm}]} \\
\end{array}$ & $\begin{array}{c}\mathrm{d} \\
{[\mathrm{mm}]}\end{array}$ & $\begin{array}{c}\mathrm{d}^{\prime} \\
{[\mathrm{mm}]}\end{array}$ & $\begin{array}{c}\mathrm{a} \\
{[\mathrm{mm}]} \\
\end{array}$ & $\begin{array}{c}\mathrm{B} \\
{[\mathrm{mm}]} \\
\end{array}$ & $\begin{array}{c}\mathrm{L} \\
{[\mathrm{mm}]}\end{array}$ & $\begin{array}{c}\mathrm{f}_{\mathrm{c}}^{\prime} \\
{[\mathrm{MPa}]}\end{array}$ & $\begin{array}{c}\mathrm{E}_{\mathrm{s}} \\
{[\mathrm{GPa}]}\end{array}$ & $\begin{array}{c}\mathrm{f}_{\mathrm{ys}} \\
{[\mathrm{MPa}]}\end{array}$ & $\begin{array}{c}\mathrm{A}_{\mathrm{s}} \\
{\left[\mathrm{mm}^{2}\right]} \\
\end{array}$ & $\begin{array}{c}\text { Reo } \\
\text { [tension] }\end{array}$ & $\begin{array}{c}\mathrm{E}_{\mathrm{s}}^{\prime} \\
{[\mathrm{GPa}]}\end{array}$ & $\begin{array}{c}\mathrm{f}_{\mathrm{y}} \\
{[\mathrm{MPa}]}\end{array}$ & $\begin{array}{c}\mathrm{A}_{\mathrm{s}}^{\prime} \\
{\left[\mathrm{mm}^{2}\right]}\end{array}$ \\
\hline \multirow[t]{6}{*}{$\overline{~ R o s s ~ e t ~ a l . ~(1999) ~}$} & 3B & 200 & 200 & 152 & 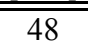 & 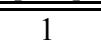 & 914 & 2742 & "54.8 & 200 & $4 \overline{410}$ & 396 & $2-15,9$ & 200 & $4 \overline{410}$ &  \\
\hline & 4B & 200 & 200 & 150.5 & 40 & 0 & 914 & - & 54.8 & 200 & 410 & 567 & -19 & 200 & 410 & 142 \\
\hline & $5 B$ & 200 & 200 & 149 & 40 & 0 & 914 & - & 54.8 & 200 & 410 & 774 & -22 & 200 & 410 & 142 \\
\hline & $6 \mathrm{~B}$ & 200 & 200 & 147 & 40 & 0 & 914 & - & 54.8 & 200 & 410 & 1019 & -26 & 200 & 410 & 142 \\
\hline & $3 \mathrm{C}$ & 200 & 200 & 152 & 48 & 1 & 914 & 2742 & 54.8 & 200 & 410 & 396 & $2-15,9$ & 200 & 410 & 143 \\
\hline & $3 \mathrm{D}$ & 200 & 200 & 152 & 48 & 1 & 914 & 2742 & 54.8 & 200 & 410 & 396 & $2-15,9$ & 200 & 410 & 143 \\
\hline Saadatmanesh et al. (1991) & B & 205 & 455 & 400 & 55 & 155 & 1983 & 4575 & 35.0 & 200 & 456 & 1013 & $2-25.4$ & 200 & 456 & 253 \\
\hline \multirow[t]{2}{*}{ Sharif et al. (1994) } & $\mathrm{P} 2$ & 150 & 150 & 114 & 36 & 75 & 393 & 1180 & 37.7 & 200 & 450 & 157 & $2-10$ & 200 & 450 & 57 \\
\hline & P3 & 150 & 150 & 114 & 36 & 75 & 393 & 1180 & 37.7 & 200 & 450 & 157 & $2-10$ & 200 & 450 & 57 \\
\hline \multirow[t]{2}{*}{ Spadea et al. (1998) } & A1.1 & 140 & 300 & 262 & 30 & 50 & 1800 & - & 24.9 & 200 & 435 & 402 & -16 & 200 & 435 & 402 \\
\hline & A 3.1 & 140 & 300 & 262 & 30 & 50 & 1800 & - & 24.9 & 200 & 435 & 402 & -16 & 200 & 435 & 402 \\
\hline \multirow[t]{7}{*}{ Tan et al. (1999) } & $\mathrm{A} 00$ & 100 & 150 & 124 & 21 & - & 600 & - & 28.6 & 200 & 500 & 157 & -10 & 200 & 500 & 57 \\
\hline & A 15 & 100 & 150 & 124 & 22 & - & 600 & - & 31.4 & 200 & 500 & 157 & -11 & 200 & 500 & 57 \\
\hline & A25 & 100 & 150 & 124 & 23 & - & 600 & - & 29.7 & 200 & 500 & 157 & -12 & 200 & 500 & 57 \\
\hline & $\mathrm{A} 40$ & 100 & 150 & 124 & 24 & - & 600 & - & 31.4 & 200 & 500 & 157 & -13 & 200 & 500 & 57 \\
\hline & A60 & 100 & 150 & 124 & 25 & - & 600 & - & 28.6 & 200 & 500 & 157 & -14 & 200 & 500 & 57 \\
\hline & A75 & 100 & 150 & 124 & 26 & - & 600 & - & 28.5 & 200 & 500 & 157 & -15 & 200 & 500 & 57 \\
\hline & A90 & 100 & 150 & 124 & 27 & - & 600 & - & 30.1 & 200 & 500 & 157 & -16 & 200 & 500 & 57 \\
\hline \multirow[t]{6}{*}{ Täljsten et al. (1997) } & $\begin{array}{l}\mathrm{SB} 1 \\
\end{array}$ & 200 & 300 & 252 & 48 & 150 & 1300 & 3600 & 51.2 & 200 & 527 & 402 & $2-16$ & 200 & 527 & 402 \\
\hline & SB2 & 200 & 300 & 252 & 48 & 200 & 1300 & 3600 & 52.0 & 200 & 527 & 402 & $2-16$ & 200 & 527 & 402 \\
\hline & SB3 & 200 & 300 & 252 & 48 & 300 & 1300 & 3600 & 52.0 & 200 & 527 & 402 & $2-16$ & 200 & 527 & 402 \\
\hline & MB1 & 200 & 300 & 252 & 48 & 150 & 1300 & 3600 & 56.0 & 200 & 527 & 402 & $2-16$ & 200 & 527 & 402 \\
\hline & HB1 & 200 & 300 & 252 & 48 & 150 & 1300 & 3600 & 56.0 & 200 & 527 & 402 & $2-16$ & 200 & 527 & 402 \\
\hline & FB1 & 200 & 300 & 252 & 48 & 150 & 1300 & 3600 & 51.2 & 200 & 527 & 402 & $2-16$ & 200 & 527 & 402 \\
\hline \multirow[t]{5}{*}{ Teng and Yao (2007) } & $\mathrm{CS}$ & 150.2 & 252.7 & 221.7 & 31 & 50 & 500 & 1500 & 25.5 & 199 & 536 & 157 & $2-10$ & 199 & 536 & 157 \\
\hline & CS-L3 & 151.1 & 253 & 222 & 31 & 50 & 500 & 1500 & 27.3 & 199 & 536 & 157 & $2-10$ & 199 & 536 & 157 \\
\hline & CS-W100 & 150.6 & 254 & 218.5 & 35.5 & 50 & 500 & 1500 & 31.4 & 199 & 536 & 157 & $2-10$ & 199 & 536 & 157 \\
\hline & $\mathrm{CP}$ & 151.1 & 252.8 & 222.8 & 30 & 50 & 500 & 1500 & 30.7 & 199 & 536 & 157 & $2-10$ & 199 & 536 & 157 \\
\hline & $\mathrm{CS}-\mathrm{C} 10$ & 151.1 & 252.7 & 240.7 & 12 & 50 & 500 & 1500 & 22.7 & 199 & 536 & 157 & $2-10$ & 199 & 536 & 157 \\
\hline \multirow[t]{3}{*}{ Triantafillou et al. (1992) } & 4 & 76 & 127 & 111 & 16 & 75 & 305 & 1220 & 44.7 & 200 & 517 & 33 & $2-4.6$ & - & - & - \\
\hline & 5 & 76 & 127 & 111 & 16 & 75 & 305 & 1220 & 44.7 & 200 & 517 & 33 & $2-4.6$ & - & - & - \\
\hline & 6 & 76 & 127 & 111 & 16 & 75 & 305 & 1220 & 44.7 & 200 & 517 & 33 & $2-4.6$ & - & - & - \\
\hline
\end{tabular}

Table A. 5: Database of beams failed by end debonding. Ross et al. [9], Saadamanesh et al. [42], Sharif et al. [43], Spadea et al. [44], Tan et al. (cited in [22]), Tälijsten et al. [45], Teng and Yao [23], Triantafillou et al. [16]. 


\begin{tabular}{|c|c|c|c|c|c|c|c|c|c|c|c|c|c|}
\hline & Beam & $\begin{array}{c}\mathrm{E}_{\mathrm{yv}} \\
{[\mathrm{GPa}]}\end{array}$ & $\begin{array}{c}\mathrm{f}_{\mathrm{yv}} \\
{[\mathrm{MPa}]}\end{array}$ & $\begin{array}{c}\mathrm{A}_{\mathrm{sv}} \\
{\left[\mathrm{mm}^{2}\right]}\end{array}$ & $\begin{array}{c}\mathrm{s} \\
{[\mathrm{mm}]}\end{array}$ & $\begin{array}{c}\mathrm{E}_{\mathrm{a}} \\
{[\mathrm{MPa}]}\end{array}$ & $\begin{array}{c}\mathrm{t}_{\mathrm{a}} \\
{[\mathrm{mm}]}\end{array}$ & $\begin{array}{c}\text { Type } \\
{[-]}\end{array}$ & $\begin{array}{c}\mathrm{E}_{\mathrm{frp}} \\
{[\mathrm{GPa}]}\end{array}$ & $\begin{array}{c}\mathrm{f}_{\text {frp }} \\
{[\mathrm{MPa}]}\end{array}$ & $\begin{array}{c}\mathrm{t}_{\mathrm{frp}} \\
{[\mathrm{mm}]}\end{array}$ & $\begin{array}{c}\mathrm{b}_{\mathrm{frp}} \\
{[\mathrm{mm}]}\end{array}$ & $\begin{array}{l}\mathrm{V}_{\text {exp }} \\
{[\mathrm{kN}]}\end{array}$ \\
\hline \multirow[t]{6}{*}{ Ross et al. (1999) } & 3B & 200 & 4410 & 143 & 102 & 8500 & 2.0 & $\overline{~ C-P}$ & 138.00 & 2206 & 0.5 & 200 & 254.50 \\
\hline & $4 \mathrm{~B}$ & 200 & 410 & 142 & 102 & - & - & C-W & 138.00 & 2206 & 0.5 & 200 & 53.80 \\
\hline & $5 B$ & 200 & 410 & 142 & 102 & - & - & $\mathrm{C}-\mathrm{W}$ & 138.00 & 2206 & 0.5 & 200 & 73.40 \\
\hline & $6 \mathrm{~B}$ & 200 & 410 & 142 & 102 & - & - & C-W & 138.00 & 2206 & 0.5 & 200 & 84.50 \\
\hline & $3 \mathrm{C}$ & 200 & 410 & 143 & 102 & 8500 & 2.0 & C-P & 138.00 & 2206 & 0.5 & 200 & 54.10 \\
\hline & $3 \mathrm{D}$ & 200 & 410 & 143 & 102 & 8500 & 2.0 & C-P & 138.00 & 2206 & 0.5 & 200 & 54.30 \\
\hline Saadatmanesh et al. (1991) & $\mathrm{B}$ & 200 & 456 & 253 & 150 & 8500 & 1.5 & G-P & 37.23 & 400 & 6.0 & 152 & 125.00 \\
\hline \multirow[t]{2}{*}{ Sharif et al. (1994) } & $\mathrm{P} 2$ & 200 & 450 & 28 & 60 & - & 1.0 & G-W & 14.90 & 170 & 2 & 100 & 34.00 \\
\hline & P3 & 200 & 450 & 28 & 60 & - & 1.0 & $\mathrm{G}-\mathrm{W}$ & 14.90 & 170 & 3 & 100 & 33.00 \\
\hline \multirow[t]{2}{*}{ Spadea et al. (1998) } & A1.1 & 200 & 435 & 57 & 150 & - & - & $\mathrm{C}-\mathrm{W}$ & 152.00 & 2400 & 1.2 & 80 & 43.40 \\
\hline & A3.1 & 200 & 435 & 25 & 150 & - & - & $\mathrm{C}-\mathrm{W}$ & 152.00 & 2400 & 1.2 & 80 & 37.40 \\
\hline \multirow[t]{7}{*}{ Tan et al. (1999) } & A00 & 200 & 500 & 57 & 75 & - & - & $\mathrm{C}-\mathrm{W}$ & 230.00 & 3400 & 0.2 & 100 & 27.50 \\
\hline & A15 & 200 & 500 & 57 & 75 & - & - & C-W & 230.00 & 3400 & 0.2 & 100 & 24.70 \\
\hline & A 25 & 200 & 500 & 57 & 75 & - & - & $\mathrm{C}-\mathrm{W}$ & 230.00 & 3400 & 0.2 & 100 & 24.30 \\
\hline & $\mathrm{A} 40$ & 200 & 500 & 57 & 75 & - & - & C-W & 230.00 & 3400 & 0.2 & 100 & 24.70 \\
\hline & A60 & 200 & 500 & 57 & 75 & - & - & C-W & 230.00 & 3400 & 0.2 & 100 & 26.00 \\
\hline & A75 & 200 & 500 & 57 & 75 & - & - & C-W & 230.00 & 3400 & 0.2 & 100 & 21.90 \\
\hline & A90 & 200 & 500 & 57 & 75 & - & - & $\mathrm{C}-\mathrm{W}$ & 230.00 & 3400 & 0.2 & 100 & 19.80 \\
\hline \multirow{6}{*}{ Täljsten et al. (1997) } & SB1 & 200 & 527 & 157 & 75 & 8500 & 2.1 & C-P & 155.00 & 2400 & 1.4 & 120 & 71.40 \\
\hline & SB2 & 200 & 527 & 157 & 75 & 8500 & 2.4 & C-P & 155.00 & 2400 & 1.4 & 120 & 75.50 \\
\hline & SB3 & 200 & 527 & 157 & 75 & 8500 & 3.0 & C-P & 155.00 & 2400 & 1.4 & 120 & 73.90 \\
\hline & MB1 & 200 & 527 & 157 & 75 & 8500 & 2.4 & C-P & 210.00 & 2000 & 1.4 & 120 & 79.60 \\
\hline & HB1 & 200 & 527 & 157 & 75 & 8500 & 2.1 & C-P & 300.00 & 1400 & 1.4 & 100 & 80.10 \\
\hline & FB1 & 200 & 527 & 157 & 75 & 8500 & 0.4 & $\mathrm{C}-\mathrm{W}$ & 95.00 & 1800 & 2.4 & 150 & 74.40 \\
\hline \multirow[t]{5}{*}{ Teng and Yao (2007) } & $\mathrm{CS}$ & 199 & 536 & 157 & 100 & - & 2.0 & $\mathrm{C}-\mathrm{W}$ & 256.00 & 4114 & 1.74 & 148 & 81.50 \\
\hline & CS-L3 & 199 & 536 & 157 & 100 & - & 2.0 & $\mathrm{C}-\mathrm{W}$ & 256.00 & 4114 & 2.63 & 148 & 78.50 \\
\hline & CS-W100 & 199 & 536 & 157 & 100 & - & 2.0 & $\mathrm{C}-\mathrm{W}$ & 256.00 & 4114 & 1.95 & 100 & 80.80 \\
\hline & $\mathrm{CP}$ & 199 & 536 & 157 & 100 & - & 2.0 & C-P & 165.00 & 2800 & 1.2 & 148 & 76.00 \\
\hline & $\mathrm{CS}-\mathrm{C} 10$ & 199 & 536 & 157 & 100 & - & 2.0 & $\mathrm{C}-\mathrm{W}$ & 256.00 & 4114 & 1.86 & 148 & 99.40 \\
\hline \multirow[t]{3}{*}{ Triantafillou et al. (1992) } & 4 & 200 & 517 & 17 & 40 & - & - & $\mathrm{C}-\mathrm{W}$ & 186.00 & 1450 & 0.7 & 63 & 14.78 \\
\hline & 5 & 200 & 517 & 17 & 40 & - & - & C-W & 186.00 & 1450 & 0.7 & 63 & 15.25 \\
\hline & 6 & 200 & 517 & 17 & 40 & - & - & C-W & 186.00 & 1450 & 0.9 & 63 & 13.95 \\
\hline
\end{tabular}

Table A. 5 (cont): Database of beams failed by end debonding. Ross et al. [9], Saadamanesh et al. [42], Sharif et al. [43], Spadea et al. [44], Tan et al. (cited in [22]), Tälijsten et al. [45], Teng and Yao [23], Triantafillou et al. [16]. 
Pag. 44

\begin{tabular}{|c|c|c|c|c|c|c|c|c|c|c|c|c|c|c|c|c|}
\hline & Beam & $\begin{array}{c}\mathrm{b} \\
{[\mathrm{mm}]}\end{array}$ & $\begin{array}{c}\mathrm{h} \\
{[\mathrm{mm}]}\end{array}$ & $\begin{array}{c}\mathrm{d} \\
{[\mathrm{mm}]}\end{array}$ & $\begin{array}{c}\mathrm{d}^{\prime} \\
{[\mathrm{mm}]}\end{array}$ & $\begin{array}{c}\mathrm{a} \\
{[\mathrm{mm}]}\end{array}$ & $\begin{array}{c}\text { B } \\
{[\mathrm{mm}]}\end{array}$ & $\begin{array}{c}\mathrm{L} \\
{[\mathrm{mm}]}\end{array}$ & $\begin{array}{c}\mathrm{f}_{\mathrm{c}}^{\prime} \\
{[\mathrm{MPa}]}\end{array}$ & $\begin{array}{c}\mathrm{E}_{\mathrm{s}} \\
{[\mathrm{GPa}]}\end{array}$ & $\begin{array}{c}\mathrm{f}_{\mathrm{ys}} \\
{[\mathrm{MPa}]}\end{array}$ & $\begin{array}{c}\mathrm{A}_{\mathrm{s}} \\
{\left[\mathrm{mm}^{2}\right]}\end{array}$ & $\begin{array}{c}\text { Reo } \\
\text { [tension] }\end{array}$ & $\begin{array}{c}\mathrm{E}_{\mathrm{s}}^{\prime} \\
{[\mathrm{GPa}]}\end{array}$ & $\begin{array}{c}\mathrm{f}_{\mathrm{y}} \\
{[\mathrm{MPa}]}\end{array}$ & $\begin{array}{c}\mathrm{A}_{\mathrm{s}}^{\prime} \\
{\left[\mathrm{mm}^{2}\right]}\end{array}$ \\
\hline \multirow[t]{2}{*}{$\begin{array}{l}\text { Triantafillou et al. (1992) } \\
\end{array}$} & 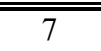 & 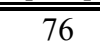 & 127 & 111 & 16 & 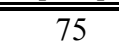 & 305 & 1220 & 444.7 & 200 & 517 & 33 & $2-4.6$ & 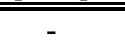 & - & - \\
\hline & 8 & 76 & 127 & 111 & 16 & 75 & 305 & 1220 & 44.7 & 200 & 517 & 33 & $2-4.6$ & - & - & - \\
\hline \multirow[t]{4}{*}{ Tumialan et al. (1999) } & A3 & 150 & 300 & 250 & - & - & 1065 & 2130 & 51.7 & 207 & 427 & 792 & $4-15.9$ & - & - & - \\
\hline & $\mathrm{A} 8$ & 150 & 300 & 250 & - & - & 1065 & 2130 & 51.7 & 207 & 427 & 792 & $4-15.9$ & - & - & - \\
\hline & $\mathrm{C} 2$ & 150 & 300 & 250 & - & - & 1065 & 2130 & 51.7 & 207 & 427 & 792 & $4-15.9$ & - & - & - \\
\hline & \multicolumn{2}{|c|}{$\overline{\text { Beam }}$} & $\begin{array}{c}\mathrm{E}_{\mathrm{yv}} \\
{[\mathrm{GPa}]}\end{array}$ & $\begin{array}{c}\mathrm{f}_{\mathrm{yv}} \\
{[\mathrm{MPa}]}\end{array}$ & $\begin{array}{c}\mathrm{A}_{\mathrm{sv}} \\
{\left[\mathrm{mm}^{2}\right]}\end{array}$ & $\begin{array}{c}\mathrm{s} \\
{[\mathrm{mm}]}\end{array}$ & $\begin{array}{c}\mathrm{E}_{\mathrm{a}} \\
{[\mathrm{MPa}]}\end{array}$ & $\begin{array}{c}\mathrm{t}_{\mathrm{a}} \\
{[\mathrm{mm}]}\end{array}$ & $\begin{array}{c}\text { Type } \\
{[-]} \\
\end{array}$ & & & $\begin{array}{c}\mathrm{f}_{\text {frp }} \\
{[\mathrm{MPa}]}\end{array}$ & $\begin{array}{c}\mathrm{t}_{\mathrm{frp}} \\
{[\mathrm{mm}]}\end{array}$ & $\begin{array}{c}\mathrm{b}_{\mathrm{frp}} \\
{[\mathrm{mm}]}\end{array}$ & & $\begin{array}{l}\mathrm{V}_{\text {exp }} \\
{[\mathrm{kN}]}\end{array}$ \\
\hline \multirow[t]{2}{*}{$\begin{array}{l}\text { Triantafillou et al. (1992) } \\
\end{array}$} & \multicolumn{2}{|c|}{$\overline{\overline{7}}$} & 200 & 517 & 17 & 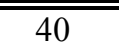 & - & - & C-W & & .00 & 1450 & 0.9 & 63 & & 12.80 \\
\hline & \multicolumn{2}{|c|}{8} & 200 & 517 & 17 & 40 & - & - & $\mathrm{C}-\mathrm{W}$ & & .00 & 1450 & 1.9 & 64 & & 18.67 \\
\hline \multirow[t]{3}{*}{ Tumialan et al. (1999) } & \multicolumn{2}{|c|}{ A3 } & 207 & 427 & 143 & 125 & 2000 & - & $\mathrm{C}-\mathrm{W}$ & & .00 & 3400 & 0.495 & 150 & & 86.10 \\
\hline & \multicolumn{2}{|c|}{ A8 } & 207 & 427 & 143 & 125 & 2000 & - & $\mathrm{C}-\mathrm{W}$ & & .00 & 3400 & 0.99 & 75 & & 98.20 \\
\hline & \multicolumn{2}{|c|}{$\mathrm{C} 2$} & 207 & 427 & 143 & 250 & 2000 & - & $\mathrm{C}-\mathrm{W}$ & & .00 & 3400 & 0.495 & 150 & & 79.30 \\
\hline
\end{tabular}

Table A. 6: Database of beams failed by end debonding. Triantafillou et al. [16], Tumialan et al. (cited in [6]). 


\section{Appendix B: Database of beams failed by intermediate crack induced debonding}

\begin{tabular}{|c|c|c|c|c|c|c|c|c|c|c|c|c|c|c|c|c|c|c|c|c|c|c|c|}
\hline & & $\begin{array}{c}\mathrm{b} \\
{[\mathrm{mm}]}\end{array}$ & $\begin{array}{c}\mathrm{h} \\
{[\mathrm{mm}]} \\
\end{array}$ & $\begin{array}{c}\mathrm{a} \\
{[\mathrm{mm}]} \\
\end{array}$ & $\begin{array}{c}\mathrm{B} \\
{[\mathrm{mm}]} \\
\end{array}$ & $\begin{array}{c}\mathrm{L} \\
{[\mathrm{mm}]} \\
\end{array}$ & $\begin{array}{c}\mathrm{d} \\
{[\mathrm{mm}]} \\
\end{array}$ & $\begin{array}{c}\mathrm{d}^{\prime} \\
{[\mathrm{mm}]} \\
\end{array}$ & $\begin{array}{c}\mathrm{f}_{\mathrm{c}}^{\prime} \\
{[\mathrm{MPa}]}\end{array}$ & $\begin{array}{c}\mathrm{E}_{\mathrm{s}} \\
{[\mathrm{GPa}]}\end{array}$ & $\begin{array}{c}\mathrm{f}_{\mathrm{ys}} \\
{[\mathrm{MPa}]}\end{array}$ & $\begin{array}{c}\mathrm{A}_{\mathrm{s}} \\
{\left[\mathrm{mm}^{2}\right]} \\
\end{array}$ & $\begin{array}{c}\mathrm{E}_{\mathrm{s}}^{\prime} \\
{[\mathrm{GPa}]} \\
\end{array}$ & $\begin{array}{c}\mathrm{f}_{\mathrm{y}}^{\prime} \\
{[\mathrm{MPa}]}\end{array}$ & $\begin{array}{c}\mathrm{A}_{\mathrm{s}}^{\prime} \\
{\left[\mathrm{mm}^{2}\right]}\end{array}$ & $\begin{array}{c}\mathrm{t}_{\mathrm{a}} \\
{[\mathrm{mm}]} \\
\end{array}$ & $\begin{array}{c}\text { Type } \\
{[-]} \\
\end{array}$ & $\begin{array}{c}\mathrm{E}_{\mathrm{fip}} \\
{[\mathrm{GPa}]}\end{array}$ & $\begin{array}{c}\mathrm{f}_{\text {fip }} \\
{[\mathrm{MPa}]}\end{array}$ & $\begin{array}{c}\mathrm{t}_{\mathrm{frp}} \\
{[\mathrm{mm}]}\end{array}$ & $\begin{array}{c}\mathrm{b}_{\mathrm{fip}} \\
{[\mathrm{mm}]}\end{array}$ & $\begin{array}{r}\mathrm{V}_{\text {exp }} \\
{[\mathrm{kN}]} \\
\end{array}$ & $\begin{array}{c}\text { type } \\
\text { of test } \\
\end{array}$ \\
\hline Bonacci (2000) & $\overline{\mathrm{B} 2}$ & 270 & 400 & 101 & 1300 & 3650 & 341 & 54 & 22.6 & 201 & 484 & 900 & 199 & $\overline{507}$ & $\overline{142}$ & & C-W & $\overline{230.00}$ & 343400 & 0.165 & 250 & 148 & $\overline{\text { f.p.b.t }}$ \\
\hline \multirow{10}{*}{ Garden et al. (1998) } & $\mathrm{C} 4 \mathrm{u}, 1.0$ & 100 & 100 & 632 & 587 & 587 & 84 & 16 & 51.2 & 215 & 350 & 85 & 215 & 350 & 57 & 2.0 & C-P & 111.00 & 1414 & 0.82 & 67 & 15.43 & t.p.b. \\
\hline & $\mathrm{C} 5 \mathrm{u}, 1.0$ & 100 & 100 & 817 & 772 & 772 & 84 & 16 & 51.2 & 215 & 350 & 85 & 215 & 350 & 57 & 2.0 & C-P & 111.00 & 1414 & 0.82 & 67 & 11.33 & t.p.b.t. \\
\hline & A1 & 150 & 300 & 0 & 1065 & 2130 & 250 & - & 51.7 & 207 & 427 & 792 & 207 & - & - & & $\mathrm{C}-\mathrm{W}$ & 230.00 & 3400 & 0.165 & 150 & 72.8 & t.p.b.t. \\
\hline & A2 & 150 & 300 & 0 & 1065 & 2130 & 250 & - & 51.7 & 207 & 427 & 792 & 207 & - & - & & $\mathrm{C}-\mathrm{W}$ & 230.00 & 3400 & 0.33 & 150 & 84.9 & t.p.b.t. \\
\hline & A7 & 150 & 300 & 0 & 1065 & 2130 & 250 & - & 51.7 & 207 & 427 & 792 & 207 & - & - & & $\mathrm{C}-\mathrm{W}$ & 230.00 & 3400 & 0.33 & 75 & 86.1 & t.p.b.t. \\
\hline & $\mathrm{C} 1$ & 150 & 300 & 0 & 1065 & 2130 & 250 & - & 51.7 & 207 & 427 & 792 & 207 & - & - & & $\mathrm{C}-\mathrm{W}$ & 230.00 & 3400 & 0.165 & 150 & 77.2 & t.p.b.t. \\
\hline & B3u, 1.0 & 100 & 100 & 20 & 340 & 900 & 84 & 16 & 43.2 & 215 & 350 & 85 & 215 & 350 & 57 & 2.0 & C-P & 111.00 & 1414 & 0.82 & 67 & 17 & f.p.b.t. \\
\hline & $\mathrm{B} 4 \mathrm{u}$, & 100 & 100 & 20 & 400 & 900 & 84 & 16 & 43.2 & 215 & 350 & 85 & 215 & 350 & 57 & 2.0 & C-P & 111.00 & 1414 & 0.82 & 67 & 17.25 & f.p.b.t. \\
\hline & $\mathrm{B} 5 \mathrm{u}$, & 100 & 100 & 20 & 400 & 900 & 84 & 16 & 43.2 & 215 & 350 & 85 & 215 & 350 & 57 & 2.0 & C-P & 111.00 & 1414 & 0.82 & 67 & 17.3 & f.p.b.t. \\
\hline & B1u, 4.5 & 145 & 230 & 40 & 1525 & 4400 & 205 & 25 & 37.6 & 220 & 556 & 226 & 220 & 556 & 101 & 2.0 & C-P & 115.00 & 1284 & 1.28 & 90 & 30 & f.p.b.t. \\
\hline \multirow[t]{6}{*}{$\overline{R a h i m i ~ e t ~ a l . ~(2001) ~}$} & B3 & 200 & 150 & 85 & 750 & 2100 & 120 & 30 & 49.2 & 210 & 460 & 157 & 210 & 460 & 157 & 2.0 & C-P & 127.00 & 1532 & 0.4 & 150 & 27.6 & f.p.b.t. \\
\hline & B4 & 200 & 150 & 85 & 750 & 2100 & 120 & 30 & 49.2 & 210 & 460 & 157 & 210 & 460 & 157 & 2.0 & C-P & 127.00 & 1532 & 0.4 & 150 & 26.3 & f.p.b \\
\hline & B5 & 200 & 150 & 85 & 750 & 2100 & 120 & 30 & 49.2 & 210 & 460 & 157 & 210 & 460 & 157 & 2.0 & C-P & 127.00 & 1532 & 1.2 & 150 & 34.9 & f.p.b.t. \\
\hline & B6 & 200 & 150 & 85 & 750 & 2100 & 120 & 30 & 49.2 & 210 & 460 & 157 & 210 & 460 & 157 & 2.0 & C-P & 127.00 & 1532 & 1.2 & 150 & 34.8 & f.p.b.t. \\
\hline & B7 & 200 & 150 & 85 & 750 & 2100 & 120 & 30 & 49.2 & 210 & 460 & 157 & 210 & 460 & 157 & 2.0 & G-P & 36.00 & 1074 & 1.8 & 150 & 29.6 & f.p.b.t. \\
\hline & B8 & 200 & 150 & 85 & 750 & 2100 & 120 & 30 & 49.2 & 210 & 460 & 157 & 210 & 460 & 157 & 2.0 & G-P & 36.00 & 1074 & 1.8 & 150 & 30.8 & f.p.b.t. \\
\hline Saadatmanesh (1991) & E & 205 & 455 & 155 & 1983 & 4575 & 400 & 55 & 35.0 & 200 & & & 200 & 456 & 253 & 1.5 & G-P & 37.23 & 400 & 6 & 152 & 32.5 & f.p.b.t. \\
\hline \multirow[t]{5}{*}{ Triantafillou (1992) } & 4 & 76 & 127 & 75 & 458 & 1220 & 111 & - & 44.7 & 200 & 517 & 33 & 200 & - & - & 2.0 & C-P & 186.00 & 1450 & 0.65 & 63.2 & 14.8 & f.p.b.t. \\
\hline & 5 & 76 & 127 & 75 & 458 & 1220 & 111 & - & 44.7 & 200 & 517 & 33 & 200 & - & - & 2.0 & C-P & 186.00 & 1450 & 0.65 & 63.2 & 15.3 & f.p.b.t. \\
\hline & 6 & 76 & 127 & 75 & 458 & 1220 & 111 & - & 44.7 & 200 & 517 & 33 & 200 & - & - & 2.0 & C-P & 186.00 & 1450 & 0.9 & 63.3 & 14 & f.p.b. \\
\hline & 7 & 76 & 127 & 75 & 458 & 1220 & 111 & - & 44.7 & 200 & 517 & 33 & 200 & - & - & 2.0 & C-P & 186.00 & 1450 & 0.9 & 63.3 & 12.8 & f.p.b.t. \\
\hline & 8 & 76 & 127 & 75 & 458 & 1220 & 111 & - & 44.7 & 200 & 517 & 33 & 200 & - & - & 2.0 & C-P & 186.00 & 1450 & 1.9 & 63.9 & 18.7 & f.p.b.t. \\
\hline \multirow[t]{6}{*}{ Yao et al. (2002) } & CP1 & 301.5 & 150.5 & 100 & 1000 & 1100 & 117.4 & - & 27.0 & 208 & 343 & 314 & 208 & 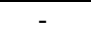 & - & 1.0 & C-P & 165.00 & 2800 & 1.2 & 50 & 19.95 & c.b.t. \\
\hline & CP2 & 303.6 & 151.9 & 100 & 1000 & 1100 & 111.3 & - & 37.7 & 208 & 343 & 314 & 208 & - & - & 1.0 & C-P & 165.00 & 2800 & 1.2 & 50 & 17.58 & c.b.t. \\
\hline & CP3 & 302.7 & 150 & 100 & 1000 & 1100 & 108.2 & - & 12.6 & 208 & 343 & 157 & 208 & - & 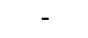 & 1.0 & C-P & 165.00 & 2800 & 1.2 & 50 & 13.31 & c.b.t. \\
\hline & CP5 & 304 & 149 & 100 & 1000 & 1100 & 117.4 & - & 25.6 & 210 & 355 & 157 & 210 & - & - & 1.0 & C-P & 165.00 & 2800 & 1.2 & 50 & 10 & c.b.t. \\
\hline & CS1 & 303 & 150.8 & 100 & 1000 & 1100 & 115.3 & - & 21.4 & 208 & 343 & 157 & 208 & - & - & 0.5 & C-W & 271.00 & 3720 & 0.165 & 50 & 8.51 & c.b.t. \\
\hline & GS1 & 302 & 151.2 & 100 & 1000 & 1100 & 117.9 & . & 22.6 & 208 & 343 & 157 & 208 & - & - & 0.3 & G-W & 20.50 & 269 & 1.27 & 89.7 & 10 & c.b.t. \\
\hline
\end{tabular}

Table B. 1: Database of beams failed by intermediate crack induced debonding. Type of test: f.p.b.t. $=$ four point bending test; c.b.t.=cantilever beam test; $3 . p . b . t=$ three point

bending test. Bonacci [46], Garden et al. [36], Rahimi et al. [10], Saadatmesh [42], Triantafillou [16], Yao et al. [47]. 


\begin{tabular}{|c|c|c|c|c|c|c|c|c|c|c|c|c|c|c|c|c|c|c|c|c|c|c|}
\hline & & $\mathrm{b}$ & $\mathrm{h}$ & $\mathrm{a}$ & B & $\mathrm{L}$ & $\mathrm{d}$ & $\mathrm{d}^{\prime}$ & $f_{c}^{\prime}$ & $\mathrm{E}_{\mathrm{s}}$ & $\mathrm{f}_{\mathrm{ys}}$ & $\mathrm{A}_{\mathrm{s}}$ & $\mathrm{E}_{\mathrm{s}}^{\prime}$ & $\mathrm{f}_{\mathrm{y}}$ & $\overline{\mathrm{A}_{\mathrm{s}}^{\prime}}$ & Type & $\mathrm{E}_{\text {frp }}$ & $f_{\text {frp }}$ & $t_{\text {frp }}$ & $\mathrm{b}_{\text {frp }}$ & $\mathrm{V}_{\text {exp }}$ & type \\
\hline & & {$[\mathrm{mm}]$} & {$[\mathrm{mm}]$} & {$[\mathrm{mm}]$} & {$[\mathrm{mm}]$} & {$[\mathrm{mm}]$} & {$[\mathrm{mm}]$} & {$[\mathrm{mm}]$} & {$[\mathrm{MPa}]$} & {$[\mathrm{GPa}]$} & {$[\mathrm{MPa}]$} & {$\left[\mathrm{mm}^{2}\right]$} & {$[\mathrm{GPa}]$} & {$[\mathrm{MPa}]$} & {$\left[\mathrm{mm}^{2}\right]$} & {$[-]$} & {$[\mathrm{GPa}]$} & {$[\mathrm{MPa}]$} & {$[\mathrm{mm}]$} & {$[\mathrm{mm}]$} & {$[\mathrm{kN}]$} & of test \\
\hline \multirow[t]{6}{*}{ Beber et al. (1999) } & VR5 & 120 & 250 & 75 & 783 & 2349 & 214 & 34 & 33.6 & 200 & 565 & 157 & 200 & 565 & 57 & C- & 230.0 & 3400 & 0.44 & 120 & 51.1 & f.p.b.t. \\
\hline & VR6 & 120 & 250 & 75 & 783 & 2349 & 214 & 34 & 33.6 & 200 & 565 & 157 & 200 & 565 & 57 & C- & 230.0 & 3400 & 0.44 & 120 & 50.3 & f.p.b.t. \\
\hline & VR7 & 120 & 250 & 75 & 783 & 2349 & 214 & 34 & 33.6 & 200 & 565 & 157 & 200 & 565 & 57 & C- & 230.0 & 3400 & 0.77 & 120 & 62.1 & f.p.b.t. \\
\hline & VR8 & 120 & 250 & 75 & 783 & 2349 & 214 & 34 & 33.6 & 200 & 565 & 157 & 200 & 565 & 57 & $\mathrm{C}-$ & 230.0 & 3400 & 0.77 & 120 & 62 & f.p.b.t. \\
\hline & VR9 & 120 & 250 & 75 & 783 & 2349 & 214 & 34 & 33.6 & 200 & 565 & 157 & 200 & 565 & 57 & C- & 230.0 & 3400 & 1.1 & 120 & 64.8 & f.p.b.t. \\
\hline & VR10 & 120 & 250 & 75 & 783 & 2349 & 214 & 34 & 33.6 & 200 & 565 & 157 & 200 & 565 & 57 & $\mathrm{C}-$ & 230.0 & 3400 & 1.1 & 120 & 68.5 & f.p.b.t. \\
\hline \multirow[t]{8}{*}{ Benjamin (2005) } & L1 & 152 & 254 & - & 2269 & 4537 & 229 & 25 & 23.3 & 200 & 429 & 398 & 200 & 429 & 157 & C- & 155.1 & 2792 & 1.4 & 25 & 39.9 & 3.p.b.t. \\
\hline & $\mathrm{H} 1$ & 152 & 254 & - & 2269 & 4537 & 229 & 25 & 23.3 & 200 & 429 & 398 & 200 & 429 & 157 & C- & 155.1 & 2792 & 1.4 & 25 & 37.7 & 3.p.b.t. \\
\hline & L2 & 152 & 254 & - & 2269 & 4537 & 229 & 25 & 23.3 & 200 & 429 & 398 & 200 & 429 & 157 & C- & 155.1 & 2792 & 1.4 & 51 & 44.3 & 3.p.b.t. \\
\hline & L2x1 & 152 & 254 & - & 2269 & 4537 & 229 & 25 & 23.3 & 200 & 429 & 398 & 200 & 429 & 157 & C- & 155.1 & 2792 & 1.4 & 51 & 45.5 & 3.p.b.t. \\
\hline & $\mathrm{H} 2$ & 152 & 254 & - & 2269 & 4537 & 229 & 25 & 23.3 & 200 & 429 & 398 & 200 & 429 & 157 & C- & 155.1 & 2792 & 1.4 & 51 & 43.5 & 3.p.b.t. \\
\hline & $\mathrm{H} 2 \mathrm{x} 1$ & 152 & 254 & - & 2269 & 4537 & 229 & 25 & 23.3 & 200 & 429 & 398 & 200 & 429 & 157 & C- & 155.1 & 2792 & 1.4 & 51 & 45.1 & 3.p.b.t. \\
\hline & L4 & 152 & 254 & - & 2269 & 4537 & 229 & 25 & 23.3 & 200 & 429 & 398 & 200 & 429 & 157 & C- & 155.1 & 2792 & 1.4 & 102 & 51.8 & 3.p.b.t. \\
\hline & $\mathrm{H} 4$ & 152 & 254 & - & 2269 & 4537 & 229 & 25 & 23.3 & 200 & 429 & 398 & 200 & 429 & 157 & C- & 155.1 & 2792 & 1.4 & 102 & 49.2 & 3.p.b.t. \\
\hline Bonacci \& Maalej (2000) & B2 & 270 & 400 & 101 & 1300 & 3650 & 350.2 & 44.8 & 22.6 & 201 & 485 & 900 & 201 & 485 & 143 & C- & 230.0 & 3400 & 0.3 & 250 & 148 & f.p.b.t. \\
\hline \multirow[t]{4}{*}{ Chan et al. (2001) } & B2 & 250 & 470 & 50 & 1600 & 4600 & 430 & 40 & 42.4 & 200 & 505 & 628 & 200 & 505 & 402 & C- & 181.0 & 3180 & 1.2 & 150 & 142.5 & f.p.b.t. \\
\hline & B3 & 250 & 470 & 50 & 1600 & 4600 & 430 & 40 & 42.4 & 200 & 505 & 943 & 200 & 505 & 402 & C- & 181.0 & 3180 & 1.2 & 150 & 176 & f.p.b.t. \\
\hline & B6 & 250 & 470 & 50 & 1600 & 4600 & 430 & 40 & 42.4 & 200 & 505 & 628 & 200 & 505 & 402 & C- & 181.0 & 3180 & 1.2 & 150 & 129 & f.p.b.t. \\
\hline & B8 & 250 & 470 & 50 & 1600 & 4600 & 430 & 40 & 42.4 & 200 & 505 & 1257 & 200 & 505 & 402 & $\mathrm{C}-$ & 181.0 & 3180 & 1.2 & 150 & 220 & f.p.b.t. \\
\hline \multirow[t]{3}{*}{ Chan and $\mathrm{Li}(2000)$} & S6-50-0 & 330 & 100 & - & 850 & 2500 & 76 & - & 53.4 & 200 & 677 & 113 & 200 & - & - & C- & 165.0 & 2940.0 & 1.2 & 50 & 14.9 & f.p.b.t. \\
\hline & S8-50-0 & 330 & 100 & - & 850 & 2500 & 76 & - & 53.4 & 200 & 653 & 201 & 200 & - & - & C- & 165.0 & 2940.0 & 1.2 & 50 & 17.9 & f.p.b.t. \\
\hline & S8-50-0F & 330 & 100 & - & 850 & 2500 & 76 & - & 53.4 & 200 & 653 & 201 & 200 & - & - & C- & 165.0 & 2940.0 & 1.2 & 50 & 16.45 & f.p.b.t. \\
\hline \multirow[t]{4}{*}{ Delaney (2006) } & R_UC_C1 & 150 & 200 & 50 & 820 & 1800 & 160 & 40 & 49.1 & 190 & 477 & 266 & 190 & 477 & 266 & C- & 50.5 & 817 & 1.4 & 150 & 44.4 & f.p.b.t. \\
\hline & R_UC_C2 & 150 & 200 & 50 & 820 & 1800 & 160 & 40 & 50.1 & 190 & 477 & 266 & 190 & 477 & 266 & C- & 50.5 & 817 & 1.4 & 150 & 49.5 & f.p.b.t. \\
\hline & R_UC_C3 & 150 & 200 & 50 & 820 & 1800 & 160 & 40 & 50.2 & 190 & 477 & 266 & 190 & 477 & 266 & C- & 50.5 & 817 & 1.4 & 150 & 45.3 & f.p.b.t. \\
\hline & R_UC_C4 & 150 & 200 & 50 & 820 & 1800 & 160 & 40 & 50.4 & 190 & 477 & 266 & 190 & 477 & 266 & C- & 50.5 & 817 & 1.4 & 150 & 48.5 & f.p.b.t. \\
\hline Esfahani et al. (2006) & 11-20D-1L: & 150 & 200 & - & 600 & 1600 & 162 & 25 & 24.1 & 200 & 350 & 628 & 200 & 365 & 157 & $\mathrm{C}-\mathrm{W}$ & 237.0 & 2845 & 0.176 & 150 & 54.455 & f.p.b.t. \\
\hline \multirow[t]{3}{*}{ Gao et al. (2004) } & A0 & 150 & 200 & 150 & 500 & 1500 & 162 & 27 & 35.7 & 200 & 531 & 157 & 200 & 531 & 101 & C- & 235.0 & 4200 & 0.2 & 75 & 40.35 & f.p.b.t. \\
\hline & $\mathrm{A} 10$ & 150 & 200 & 150 & 500 & 1500 & 162 & 27 & 35.7 & 200 & 531 & 157 & 200 & 531 & 101 & C- & 235.0 & 4200 & 0.2 & 75 & 39.35 & f.p.b.t. \\
\hline & $\mathrm{A} 20$ & 150 & 200 & 150 & 500 & 1500 & 162 & 27 & 35.7 & 200 & 531 & 157 & 200 & 531 & 101 & C- & 235.0 & 4200 & 0.2 & 75 & 43.95 & f.p.b.t. \\
\hline \multirow[t]{4}{*}{ Kishi et al. (1998) } & A200-1 & 150 & 250 & 50 & 1050 & 2600 & 210 & 40 & 24.8 & 206 & 378 & 402 & 206 & 378 & 402 & A- & 126.5 & 2480 & 0.1 & 130 & 37 & f.p.b.t. \\
\hline & A200-2 & 150 & 250 & 50 & 1050 & 2600 & 210 & 40 & 24.8 & 206 & 378 & 402 & 206 & 378 & 402 & A- & 126.5 & 2480 & 0.1 & 130 & 38 & f.p.b.t. \\
\hline & A415-1 & 150 & 250 & 50 & 1050 & 2600 & 210 & 40 & 24.8 & 206 & 378 & 402 & 206 & 378 & 402 & A- & 126.5 & 2480 & 0.3 & 130 & 41.7 & f.p.b.t. \\
\hline & A623-1 & 150 & 250 & 50 & 1050 & 2600 & 210 & 40 & 24.8 & 206 & 378 & 402 & 206 & 378 & 402 & A- & 126.5 & 2480 & 0.4 & 130 & 39.5 & f.p.b.t. \\
\hline
\end{tabular}

Table B. 2: Database of beams failed by intermediate crack induced debonding. Type of test: f.p.b.t.=four point bending test; c.b.t.=cantilever beam test; 3.p.b.t=three point bending test. Beber et al. (as cite in [3]), Benjamin (as cite in [3]), Bonacci and Maalej [46], Chan et al. (as cite in [3]), Chan and Li (as cite in [3]), Delaney (as cite in [3]), Esfahani et al. [34], Gao et al. [48], Kishi et al. (as cite in [3]). 


\begin{tabular}{|c|c|c|c|c|c|c|c|c|c|c|c|c|c|c|c|c|c|c|c|c|c|c|}
\hline & & $\begin{array}{c}\mathrm{b} \\
{[\mathrm{mm}]}\end{array}$ & $\begin{array}{c}\mathrm{h} \\
{[\mathrm{mm}]}\end{array}$ & $\begin{array}{c}\mathrm{a} \\
{[\mathrm{mm}]}\end{array}$ & $\begin{array}{c}\mathrm{B} \\
{[\mathrm{mm}]}\end{array}$ & $\begin{array}{c}\mathrm{L} \\
{[\mathrm{mm}]}\end{array}$ & $\begin{array}{c}\mathrm{d} \\
{[\mathrm{mm}]}\end{array}$ & $\begin{array}{c}\mathrm{d}^{\prime} \\
{[\mathrm{mm}]}\end{array}$ & $\begin{array}{c}\mathrm{f}_{\mathrm{c}}^{\prime} \\
{[\mathrm{MPa}]}\end{array}$ & $\begin{array}{c}\mathrm{E}_{\mathrm{s}} \\
{[\mathrm{GPa}]}\end{array}$ & $\begin{array}{c}\mathrm{f}_{\mathrm{ys}} \\
{[\mathrm{MPa}]}\end{array}$ & $\begin{array}{c}\mathrm{A}_{\mathrm{s}} \\
{\left[\mathrm{mm}^{2}\right]}\end{array}$ & $\begin{array}{c}\mathrm{E}_{\mathrm{s}}^{\prime} \\
{[\mathrm{GPa}]}\end{array}$ & $\begin{array}{c}\mathrm{f}_{\mathrm{y}}^{\prime} \\
{[\mathrm{MPa}]}\end{array}$ & $\begin{array}{c}\mathrm{A}_{\mathrm{s}}^{\prime} \\
{\left[\mathrm{mm}^{2}\right]}\end{array}$ & $\begin{array}{c}\text { Type } \\
{[-]}\end{array}$ & $\begin{array}{c}\mathrm{E}_{\mathrm{frp}} \\
{[\mathrm{GPa}]}\end{array}$ & $\begin{array}{c}\mathrm{f}_{\text {frp }} \\
{[\mathrm{MPa}]}\end{array}$ & $\begin{array}{c}t_{\text {frp }} \\
{[\mathrm{mm}]}\end{array}$ & $\begin{array}{c}\mathrm{b}_{\text {frp }} \\
{[\mathrm{mm}]}\end{array}$ & $\begin{array}{r}\mathrm{V}_{\text {exp }} \\
{[\mathrm{kN}]}\end{array}$ & $\begin{array}{c}\text { type } \\
\text { of test }\end{array}$ \\
\hline \multirow[t]{5}{*}{ Kishi et al. (1998) } & $\begin{array}{l}\mathrm{A} 623-2 \\
\end{array}$ & 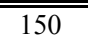 & $=250$ & $\overline{50}$ & "1050 & $\overline{2600}$ & $\overline{210}$ & 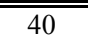 & 24.8 & 206 & $\overline{378}$ & 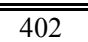 & $\overline{206}$ & $\overline{378}$ & $\overline{402}$ & A- & 126.5 & 2480 & $\overline{0.4}$ & 130 & 240.25 & f.p.b.t. \\
\hline & C300-1 & 150 & 250 & 50 & 1050 & 2600 & 210 & 40 & 24.8 & 206 & 378 & 402 & 206 & 378 & 402 & $\mathrm{C}-$ & 230.5 & 4070 & 0.2 & 130 & 39.6 & f.p.b.t. \\
\hline & $\mathrm{C} 300-2$ & 150 & 250 & 50 & 1050 & 2600 & 210 & 40 & 24.8 & 206 & 378 & 402 & 206 & 378 & 402 & $\mathrm{C}-$ & 230.5 & 4070 & 0.2 & 130 & 37.5 & f.p.b.t. \\
\hline & C445-1 & 150 & 250 & 50 & 1050 & 2600 & 210 & 40 & 24.8 & 206 & 378 & 402 & 206 & 378 & 402 & $\mathrm{C}-$ & 230.5 & 4070 & 0.2 & 130 & 42 & f.p.b.t. \\
\hline & C445-2 & 150 & 250 & 50 & 1050 & 2600 & 210 & 40 & 24.8 & 206 & 378 & 402 & 206 & 378 & 402 & $\mathrm{C}-$ & 230.5 & 4070 & 0.2 & 130 & 41.4 & f.p.b.t. \\
\hline \multirow[t]{2}{*}{ Kishi et al. (2003) } & A-250-1 & 150 & 250 & 100 & 1050 & 2600 & 210 & 40 & 29.6 & 210 & 406 & 402 & 210 & 406 & 402 & A- & 118.0 & 2060 & 0.3 & 130 & 42.1 & f.p.b.t. \\
\hline & A-400-2 & 150 & 400 & 100 & 1050 & 2600 & 360 & 40 & 29.6 & 210 & 406 & 402 & 210 & 406 & 402 & A- & 118.0 & 2060 & 0.6 & 130 & 80 & f.p.b.t. \\
\hline \multirow[t]{6}{*}{ Kotynia (2005) } & B-08/S1 & 150 & 300 & 150 & 800 & 3000 & 270 & 30 & 33.8 & 195 & 490 & 339 & 195 & 490 & 157 & $\mathrm{C}-$ & 172.0 & 2915 & 1.2 & 80 & 90 & f.p.b.t. \\
\hline & BF-04/0.5S & 150 & 300 & 150 & 1500 & 3000 & 270 & 30 & 33.0 & 199 & 421 & 157 & 199 & 421 & 157 & $\mathrm{C}-$ & 172.0 & 2915 & 1.2 & 40 & 48 & 3.p.b.t. \\
\hline & BF-06/S & 150 & 300 & 150 & 1500 & 3000 & 270 & 30 & 32.5 & 195 & 490 & 226 & 195 & 490 & 157 & $\mathrm{C}-$ & 172.0 & 2915 & 1.2 & 80 & 86 & 3.p.b.t. \\
\hline & B-08/M & 150 & 300 & 75 & 1400 & 4200 & 270 & 30 & 37.3 & 220 & 436 & 339 & 220 & 436 & 157 & $\mathrm{C}-$ & 220.0 & 2742 & 1.4 & 120 & 70 & f.p.b.t. \\
\hline & B- $08 / \mathrm{S} 2$ & 150 & 300 & 75 & 1400 & 4200 & 270 & 30 & 32.3 & 220 & 436 & 339 & 220 & 436 & 157 & $\mathrm{C}-$ & 172.0 & 2915 & 1.2 & 50 & 47 & f.p.b.t. \\
\hline & B- $083 m$ & 150 & 300 & 75 & 1400 & 4200 & 270 & 30 & 34.4 & 220 & 436 & 339 & 220 & 436 & 157 & C- & 170.0 & 2915 & 0.4 & 150 & 46 & f.p.b.t. \\
\hline \multirow[t]{3}{*}{ Kurihashi et al. (1999) } & B0-A & 150 & 250 & 100 & 1100 & 2200 & 200 & 50 & 23.9 & 206 & 364 & 266 & 206 & 364 & 266 & A- & 126.5 & 2480 & 0.3 & 80 & 56.1 & 3.p.b.t. \\
\hline & B40-A & 150 & 250 & 100 & 1100 & 2600 & 200 & 50 & 23.9 & 206 & 364 & 266 & 206 & 364 & 266 & A- & 126.5 & 2480 & 0.3 & 80 & 26.15 & f.p.b.t. \\
\hline & B0-C & 150 & 250 & 100 & 1100 & 2200 & 200 & 50 & 23.9 & 206 & 364 & 266 & 206 & 364 & 266 & $\mathrm{C}-$ & 126.5 & 4070 & 0.2 & 80 & 55.1 & 3.p.b.t. \\
\hline \multirow[t]{5}{*}{ Kurihashi et al. (2000) } & R7-2 & 150 & 250 & 100 & 1450 & 3400 & 210 & 40 & 28.2 & 206 & 378 & 402 & 206 & 378 & 402 & A- & 126.5 & 2480 & 0.6 & 130 & 34.95 & f.p.b.t. \\
\hline & R6-2 & 150 & 250 & 100 & 1260 & 3020 & 210 & 40 & 28.2 & 206 & 378 & 402 & 206 & 378 & 402 & A- & 126.5 & 2480 & 0.6 & 130 & 41.3 & f.p.b.t. \\
\hline & R5-2 & 150 & 250 & 100 & 1050 & 2600 & 210 & 40 & 28.2 & 206 & 378 & 402 & 206 & 378 & 402 & A- & 126.5 & 2480 & 0.6 & 130 & 46.5 & f.p.b.t. \\
\hline & R4-2 & 150 & 250 & 100 & 840 & 2180 & 210 & 40 & 28.2 & 206 & 378 & 402 & 206 & 378 & 402 & A- & 126.5 & 2480 & 0.6 & 130 & 58.6 & f.p.b.t. \\
\hline & R3-2 & 150 & 250 & 100 & 650 & 1800 & 210 & 40 & 28.2 & 206 & 378 & 402 & 206 & 378 & 402 & A- & 126.5 & 2480 & 0.6 & 130 & 77.55 & f.p.b.t. \\
\hline \multirow[t]{12}{*}{ Leung (2004) } & B11 & 300 & 800 & 800 & 2400 & 7200 & 740 & 60 & 41.5 & 200 & 526 & 2513 & 200 & 526 & 1030 & C- & 235.0 & 4200 & 0.9 & 300 & 508.8 & f.p.b.t. \\
\hline & B12 & 300 & 800 & 800 & 2400 & 7200 & 740 & 60 & 41.5 & 200 & 526 & 2513 & 200 & 526 & 1030 & C- & 235.0 & 4200 & 0.9 & 300 & 516.5 & f.p.b.t. \\
\hline & B21 & 150 & 400 & 400 & 1200 & 3600 & 370 & 30 & 41.5 & 200 & 535 & 603 & 200 & 535 & 226 & $\mathrm{C}-$ & 235.0 & 4200 & 0.4 & 150 & 137.2 & f.p.b.t. \\
\hline & B22 & 150 & 400 & 400 & 1200 & 3600 & 370 & 30 & 41.5 & 200 & 535 & 603 & 200 & 535 & 226 & C- & 235.0 & 4200 & 0.4 & 150 & 136.25 & f.p.b.t. \\
\hline & B31 & 75 & 200 & 200 & 600 & 1800 & 170 & 30 & 41.5 & 200 & 599 & 157 & 200 & 599 & 101 & C- & 235.0 & 4200 & 0.2 & 75 & 32.1 & f.p.b.t. \\
\hline & B32 & 75 & 200 & 200 & 600 & 1800 & 170 & 30 & 41.5 & 200 & 599 & 157 & 200 & 599 & 101 & C- & 235.0 & 4200 & 0.2 & 75 & 32.15 & f.p.b.t. \\
\hline & B41 & 75 & 200 & 200 & 600 & 1800 & 185 & 15 & 41.5 & 200 & 599 & 157 & 200 & 599 & 101 & C- & 235.0 & 4200 & 0.2 & 75 & 34.8 & f.p.b.t. \\
\hline & B42 & 75 & 200 & 200 & 600 & 1800 & 185 & 15 & 41.5 & 200 & 599 & 157 & 200 & 599 & 101 & C- & 235.0 & 4200 & 0.2 & 75 & 37.85 & f.p.b.t. \\
\hline & NB1-8 & 300 & 800 & 60 & 2400 & 7200 & 740 & 60 & 29.0 & 200 & 519 & 2513 & 200 & 519 & 1030 & C- & 235.0 & 4200 & 0.9 & 300 & 512 & f.p.b.t. \\
\hline & NB1-16 & 300 & 800 & 60 & 2400 & 7200 & 740 & 60 & 29.0 & 200 & 519 & 2513 & 200 & 519 & 1030 & C- & 235.0 & 4200 & 1.8 & 300 & 548.5 & f.p.b.t. \\
\hline & NB2-2 & 150 & 400 & 30 & 1200 & 3600 & 370 & 30 & 29.0 & 200 & 521 & 603 & 200 & 521 & 226 & C- & 235.0 & 4200 & 0.2 & 150 & 108.1 & f.p.b.t. \\
\hline & NB2-4 & 150 & 400 & 30 & 1200 & 3600 & 370 & 30 & 29.0 & 200 & 521 & 603 & 200 & 521 & 226 & C- & 235.0 & 4200 & 0.4 & 150 & 119.55 & f.p.b.t. \\
\hline
\end{tabular}

Table B. 3: Database of beams failed by intermediate crack induced debonding.Type of test: f.p.b.t.=four point bending test; c.b.t.=cantilever beam test; 3.p.b.t=three poin bending test. Kishi et al. (as cite in [3]), Kishi et al. (as cite in [3]), Kotynia (as cite in [3]), Kurihashi et al. (as cite in [3]), Kurihashi et al. (as cite in [3]), Leung (as cite in [3]) 


\begin{tabular}{|c|c|c|c|c|c|c|c|c|c|c|c|c|c|c|c|c|c|c|c|c|c|c|}
\hline & & $\mathrm{b}$ & $\mathrm{h}$ & $\mathrm{a}$ & $\mathrm{B}$ & $\mathrm{L}$ & $\mathrm{d}$ & $\overline{d^{\prime}}$ & $f_{c}^{\prime}$ & $\overline{\mathrm{E}_{\mathrm{s}}}$ & $\overline{f_{y s}}$ & $\overline{A_{s}}$ & $\mathrm{E}_{\mathrm{s}}^{\prime}$ & $\mathrm{f}_{\mathrm{y}}^{\prime}$ & $\overline{\mathrm{A}_{\mathrm{s}}^{\prime}}$ & Type & $\overline{E_{\text {frp }}}$ & $\overline{f_{\text {frp }}}$ & $\overline{t_{\text {frp }}}$ & $\mathrm{b}_{\text {frp }}$ & $\overline{V_{\text {exp }}}$ & type \\
\hline & & {$[\mathrm{mm}]$} & {$[\mathrm{mm}]$} & {$[\mathrm{mm}]$} & {$[\mathrm{mm}]$} & {$[\mathrm{mm}]$} & {$[\mathrm{mm}]$} & {$[\mathrm{mm}]$} & {$[\mathrm{MPa}]$} & {$[\mathrm{GPa}]$} & {$[\mathrm{MPa}]$} & {$\left[\mathrm{mm}^{2}\right]$} & {$[\mathrm{GPa}]$} & {$[\mathrm{MPa}]$} & {$\left[\mathrm{mm}^{2}\right]$} & {$[-]$} & {$[\mathrm{GPa}]$} & [MPa] & {$[\mathrm{mm}]$} & {$[\mathrm{mm}]$} & {$[\mathrm{kN}]$} & of test \\
\hline \multirow[t]{4}{*}{ Leung (2004) } & NB2-6 & 150 & 400 & 30 & 1200 & 3600 & 370 & 30 & 29.0 & 200 & 521 & 2603 & 200 & 521 & 226 & $\overline{C-}$ & 235.0 & "4200 & 0.7 & 150 & 127.6 & f.p.b.t. \\
\hline & NB2-8 & 150 & 400 & 30 & 1200 & 3600 & 370 & 30 & 29.0 & 200 & 521 & 603 & 200 & 521 & 226 & $\mathrm{C}-$ & 235.0 & 4200 & 0.9 & 150 & 137.95 & f.p.b.t. \\
\hline & NB3-2 & 75 & 200 & 15 & 600 & 1800 & 185 & 15 & 29.0 & 200 & 599 & 157 & 200 & 599 & 101 & $\mathrm{C}-$ & 235.0 & 4200 & 0.2 & 75 & \begin{tabular}{|l|}
34.45 \\
\end{tabular} & f.p.b.t. \\
\hline & NB3-4 & 75 & 200 & 15 & 600 & 1800 & 185 & 15 & 29.0 & 200 & 599 & 157 & 200 & 599 & 101 & C- & 235.0 & 4200 & 0.4 & 75 & 37.2 & f.p.b.t. \\
\hline \multirow[t]{10}{*}{ Maalej and Leong (2005) } & A3 & 115 & 146 & 25 & 500 & 1500 & 120 & 26 & 42.8 & 180 & 547 & 236 & 180 & 547 & 157 & $\mathrm{C}-$ & 235.0 & 3550 & 0.2 & 108 & 38.75 & f.p.b.t. \\
\hline & A4 & 115 & 146 & 25 & 500 & 1500 & 120 & 26 & 42.8 & 180 & 547 & 236 & 180 & 547 & 157 & $\mathrm{C}-$ & 235.0 & 3550 & 0.2 & 108 & \begin{tabular}{|l|}
37.75 \\
\end{tabular} & f.p.b.t. \\
\hline & A5 & 115 & 146 & 25 & 500 & 1500 & 120 & 26 & 42.8 & 180 & 547 & 236 & 180 & 547 & 157 & C- & 235.0 & 3550 & 0.3 & 108 & 43.7 & f.p.b.t. \\
\hline & A6 & 115 & 146 & 25 & 500 & 1500 & 120 & 26 & 42.8 & 180 & 547 & 236 & 180 & 547 & 157 & $\mathrm{C}-$ & 235.0 & 3550 & 0.3 & 108 & 42.9 & f.p.b.t. \\
\hline & B3 & 230 & 292 & 50 & 1000 & 3000 & 240 & 52 & 42.8 & 183 & 544 & 943 & 183 & 544 & 628 & $\mathrm{C}-$ & 235.0 & 3550 & 0.3 & 216 & 131.75 & f.p.b.t. \\
\hline & B4 & 230 & 292 & 50 & 1000 & 3000 & 240 & 52 & 42.8 & 183 & 544 & 943 & 183 & 544 & 628 & C- & 235.0 & 3550 & 0.3 & 216 & 130.15 & f.p.b.t. \\
\hline & B5 & 230 & 292 & 50 & 1000 & 3000 & 240 & 52 & 42.8 & 183 & 544 & 943 & 183 & 544 & 628 & C- & 235.0 & 3550 & 0.7 & 216 & 147.35 & f.p.b.t. \\
\hline & B6 & 230 & 292 & 50 & 1000 & 3000 & 240 & 52 & 42.8 & 183 & 544 & 943 & 183 & 544 & 628 & C- & 235.0 & 3550 & 0.7 & 216 & 142.15 & f.p.b.t. \\
\hline & $\mathrm{C} 3$ & 368 & 467.2 & 80 & 1600 & 4800 & 384 & 83.2 & 42.4 & 181 & 552 & 2413 & 181 & 552 & 1609 & C- & 235.0 & 3550 & 0.5 & 368 & 326.45 & f.p.b.t. \\
\hline & $\mathrm{C} 4$ & 368 & 467.2 & 80 & 1600 & 4800 & 384 & 83.2 & 42.4 & 181 & 552 & 2413 & 181 & 552 & 1609 & C- & 235.0 & 3550 & 0.5 & 368 & 334.65 & f.p.b.t. \\
\hline \multirow[t]{2}{*}{$\overline{\text { Maeda et al. (2001) }}$} & SP-C & 200 & 200 & 30 & 750 & 1800 & 165 & 35 & 35.0 & 200 & 360 & 266 & 200 & 360 & 266 & $\mathrm{C}-$ & 236.0 & 4120 & 0.2 & 200 & \begin{tabular}{|l|}
39.15 \\
\end{tabular} & f.p.b.t. \\
\hline & SP-C2 & 200 & 200 & 30 & 750 & 1800 & 165 & 35 & 35.0 & 200 & 360 & 266 & 200 & 360 & 266 & C- & 236.0 & 4120 & 0.3 & 200 & 54.5 & f.p.b.t. \\
\hline M'Bazaa et al. (1996) & $\begin{array}{ll}\text { P111 } \\
\end{array}$ & 200 & 300 & 50 & 1000 & 3000 & 240 & - & 44.3 & 200 & 439 & 157 & 200 & - & - & $\mathrm{C}-$ & 82.0 & & 0.9 & 167 & 49.9 & f.p.b.t. \\
\hline Mikami et al. (1999) & A-140 & 150 & 250 & 100 & 1500 & 3000 & 200 & 50 & 23.9 & 200 & 364 & 266 & 200 & 364 & 266 & $\mathrm{C}-$ & 126.5 & 2480 & 0.3 & 80 & 40.2 & 3.p.b.t. \\
\hline \multirow[t]{11}{*}{ Niu et al. (2006) } & $\mathrm{A} 1$ & 960 & 203 & 475 & 2100 & 4200 & 168 & - & 31.6 & 192 & 452 & 861 & 192 & - & - & $\mathrm{C}-$ & 184.0 & 2446 & 1.3 & 200 & 127.8 & 3.p.b.t. \\
\hline & A2 & 960 & 203 & 475 & 2100 & 4200 & 168 & - & 33.4 & 192 & 452 & 861 & 192 & - & - & $\mathrm{C}-$ & 195.0 & 2384 & 1.2 & 200 & 130.4 & 3.p.b.t. \\
\hline & A3 & 960 & 203 & 475 & 2100 & 4200 & 168 & - & 35.2 & 192 & 452 & 861 & 192 & - & - & $\mathrm{C}-$ & 80.4 & 724 & 1.4 & 300 & 102.7 & 3.p.b.t. \\
\hline & A4 & 960 & 203 & 475 & 2100 & 4200 & 168 & - & 34.4 & 192 & 452 & 861 & 192 & - & - & $\mathrm{C}-$ & 108.5 & 859 & 2.6 & 300 & \begin{tabular}{|l|l} 
& 133.7
\end{tabular} & 3.p.b.t. \\
\hline & A5 & 960 & 203 & 475 & 2100 & 4200 & 168 & - & 35.9 & 192 & 452 & 861 & 192 & - & - & C- & 108.5 & 859 & 2.6 & 200 & \begin{tabular}{|l|l}
107.4 \\
\end{tabular} & 3.p.b.t. \\
\hline & A6 & 960 & 203 & 475 & 2100 & 4200 & 168 & - & 35.1 & 192 & 452 & 861 & 192 & - & - & C- & 80.4 & 724 & 1.4 & 200 & 93.7 & 3.p.b.t. \\
\hline & B1 & 960 & 203 & 475 & 1600 & 4200 & 168 & - & 35.2 & 192 & 452 & 861 & 192 & - & - & C- & 184.0 & 2446 & 1.3 & 200 & \begin{tabular}{|l}
1.85 \\
\end{tabular} & f.p.b.t. \\
\hline & B2 & 960 & 203 & 475 & 1600 & 4200 & 168 & - & 34.5 & 192 & 452 & 861 & 192 & - & - & C- & 80.4 & 724 & 1.4 & 300 & 56.7 & f.p.b.t. \\
\hline & B3 & 960 & 203 & 475 & 1600 & 4200 & 168 & - & 34.7 & 192 & 452 & 861 & 192 & - & - & C- & 80.4 & 724 & 1.4 & 200 & \begin{tabular}{|l|l} 
& 54.15
\end{tabular} & f.p.b.t. \\
\hline & $\mathrm{C} 2$ & 960 & 203 & 475 & 2100 & 4200 & 168 & - & 33.3 & 196 & 446 & 896 & 196 & - & - & C- & 184.0 & 2446 & 1.3 & 200 & \begin{tabular}{|l}
133.8 \\
\end{tabular} & 3.p.b.t. \\
\hline & $\mathrm{C} 3$ & 960 & 203 & 475 & 2100 & 4200 & 168 & - & 34.1 & 196 & 446 & 896 & 196 & - & - & C- & 80.4 & 724 & 1.4 & 300 & \begin{tabular}{|l}
107.2 \\
\end{tabular} & 3.p.b.t. \\
\hline
\end{tabular}

Table B. 4: Database of beams failed by intermediate crack induced debonding. Type of test: f.p.b.t.=four point bending test; c.b.t.=cantilever beam test; 3.p.b.t=three point bending test. Leung (as cite in [3]), Maalej and Leong (as cite in [3]), Maeda et al. (as cite in [3]), M'Bazaa et al. (as cite in [3]), Mikami et al. (as cite in [3]), Niu et al [49]. 


\begin{tabular}{|c|c|c|c|c|c|c|c|c|c|c|c|c|c|c|c|c|c|c|c|c|c|c|}
\hline & & $\mathrm{b}$ & $\mathrm{h}$ & $\mathrm{a}$ & B & $\mathrm{L}$ & $\mathrm{d}$ & $\mathrm{d}^{\prime}$ & $f_{c}^{\prime}$ & $\mathrm{E}_{\mathrm{s}}$ & $\mathrm{f}_{\mathrm{ys}}$ & $\mathrm{A}_{\mathrm{s}}$ & $\overline{E_{s}^{\prime}}$ & $\frac{f_{y}^{\prime}}{f_{y}}$ & $\overline{\mathrm{A}_{\mathrm{s}}^{\prime}}$ & Type & $\overline{\mathrm{E}_{\text {frp }}}$ & $f_{\text {frp }}$ & $\mathrm{t}_{\text {frp }}$ & $\mathrm{b}_{\text {frp }}$ & $\mathrm{V}_{\text {exp }}$ & type \\
\hline & & {$[\mathrm{mm}]$} & {$[\mathrm{mm}]$} & {$[\mathrm{mm}]$} & {$[\mathrm{mm}]$} & {$[\mathrm{mm}]$} & {$[\mathrm{mm}]$} & {$[\mathrm{mm}]$} & [MPa] & [GPa] & {$[\mathrm{MPa}]$} & {$\left[\mathrm{mm}^{2}\right]$} & [GPa] & {$[\mathrm{MPa}]$} & {$\left[\mathrm{mm}^{2}\right]$} & {$[-]$} & [GPa] & [MPa] & {$[\mathrm{mm}]$} & {$[\mathrm{mm}]$} & {$[\mathrm{kN}]$} & of test \\
\hline Niu et al. (2006) & $\overline{\mathrm{C} 4}$ & 960 & 203 & 475 & 2100 & 4200 & 168 & $\overline{-}$ & 34.5 & 196 & 446 & 896 & 196 & - & $\overline{-}$ & C- & 80.4 & 724 & 1.4 & 200 & 90.5 & $\overline{\text { 3.p.b.t. }}$ \\
\hline \multirow[t]{6}{*}{$\overline{\text { Seim et al. (2001) }}$} & S11 & 480 & 102 & 100 & 1015 & 2030 & 81 & - & 33.2 & 205 & 462 & 214 & 205 & - & - & C- & $\begin{array}{l}198.0 \\
\end{array}$ & 2270 & 1.2 & 100 & 40.8 & 3.p.b.t. \\
\hline & $\mathrm{S} 12$ & 480 & 102 & 100 & 1015 & 2030 & 81 & - & 33.2 & 205 & 462 & 214 & 205 & - & - & $\mathrm{C}-$ & 198.0 & 2270 & 1.2 & 100 & 42.5 & 3.p.b.t. \\
\hline & S5 & 480 & 102 & 100 & 1015 & 2030 & 81 & - & 33.2 & 205 & 462 & 214 & 205 & - & - & C- & 198.0 & 2270 & 1.2 & 100 & 43.2 & 3.p.b.t. \\
\hline & $\mathrm{S} 1 \mathrm{~m}$ & 480 & 102 & 285 & 1015 & 2030 & 81 & - & 33.2 & 205 & 462 & 214 & 205 & - & - & C- & 198.0 & 2270 & 1.2 & 100 & 41.9 & 3.p.b.t. \\
\hline & $\mathrm{C} 12$ & 480 & 102 & 100 & 1015 & 2030 & 81 & - & 33.2 & 205 & 462 & 214 & 205 & - & - & G- & 63.8 & 675 & 1.1 & 480 & 80.8 & 3.p.b.t. \\
\hline & $\mathrm{C} 21$ & 480 & 102 & 100 & 1015 & 2030 & 81 & - & 33.2 & 205 & 462 & 214 & 205 & - & - & G- & 91.5 & 724 & 1.2 & 480 & 71.3 & 3.p.b.t. \\
\hline \multirow[t]{2}{*}{ Spadea et al. (1998) } & $\begin{array}{l}\mathrm{A} 1.1 \\
\end{array}$ & 140 & 300 & 50 & 1800 & 4800 & 261 & 39 & 27.4 & 200 & 435 & 402 & 200 & 435 & 402 & G- & 152.0 & 2300 & 1.2 & 80 & 43.4 & f.p.b.t. \\
\hline & A3.1 & 140 & 300 & 50 & 1800 & 4800 & 263 & 37 & 28.5 & 200 & 435 & 402 & 200 & 435 & 402 & C- & 152.0 & 2300 & 1.2 & 80 & 37.4 & f.p.b.t. \\
\hline \multirow[t]{5}{*}{ Takahashi and Sato (2003) } & F1 & 200 & 300 & 50 & 700 & 1600 & 250 & 50 & 35.8 & 200 & 371 & 573 & 200 & 371 & 63 & C- & 230.0 & 3480 & 0.2 & 200 & 113.5 & f.p.b.t. \\
\hline & F2 & 200 & 300 & 50 & 700 & 1600 & 250 & 50 & 40.2 & 200 & 371 & 573 & 200 & 371 & 63 & C- & 230.0 & 3480 & 0.3 & 200 & 122 & f.p.b.t. \\
\hline & F3 & 200 & 300 & 50 & 700 & 1600 & 250 & 50 & 39.0 & 200 & 371 & 573 & 200 & 371 & 63 & C- & 230.0 & 3480 & 0.5 & 200 & 135 & f.p.b.t. \\
\hline & F5 & 200 & 300 & 50 & 700 & 1600 & 250 & 50 & 50.3 & 200 & 371 & 573 & 200 & 371 & 63 & C- & 230.0 & 3480 & 0.3 & 200 & 139 & f.p.b.t. \\
\hline & F6 & 200 & 300 & 50 & 700 & 1600 & 250 & 50 & 49.5 & 200 & 371 & 573 & 200 & 371 & 63 & C- & 230.0 & 3480 & 0.5 & 200 & 155.5 & f.p.b.t. \\
\hline \multirow[t]{6}{*}{ Takeo et al. (1999) } & No.2 & 160 & 260 & 70 & 1000 & 2000 & 225 & 35 & 31.3 & 200 & 356 & 266 & 200 & 356 & 266 & $\mathrm{C}-$ & 230.0 & 3480 & 0.2 & 140 & 33.85 & 3.p.b.t. \\
\hline & No.3 & 160 & 260 & 70 & 800 & 2000 & 225 & 35 & 31.3 & 200 & 356 & 266 & 200 & 356 & 266 & $\mathrm{C}-$ & 230.0 & 3480 & 0.2 & 140 & 38.35 & f.p.b.t. \\
\hline & No.4 & 160 & 260 & 70 & 700 & 2000 & 225 & 35 & 31.3 & 200 & 356 & 266 & 200 & 356 & 266 & $\mathrm{C}-$ & 230.0 & 3480 & 0.2 & 140 & 43.5 & f.p.b.t. \\
\hline & No. 5 & 160 & 260 & 70 & 550 & 2000 & 225 & 35 & 39.0 & 200 & 356 & 266 & 200 & 356 & 266 & C- & 230.0 & 3480 & 0.2 & 140 & 66 & f.p.b.t. \\
\hline & No.6 & 160 & 260 & 70 & 1000 & 2000 & 225 & 35 & 39.0 & 200 & 356 & 266 & 200 & 356 & 266 & $\mathrm{C}-$ & 230.0 & 3480 & 0.2 & 140 & 78.6 & 3.p.b.t. \\
\hline & No.7 & 160 & 260 & 70 & 1000 & 2000 & 225 & 35 & 39.0 & 200 & 356 & 266 & 200 & 356 & 266 & $\mathrm{C}-$ & 230.0 & 3480 & 0.2 & 140 & 85.6 & 3.p.b.t. \\
\hline \multirow[t]{2}{*}{ Teng and Yao (2007) } & CS-W50 & 150.6 & 255.3 & 50 & 500 & 1500 & 222.8 & 32.5 & 32.8 & 199 & 536 & 157.08 & 199 & 536 & 157.08 & $\mathrm{C}-\mathrm{W}$ & 256.0 & 4114 & 2.01 & 50 & 71.3 & f.p.b.t. \\
\hline & GS & 151.1 & 252.2 & 50 & 500 & 1500 & 217.7 & 34.5 & 32.3 & 199 & 536 & 157.08 & 199 & 536 & 157.08 & G-W & 22.5 & 351 & 1.67 & 148 & 82 & f.p.b.t. \\
\hline \multirow[t]{2}{*}{ Wu et al. (1999) } & H-s CFRP & 150 & 200 & 50 & 600 & 1800 & 150 & 50 & 33.8 & 210 & 390 & 402 & 210 & 390 & 266 & $\mathrm{C}-$ & 230.0 & 4200 & 0.3 & 150 & 68.25 & f.p.b.t. \\
\hline & H-m CFRP & 150 & 200 & 50 & 600 & 1800 & 150 & 50 & 33.8 & 210 & 390 & 402 & 210 & 390 & 266 & C- & 290.0 & 4000 & 0.3 & 150 & 78.45 & f.p.b.t. \\
\hline \multirow[t]{3}{*}{ Wu et al. (2000) } & RC-1 & 150 & 200 & 50 & 900 & 1800 & 160 & 40 & 30.2 & 210 & 360 & 402 & 210 & 360 & 266 & $\mathrm{C}-$ & 230.0 & 3200 & 0.1 & 140 & 65 & 3.p.b.t. \\
\hline & RC-2 & 150 & 200 & 50 & 900 & 1800 & 160 & 40 & 30.2 & 210 & 360 & 402 & 210 & 360 & 266 & C- & 230.0 & 3200 & 0.1 & 140 & 68.9 & 3.p.b.t. \\
\hline & RCS-1 & 150 & 200 & 50 & 900 & 1800 & 160 & 40 & 34.6 & 210 & 360 & 402 & 210 & 360 & 266 & $\mathrm{C}-$ & 230.0 & 3200 & 0.222 & 140 & 73.5 & 3.p.b.t. \\
\hline \multirow[t]{6}{*}{ Yao et al. (2005) } & CP4 & 304.5 & 150.3 & 100 & 1000 & 1100 & 120.2 & - & 46.2 & 208 & 343 & 157 & 208 & - & - & C- & 165.0 & 2800 & 1.2 & 50 & 13.5 & c.b.t. \\
\hline & II-1 & 303 & 153 & 100 & 1000 & 1100 & 117.5 & - & 25.6 & 208 & 349 & 157 & 208 & - & - & $\mathrm{C}-$ & 257.0 & 4519 & 0.2 & 30 & 7.2 & c.b.t. \\
\hline & $\mathrm{I}-2$ & 305 & 149 & 100 & 1000 & 1100 & 116.5 & - & 25.3 & 208 & 332 & 157 & 208 & - & - & C- & 257.0 & 4519 & 0.2 & 50 & 8.4 & c.b.t. \\
\hline & II-3 & 305 & 150 & 100 & 1000 & 1100 & 117.5 & - & 30.2 & 208 & 332 & 157 & 208 & - & - & C- & 257.0 & 4519 & 0.2 & 70 & 8.9 & c.b.t. \\
\hline & II-4 & 302 & 150 & 100 & 1000 & 1100 & 118.7 & - & 21.9 & 208 & 332 & 157 & 208 & - & - & $\mathrm{C}-$ & 257.0 & 4519 & 0.2 & 90 & 10.2 & c.b.t. \\
\hline & II-8 & 203.5 & 152 & 100 & 1000 & 1100 & 114.5 & - & 23.8 & 208 & 364 & 157 & 208 & - & - & C- & 257.0 & 4519 & 0.2 & 50 & 8.4 & c.b.t. \\
\hline
\end{tabular}

Table B. 5: Database of beams failed by intermediate crack induced debonding. Type of test: f.p.b.t.=four point bending test; c.b.t.=cantilever beam test; 3.p.b.t=three poin bending test. Niu et al. [49], Seim et al. [50], Spadea et al. [44], Takahashi and Sato (as cited in [3]), Takeo et al. (as cited in [3]), Teng and Yao [23], Wu et al. 1999,2000 (as cited in [3]), Yao et al. [47]. 
Pag. 50

\begin{tabular}{|c|c|c|c|c|c|c|c|c|c|c|c|c|c|c|c|c|c|c|c|c|c|c|}
\hline & & $\mathrm{b}$ & $\mathrm{h}$ & $\mathrm{a}$ & $\mathrm{B}$ & $\mathrm{L}$ & $\overline{\mathrm{d}}$ & $\mathrm{d}^{\prime}$ & $f_{c}^{\prime}$ & $\overline{E_{s}}$ & $\mathrm{f}_{\mathrm{ys}}$ & $\mathrm{A}_{\mathrm{s}}$ & $\mathrm{E}_{\mathrm{s}}^{\prime}$ & $\mathrm{f}_{\mathrm{y}}^{\prime}$ & $\mathrm{A}_{\mathrm{s}}^{\prime}$ & Type & $\overline{E_{\text {frp }}}$ & $\overline{f_{\text {frp }}}$ & $\mathrm{t}_{\mathrm{frp}}$ & $\mathrm{b}_{\text {frp }}$ & $\mathrm{V}_{\text {exp }}$ & type \\
\hline & & {$[\mathrm{mm}]$} & {$[\mathrm{mm}]$} & {$[\mathrm{mm}]$} & {$[\mathrm{mm}]$} & {$[\mathrm{mm}]$} & {$[\mathrm{mm}]$} & {$[\mathrm{mm}]$} & {$[\mathrm{MPa}]$} & {$[\mathrm{GPa}]$} & {$[\mathrm{MPa}]$} & {$\left[\mathrm{mm}^{2}\right]$} & {$[\mathrm{GPa}]$} & {$[\mathrm{MPa}]$} & {$\left[\mathrm{mm}^{2}\right]$} & {$[-]$} & [GPa] & {$[\mathrm{MPa}]$} & {$[\mathrm{mm}]$} & {$[\mathrm{mm}]$} & {$[\mathrm{kN}]$} & of test \\
\hline \multirow[t]{4}{*}{ Yao et al. (2005) } & 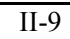 & 320 & 151 & 100 & $\overline{1000}$ & 1100 & 117 & - & 22.2 & 208 & 332 & 157 & 208 & - & - & 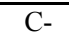 & 257.0 & 24519 & 0.2 & 30 & 6.9 & c.b.t. \\
\hline & III-1 & 203 & 155 & 100 & 1000 & 2000 & 121 & - & 22.5 & 208 & 346 & 157 & 208 & - & - & $\mathrm{C}-$ & 257.0 & 4519 & 0.2 & 50 & 15 & 3.p.b.t. \\
\hline & III-2 & 199 & 156.5 & 100 & 1000 & 2000 & 122.5 & - & 21.2 & 210 & 373 & 157 & 210 & - & - & C- & 257.0 & 4519 & 0.2 & 100 & 21.4 & 3.p.b.t. \\
\hline & III-4 & 150.1 & 153.5 & 100 & 1000 & 2000 & 122 & - & 22.4 & 206 & 351 & 157 & 206 & - & e & $\mathrm{C}-$ & 257.0 & 4519 & 0.2 & 50 & 18.4 & 3.p.b.t. \\
\hline \multirow[t]{2}{*}{ Zarniç et al. (1999) } & 1 & 200 & 300 & 100 & 960 & 2900 & 270 & 30 & 25.0 & 205 & 450 & 339 & 205 & 450 & 226 & $\mathrm{C}-$ & 150.0 & 2400 & 1.2 & 50 & 58.4 & f.p.b.t. \\
\hline & 2 & 800 & 120 & 100 & 960 & 2900 & 105 & 15 & 25.0 & 205 & 450 & 339 & 205 & 450 & 156 & $\mathrm{C}-$ & 150.0 & 2400 & 1.2 & 100 & 31.5 & f.p.b.t. \\
\hline \multirow[t]{20}{*}{ Zhang et al. (2005) } & A-1 & 150 & 340 & 100 & 1200 & 3000 & 300 & 40 & 31.5 & 210 & 407 & 402 & 210 & 407 & 402 & A- & 118.0 & 2060 & 0.6 & 130 & 63.35 & f.p.b.t. \\
\hline & A-2 & 150 & 340 & 100 & 1200 & 3000 & 300 & 40 & 31.5 & 210 & 407 & 402 & 210 & 407 & 402 & A- & 118.0 & 2060 & 0.6 & 130 & 63.5 & f.p.b.t. \\
\hline & A-3 & 150 & 340 & 100 & 1200 & 3000 & 300 & 40 & 31.5 & 210 & 407 & 402 & 210 & 407 & 402 & A- & 118.0 & 2060 & 0.6 & 130 & 63.1 & f.p.b.t. \\
\hline & A-4 & 150 & 340 & 100 & 1200 & 3000 & 300 & 40 & 31.5 & 210 & 407 & 402 & 210 & 407 & 402 & A- & 118.0 & 2060 & 0.6 & 130 & 65.8 & f.p.b.t. \\
\hline & A-5 & 150 & 340 & 100 & 1200 & 3000 & 300 & 40 & 31.5 & 210 & 407 & 402 & 210 & 407 & 402 & A- & 118.0 & 2060 & 0.6 & 130 & 62.15 & f.p.b.t. \\
\hline & A-6 & 150 & 340 & 100 & 1200 & 3000 & 300 & 40 & 31.5 & 210 & 407 & 402 & 210 & 407 & 402 & A- & 118.0 & 2060 & 0.6 & 130 & 62.1 & f.p.b.t. \\
\hline & B-2 & 150 & 250 & 100 & 1050 & 2600 & 210 & 40 & 31.5 & 210 & 407 & 402 & 210 & 407 & 402 & C- & 230.0 & 3400 & 0.2 & 130 & 40.45 & f.p.b.t. \\
\hline & B-3 & 150 & 250 & 100 & 1050 & 2600 & 210 & 40 & 31.5 & 210 & 407 & 402 & 210 & 407 & 402 & A- & 118.0 & 2060 & 0.3 & 130 & 42.1 & f.p.b.t. \\
\hline & B-4 & 150 & 250 & 100 & 1050 & 2600 & 210 & 40 & 31.5 & 210 & 407 & 402 & 210 & 407 & 402 & A- & 78.5 & 2350 & 0.4 & 130 & 41.05 & f.p.b.t. \\
\hline & B-6 & 150 & 400 & 100 & 1050 & 2600 & 360 & 40 & 31.5 & 210 & 407 & 402 & 210 & 407 & 402 & C- & 230.0 & 3400 & 0.3 & 130 & 78.15 & f.p.b.t. \\
\hline & B-7 & 150 & 400 & 100 & 1050 & 2600 & 360 & 40 & 31.5 & 210 & 407 & 402 & 210 & 407 & 402 & A- & 118.0 & 2060 & 0.6 & 130 & 79.6 & f.p.b.t. \\
\hline & B-8 & 150 & 400 & 100 & 1050 & 2600 & 360 & 40 & 31.5 & 210 & 407 & 402 & 210 & 407 & 402 & A- & 78.5 & 2350 & 0.8 & 130 & 78.1 & f.p.b.t. \\
\hline & C-1 & 150 & 235 & 100 & 650 & 1800 & 210 & 40 & 31.5 & 210 & 407 & 402 & 210 & 407 & 402 & A- & 118.0 & 2060 & 0.6 & 130 & 74.95 & f.p.b.t. \\
\hline & C-2 & 150 & 250 & 100 & 650 & 1800 & 210 & 40 & 31.5 & 210 & 407 & 402 & 210 & 407 & 402 & A- & 118.0 & 2060 & 0.6 & 130 & 75.95 & f.p.b.t. \\
\hline & C-4 & 150 & 235 & 100 & 1050 & 2600 & 210 & 40 & 31.5 & 210 & 407 & 402 & 210 & 407 & 402 & A- & 118.0 & 2060 & 0.6 & 130 & 45.25 & f.p.b.t. \\
\hline & C-5 & 150 & 250 & 100 & 1050 & 2600 & 210 & 40 & 31.5 & 210 & 407 & 402 & 210 & 407 & 402 & A- & 118.0 & 2060 & 0.6 & 130 & 47.2 & f.p.b.t. \\
\hline & C-6 & 150 & 270 & 100 & 1050 & 2600 & 205 & 40 & 31.5 & 210 & 407 & 402 & 210 & 407 & 402 & A- & 118.0 & 2060 & 0.6 & 130 & 48.5 & f.p.b.t. \\
\hline & C-7 & 150 & 235 & 100 & 1450 & 3500 & 210 & 40 & 31.5 & 210 & 407 & 402 & 210 & 407 & 402 & A- & 118.0 & 2060 & 0.6 & 130 & 34.4 & f.p.b.t. \\
\hline & C-8 & 150 & 250 & 100 & 1450 & 3500 & 210 & 40 & 31.5 & 210 & 407 & 402 & 210 & 407 & 402 & A- & 118.0 & 2060 & 0.6 & 130 & 34 & f.p.b.t. \\
\hline & C-9 & 150 & 270 & 100 & 1450 & 3500 & 205 & 40 & 31.5 & 210 & 407 & 402 & 210 & 407 & 402 & A- & 118.0 & 2060 & 0.6 & 130 & 35.4 & f.p.b.t. \\
\hline
\end{tabular}

Table B. 6: Database of beams failed by intermediate crack induced debonding. Type of test: f.p.b.t.=four point bending test; c.b.t. $=$ cantilever beam test; 3.p.b.t=three point bending test. Yao et al. [47], Zaniç et al. (as cited in [3]), Zhang et al. (as cited in [3]). 

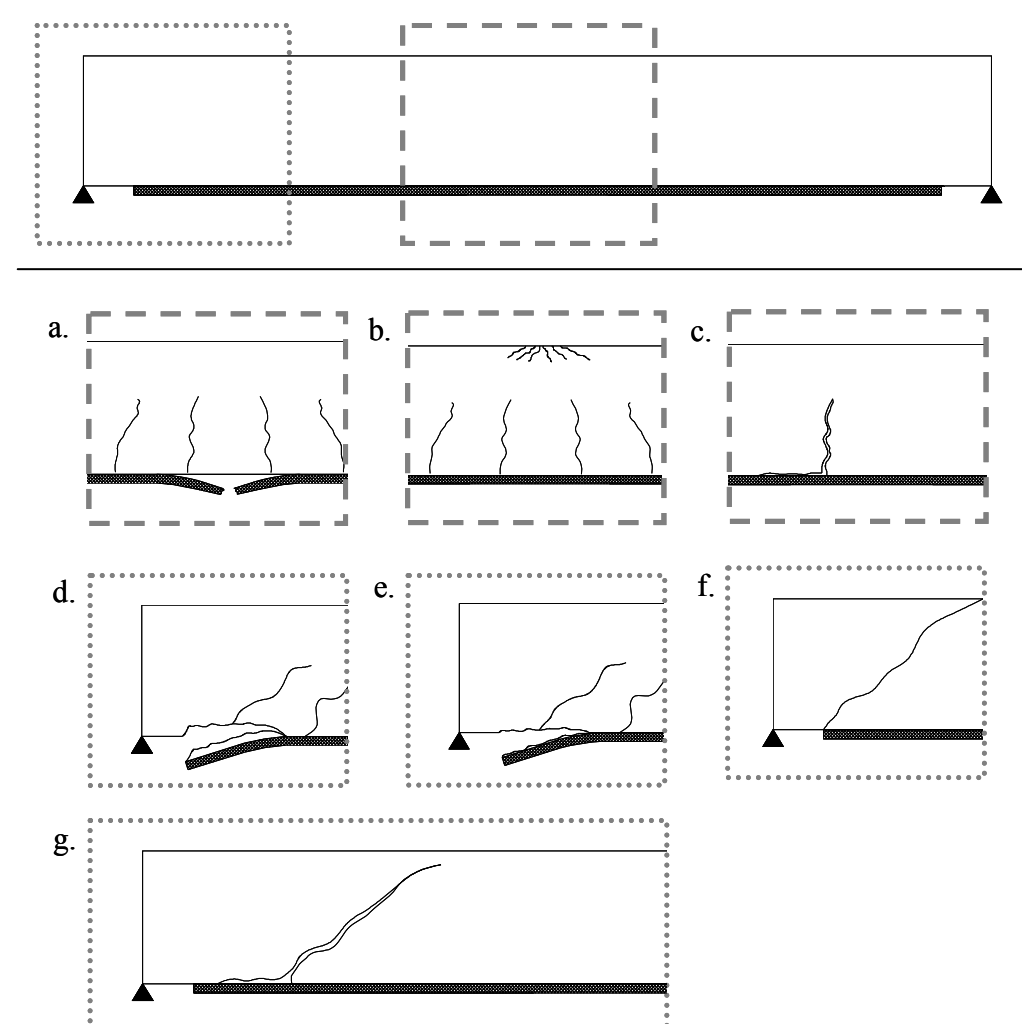

Figure 1: Failure modes of FRP-strengthened beams. a. FRP rupture; b. Crushing of compression concrete; c. Intermediate crack induced interfacial debonding; d. Concrete cover separation; e. Plate end interfacial debonding; f. Shear failure; g. Critical diagonal crack. 


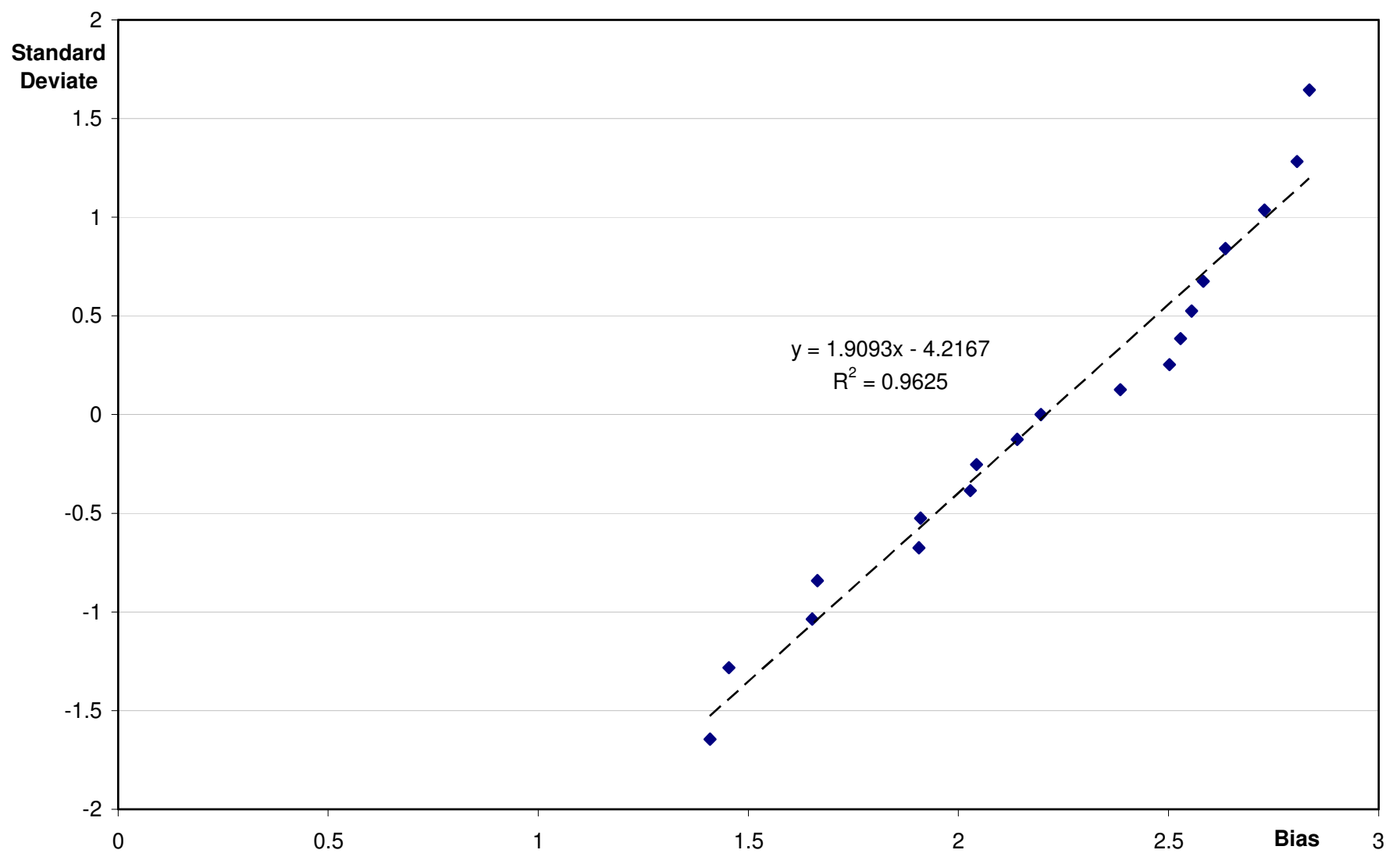

Figure 2: Plot of $\mathrm{V}_{\text {exp }} / \mathrm{V}_{\text {an }}$ of wet lay-up installations for the Casas and Pascual model on Normal probability scale (19 experimental tests). 




Figure 3: Plot of $\mathrm{V}_{\text {exp }} / \mathrm{V}_{\text {an }}$ of wet lay-up installations for the Casas and Pascual model on Lognormal probability scale (19 experimental tests). 


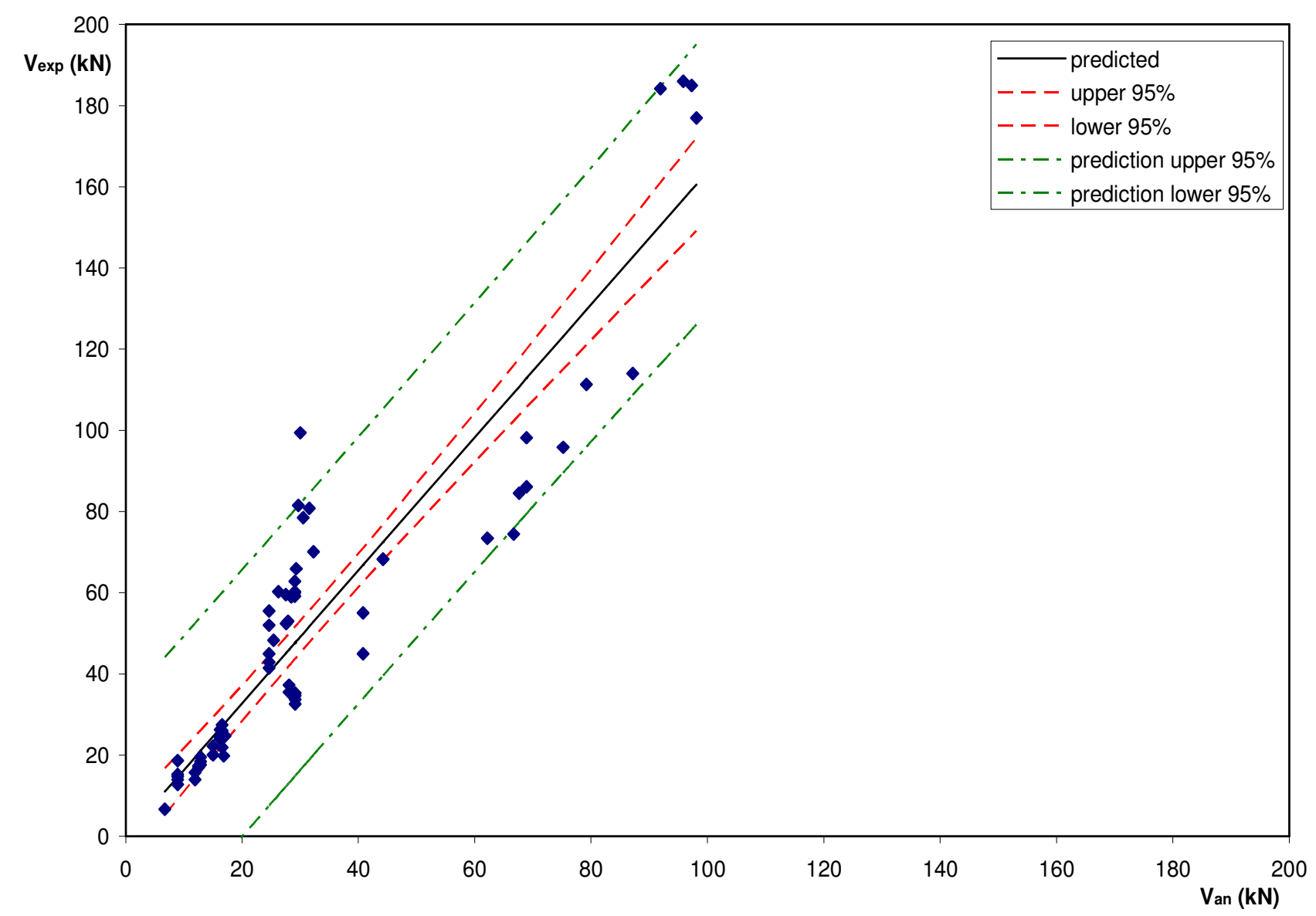

Figure 4: Regression analysis of Teng and Smith model for end debonding for wet lay-up (69 experimental tests). 


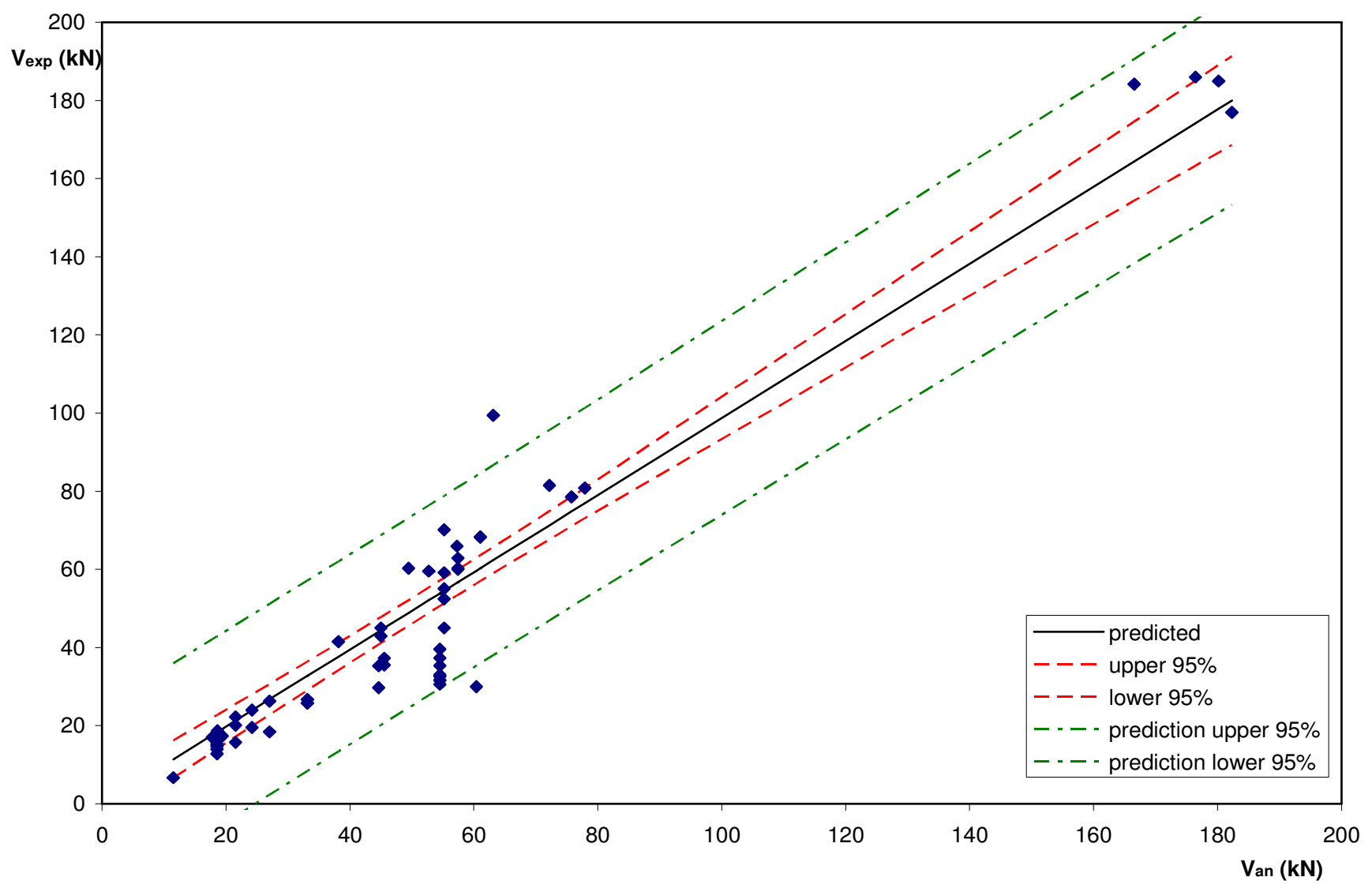

Figure 5: Regression analysis of Colotti model for end debonding for wet lay-up (55 experimental tests). 


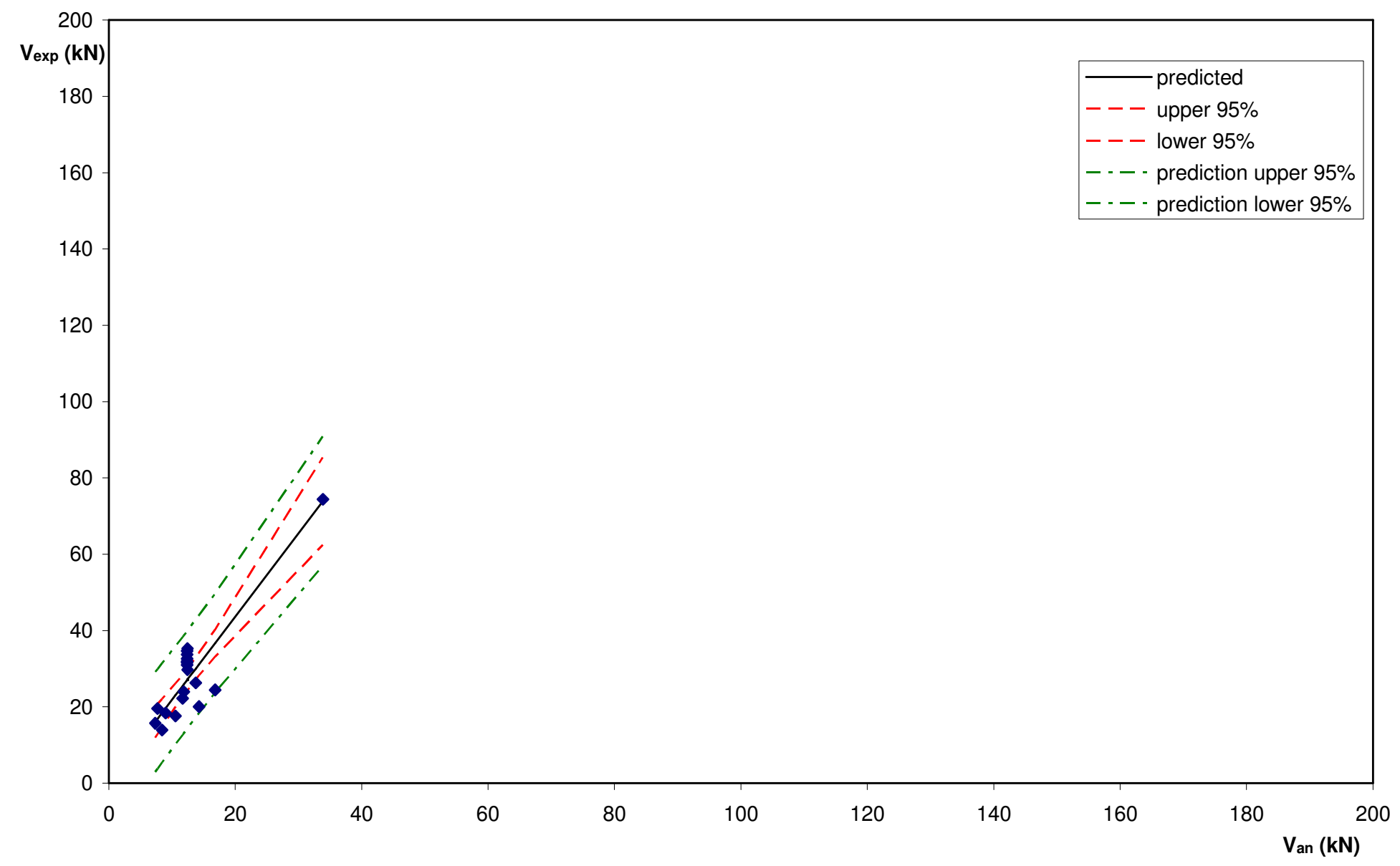

Figure 6 Regression analysis of Casas and Pascual model for end debonding for wet lay-up (19 experimental tests). 


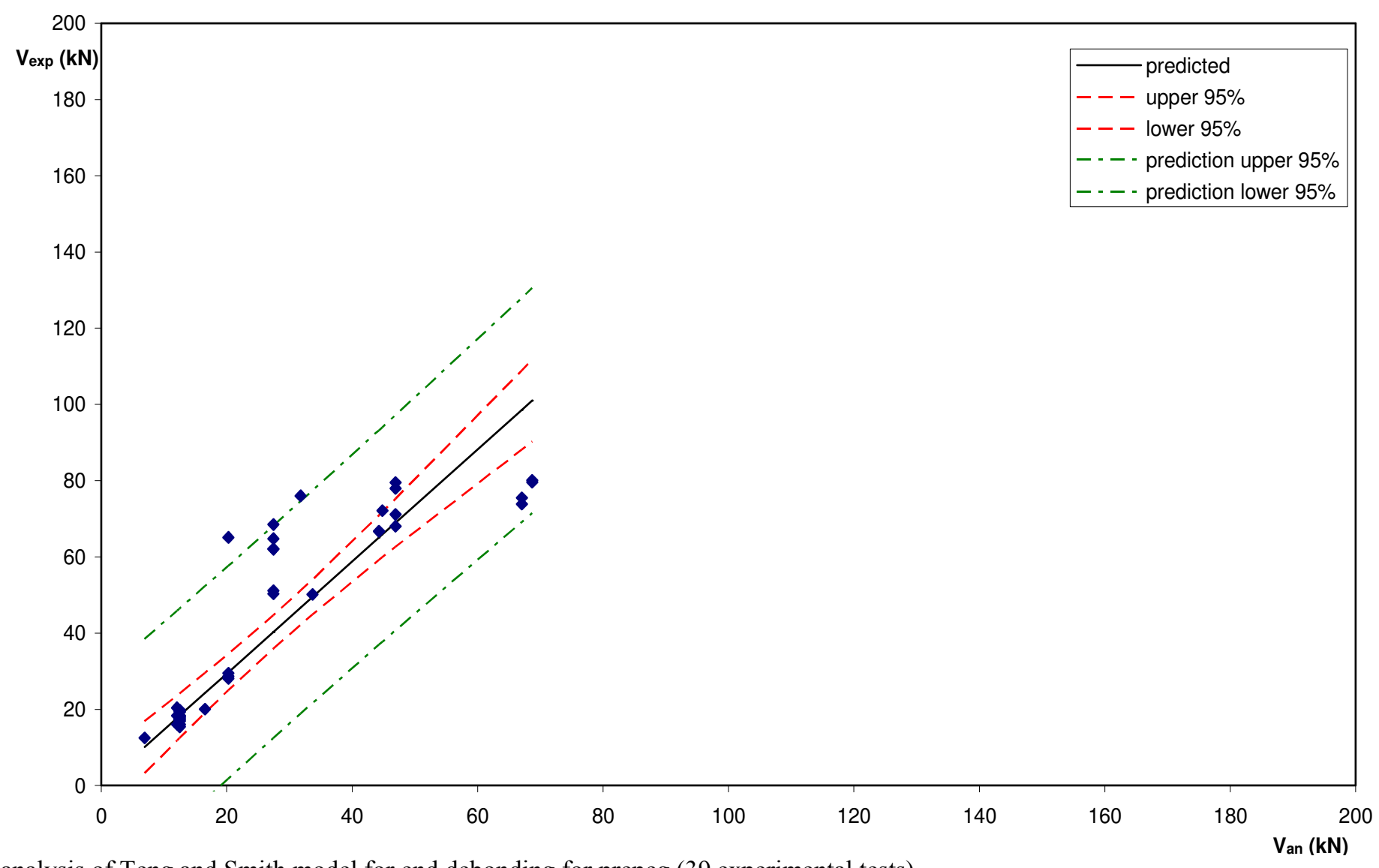

Figure 7 : Regression analysis of Teng and Smith model for end debonding for prepeg (39 experimental tests). 


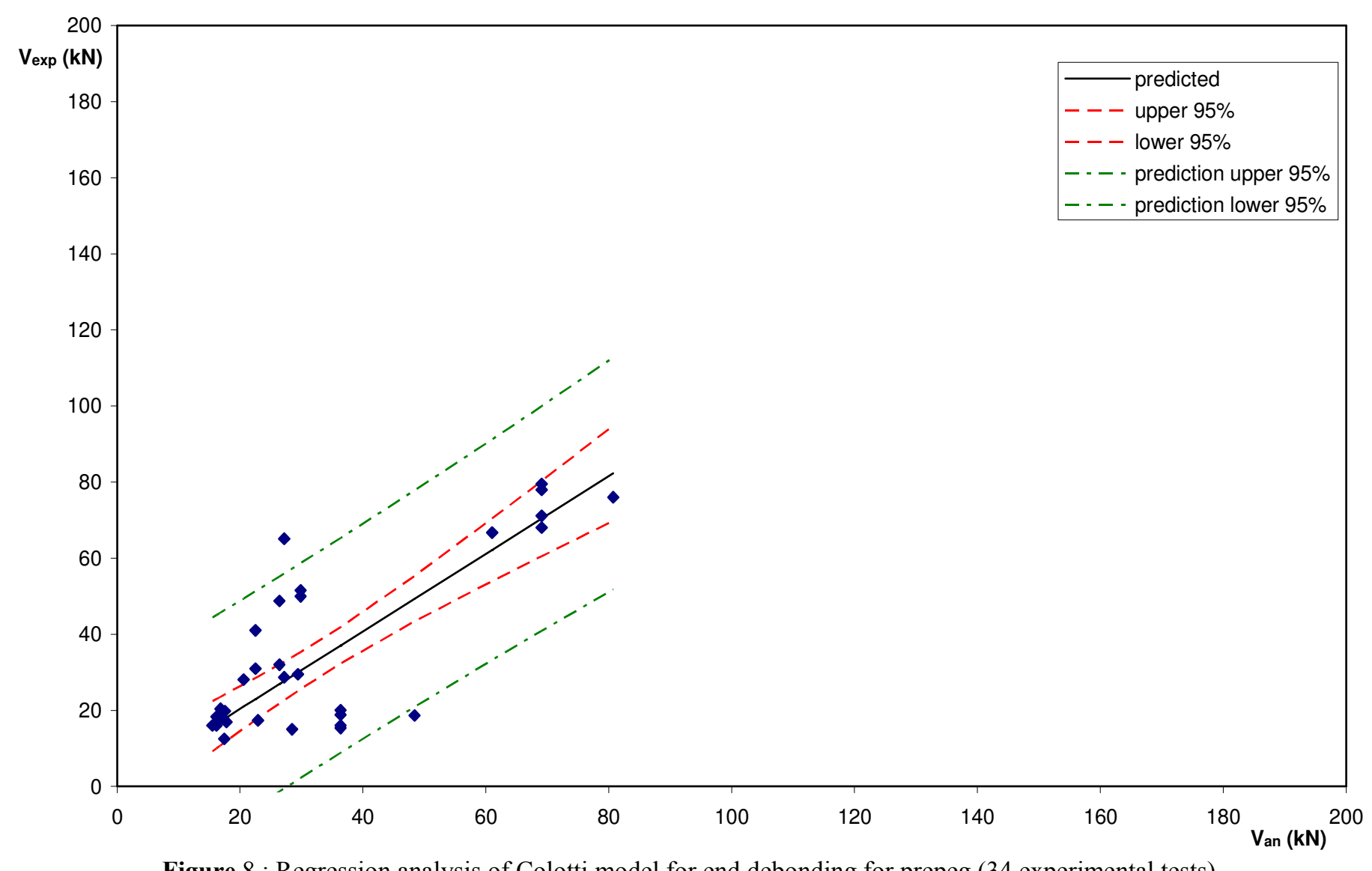

Figure 8 : Regression analysis of Colotti model for end debonding for prepeg (34 experimental tests). 


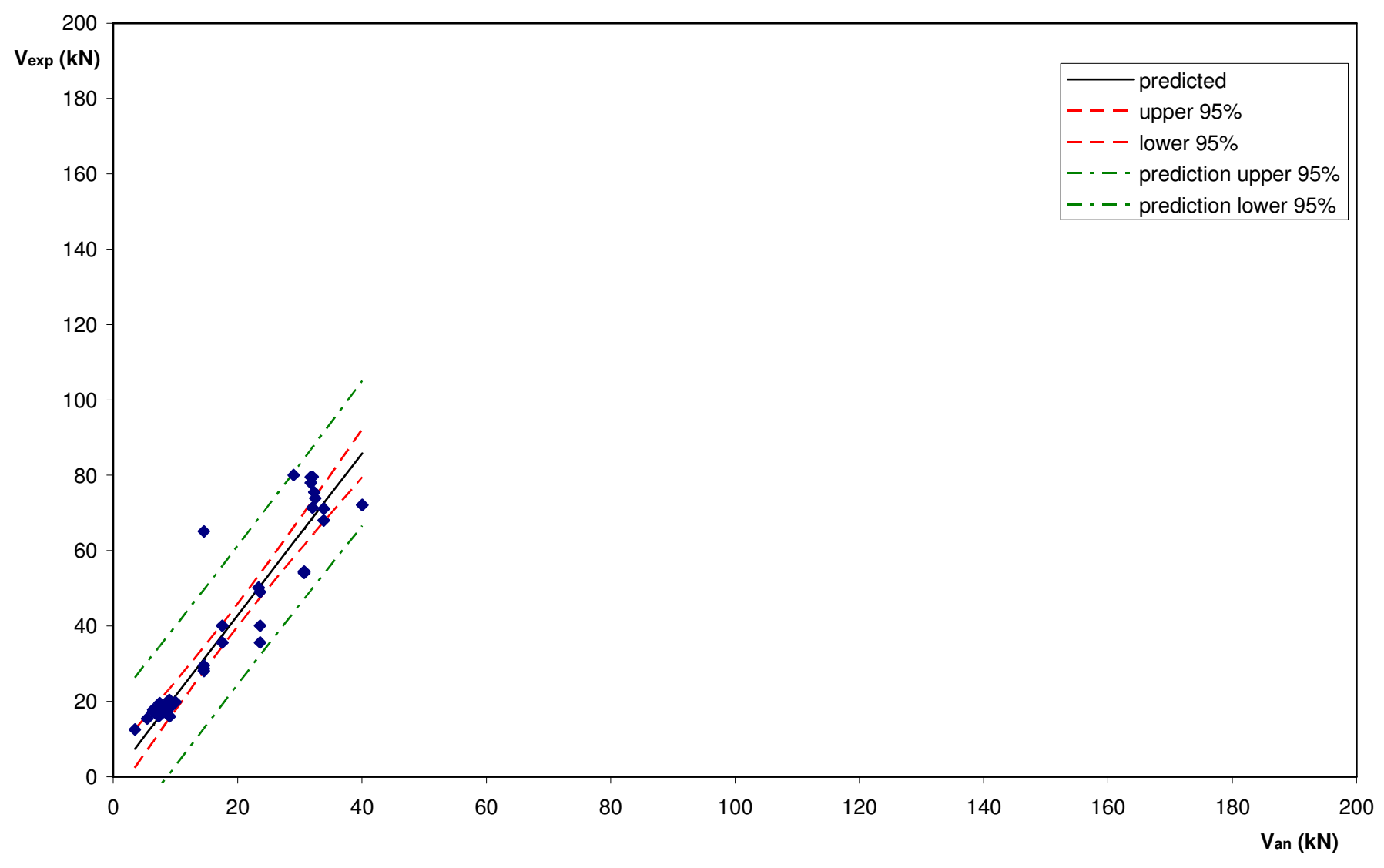

Figure 9 : Regression analysis of Casas and Pascual model for end debonding for prepeg (38 experimental tests). 


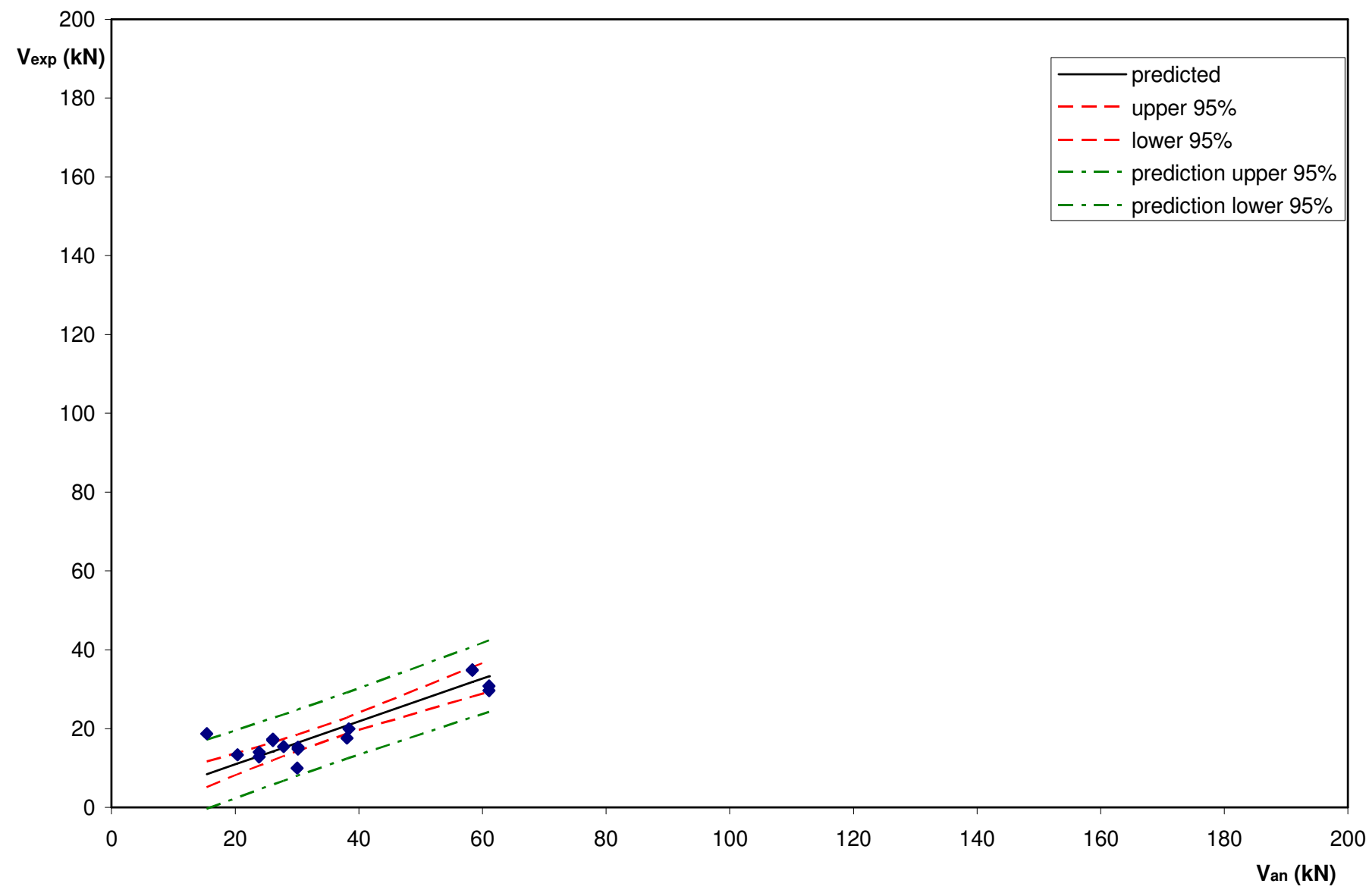

Figure 10 : Regression analysis of $\mathrm{Wu}$ and Niu model for intermediate debonding (15 tests). 


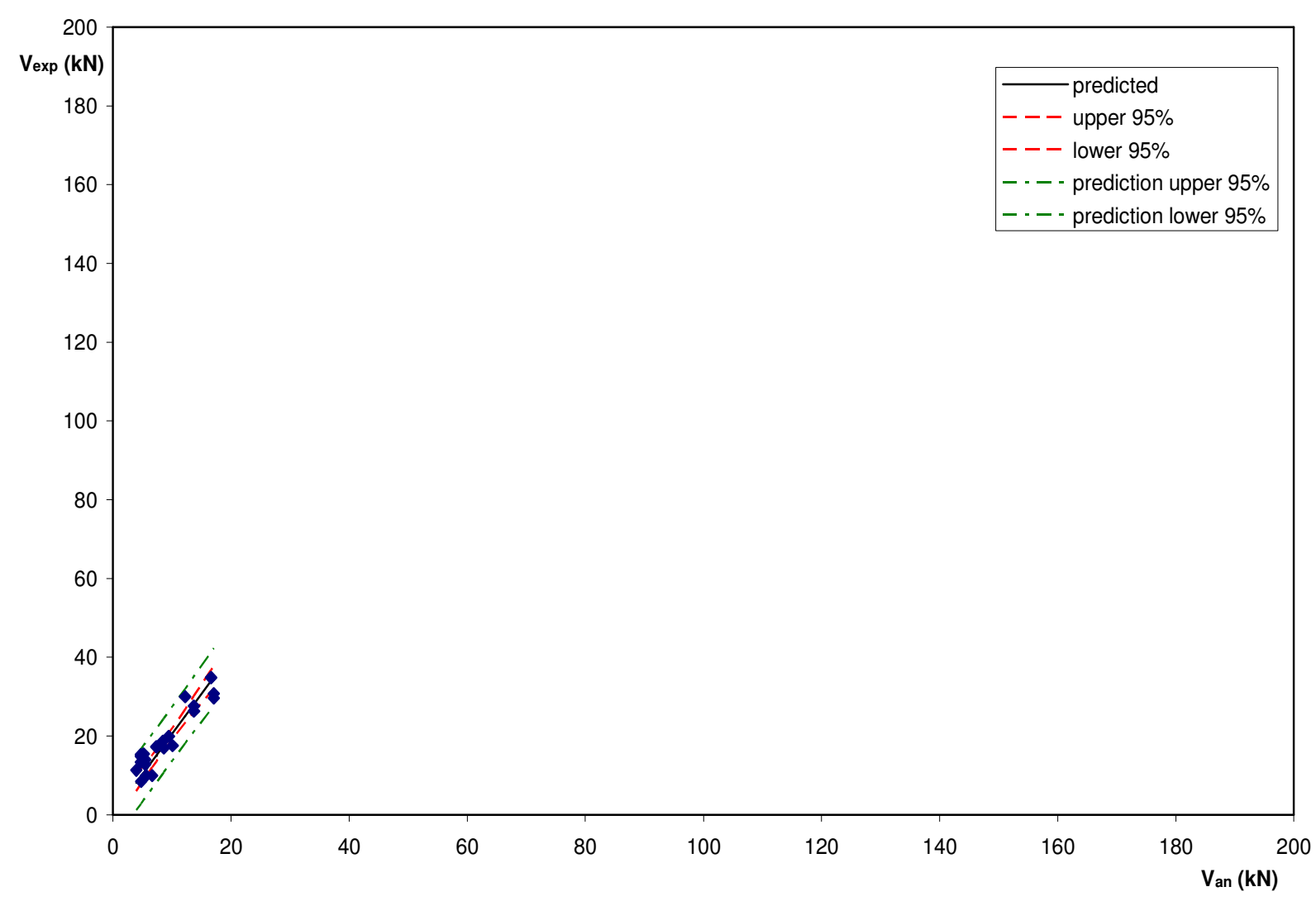

Figure 11 : Regression analysis of Casas and Pascual model for intermediate debonding (20 tests). 


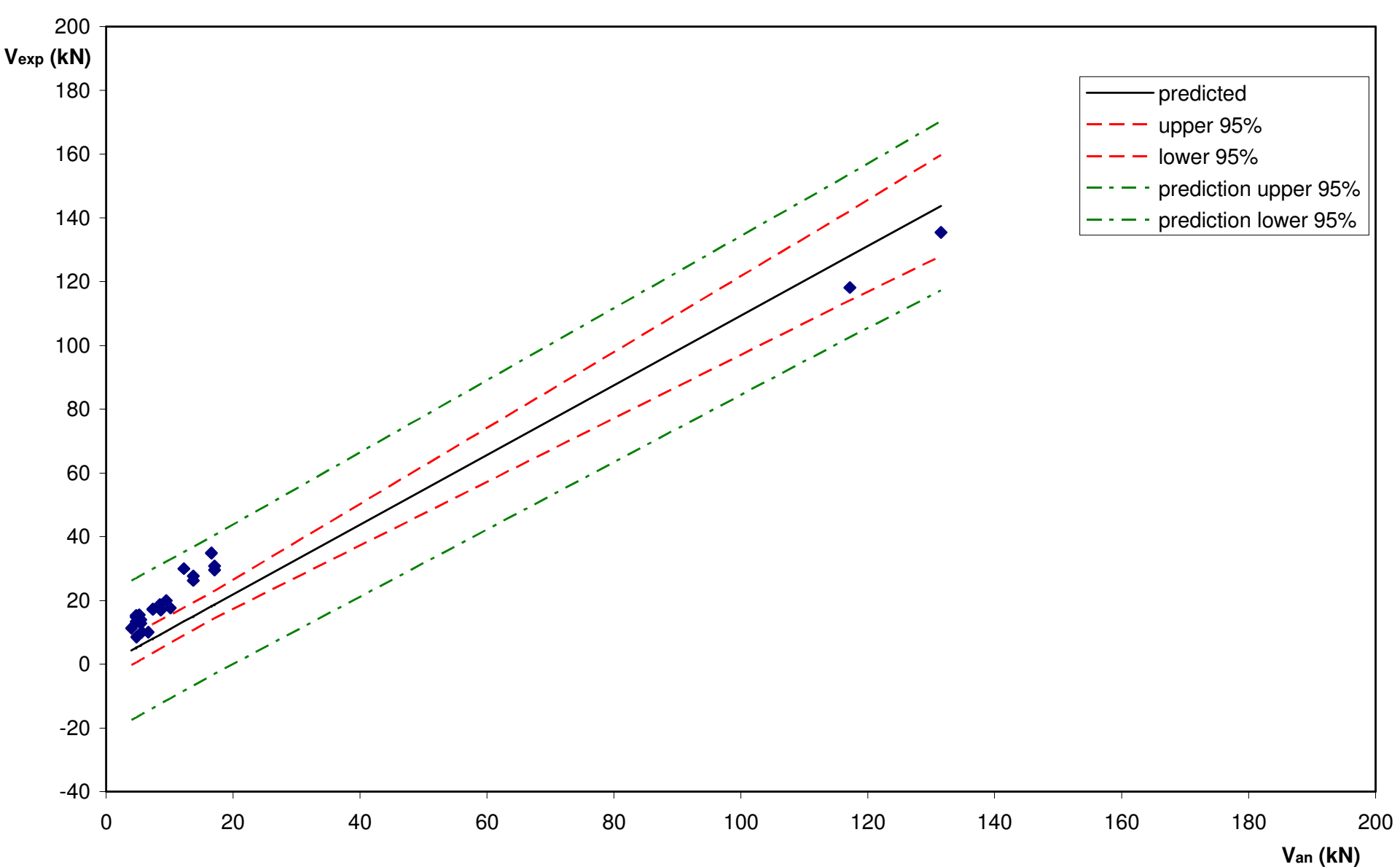

Figure 12 : Regression analysis of Casas and Pascual model for intermediate debonding including full scale beam tests (22 tests). 


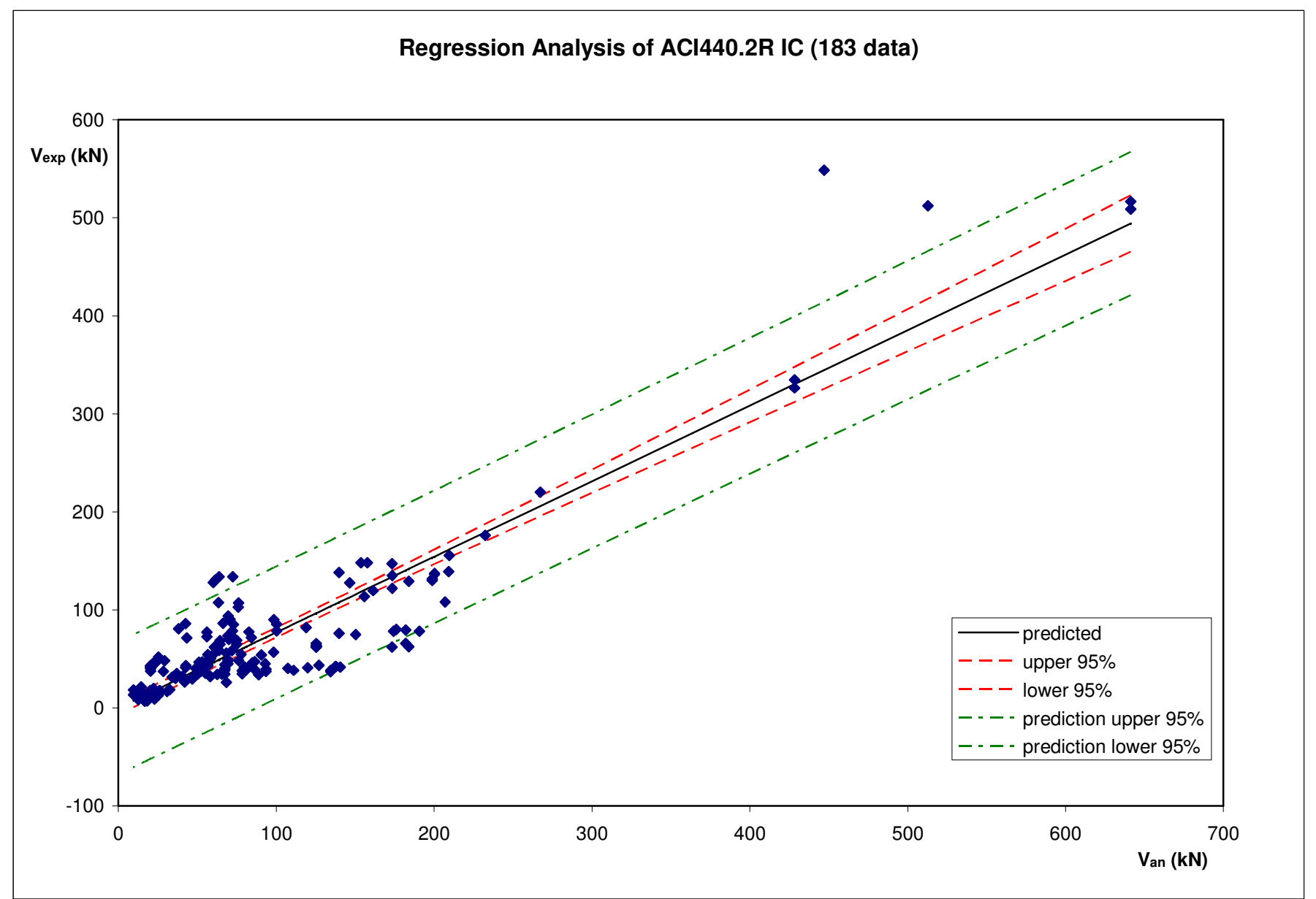

Figure 13 : Regression analysis of ACI model for intermediate debonding including the complete data set (183 experimental tests). 